UNIVERSIDADE ESTADUAL PAULISTA “JÚLIO DE MESQUITA FILHO” FACULDADE DE CIÊNCIAS AGRONÔMICAS

CAMPUS DE BOTUCATU

EFEITO DO BIOCARVÃO SOBRE O COMPORTAMENTO DA MATÉRIA ORGÂNICA E DO FÓSFORO EM SOLO DEGRADADO

MARINA MOURA MORALES

Tese apresentada à Faculdade de Ciências Agronômicas da UNESP - Campus de Botucatu, para obtenção do título de Doutora em Agronomia (Energia na Agricultura).

BOTUCATU - SP

Janeiro - 2010 
UNIVERSIDADE ESTADUAL PAULISTA “JÚLIO DE MESQUITA FILHO” FACULDADE DE CIÊNCIAS AGRONÔMICAS

CAMPUS DE BOTUCATU

\title{
EFEITO DO BIOCARVÃO SOBRE O COMPORTAMENTO DA MATÉRIA ORGÂNICA E DO FÓSFORO EM SOLO DEGRADADO
}

\author{
MARINA MOURA MORALES \\ Orientador: Prof. Dr. Iraê Amaral Guerrini \\ Co-orientador: Prof. Dr. Nicholas Brian Comerford
}

Tese apresentada à Faculdade de Ciências Agronômicas da UNESP - Campus de Botucatu, para obtenção do título de Doutora em Agronomia (Energia na Agricultura).

BOTUCATU - SP

Janeiro - 2010 
FICHA CATALOGRÁFICA ELABORADA PELA SEÇÃO TÉCNICA DE AQUISIÇĀO E TRATAMENTO DA INFORMAÇĀO - SERVIÇO TÉCNICO DE BIBLIOTECA E DOCUMENTAÇĀO UNESP - FCA LAGEADO - BOTUCATU (SP)

Morales, Marina Moura, 1981 -
Efeito do biocarväo sobre o comportamento da matéria or-
gânica e do fósforo em solo degradado / Marina Moura Morales.
Botucatu, [s.n.], 2010 .
xi, 75 f. : il., color., grafs., tabs.
Tese (Doutorado) - Universidade Estadual Paulista, Facul-
dade de Ciências Agronômicas, Botucatu, 2010
Orientador: Iraê Amaral Guerrini
Co-orientador: Nicholas Brian Comerford
Inclui bibliografia
1. Fertilidade do solo. 2. Sorção. 3. Dessorção. 4. Mine-
ralizaçâo. I. Guerrini, Iraê Amaral. II. Comerford, Nicholas
Brian. III. Universidade Estadual Paulista"Júlio de Mesqui-
ta Filho" (Campus de Botucatu). Faculdade de Ciências Agronô-
micas. IV. Título.




\section{UNIVERSIDADE ESTADUAL PAULISTA "JÛLIO DE MESQUTTA FILHO"}

\section{FACULDADE DE CIÊNCIAS AGRONÔMICAS}

\section{CAMPUS DE BOTLCATL}

\section{CERTIFICADO DE APROVACío}

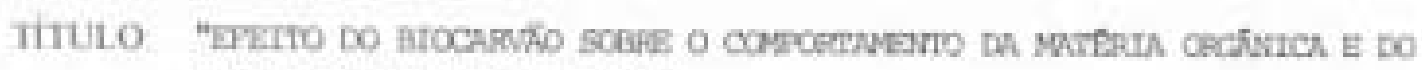

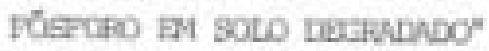

ALUNA MARINA MOURA MORALES

ORIENTADOR PROF DR IRAÊ AMARAL GUERRINI

CO-ORIENTADOR. PROF DR. NICHOLAAS BRIAN COMERFORD

Aprovado pela Comissilo Examinadora

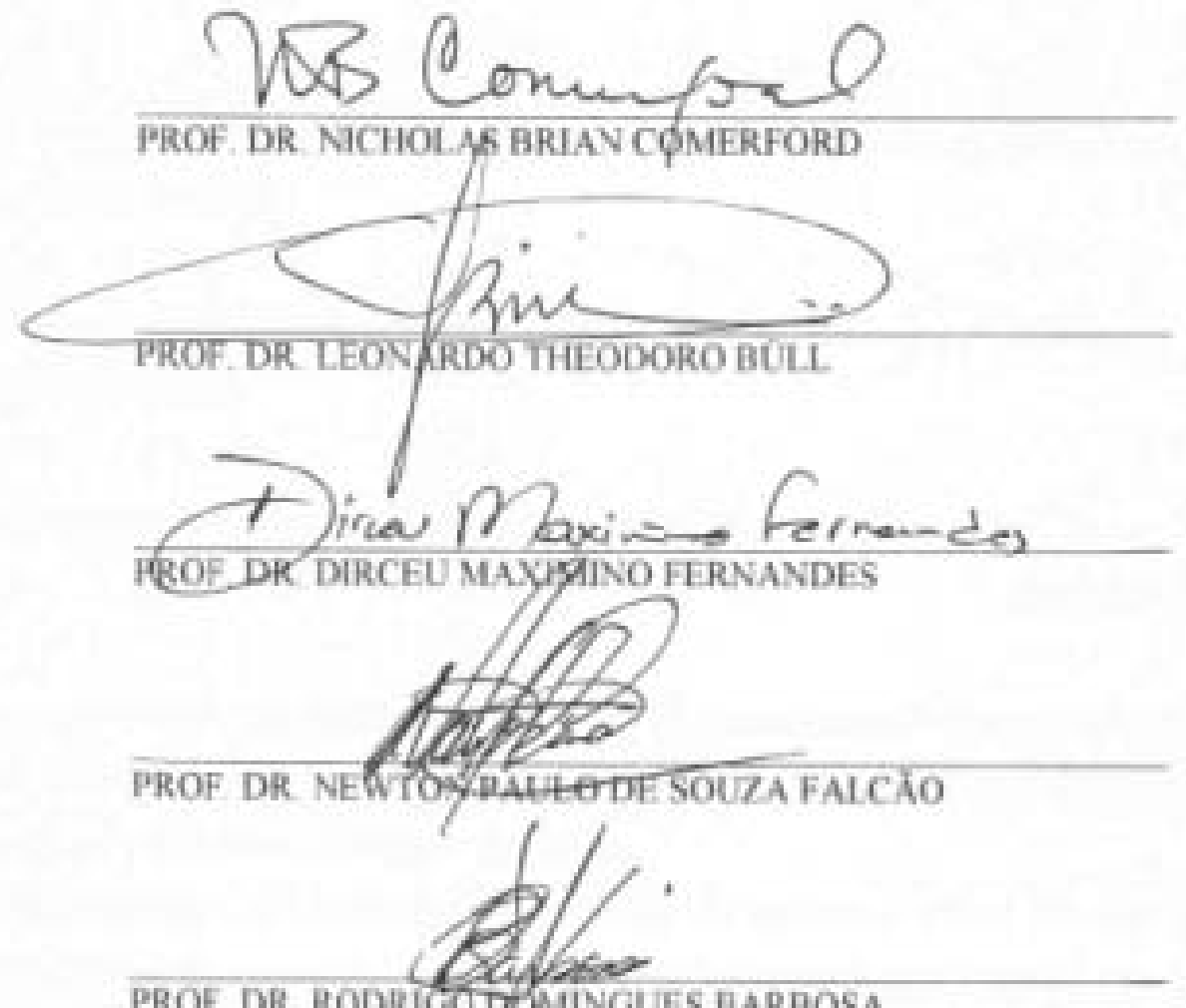

PROF. DR. RODRICOTRAMINGUES BARBOSA 


\section{AGRADECIMENTOS}

Deus, nosso Pai, Filho e Espírito Santo, contemplou-nos com a benção trina da Água + Luz + Solo, a equação da vida na Terra, no Livro do Gênesis, capítulo 1, versículo 1-5, diz:

“No princípio, Deus criou o Céu e a Terra. A Terra, porém, estava informe e vazia, e as trevas cobriam Abismo, mas o Espírito de Deus pairava sobre as águas. Disse Deus : "Haja luz. E houve luz. Viu Deus que a luz era boa; e Deus separou a luz das trevas. Deus chamou à luz "dia" e às trevas "noite". "Houve tarde e houve manhã: um primeiro dia"

Uma fórmula simples, mas detentora da combinação de processos químicos, físicos e biológicos complexos, dinâmicos e permanentes, descrito pelo próprio Criador, no Gênesis, 3 , 19:

“Com o suor do seu rosto, comerás o pão; até que voltes a terra, donde foste tirado. Porque és pó e em pó te tornarás”.

Que o homem, busca incessantemente desvendar, com suas Teorias + Métodos + Técnicas e define como ciência:

"Na natureza nada se cria, nada se perde. Tudo se transforma" $e$

(Lavoisier)

A mim, em particular, Ele abençoou com grandes mestres, que mais do que ensinar, deram condições ao meu desenvolvimento como pesquisadora e pessoa, assim como o solo dá às menores plantinhas, tornando-as vigorosas e produtivas.

Com grandes amigos, que iluminam minha trajetória, me ajudando a crescer como ser humano, e ainda mantêm meu caminho a uma temperatura indiscutivelmente perfeita para 
uma cervejinha gelada, aperitivos apetitosos e longos e valiosos papos, os quais costumo chamar de "terapia em grupo".

Com pessoas dos mais variados perfis, algumas que vem como chuvas torrenciais até as que vem como tempestades, proporcionando meus melhores momentos de reflexão, cabendo a mim medir a quantidade ideal a ser aproveitada ao meu crescimento.

E com a minha família, que é a junção dessas três bençãos, me suportando como o solo suporta até mesmo os maiores Jequitibás, me fazendo crescer como a luz faz com as plantas, com o auxílio da milagrosa reação da fotossíntese, e com uma quantidade diária perfeita de amor, que como a água para a planta deve ser na medida exata para seu desenvolvimento, nem muito que a sufoque nem pouco que a faça murchar, simplesmente o suficiente. Fazendo da equação: $\mathrm{Luz}+$ Água + Solo = Minha Vida.

Por isso, aqui, a todos vocês, fica o meu mais sincero, MUITO OBRIGADA e que o nosso Deus trino continue os abençoando a cada dia.

Agradeço também, à Faculdade de Ciências Agronômicas/UNESP/Botucatu-SP ao Departamento de Engenharia Rural e Recursos Naturais/Ciência do Solo e a Faculdade de Ciências Agronômicas, ao Departamento de Ciência do Solo e da Água e a Universidade da Flórida.

Ao Conselho Nacional de Pesquisa e Desenvolvimento (CNPq), ao Conselho Nacional de Apoio Pessoal de Nível Superior (CAPES) e a Fundação de Amparo a Pesquisa do Estado de São Paulo (FAPESP), pelo suporte financeiro durante o curso de pós-graduação. 
À minha família dedico, 


\section{SUMÁRIO}

LISTA DE FIGURAS............................................................................... viii

LISTA DE TABELAS ….....................................................................

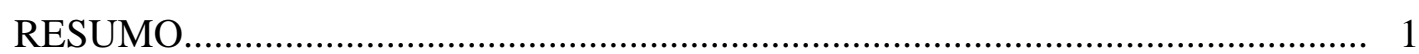

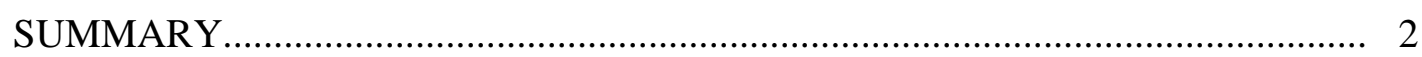

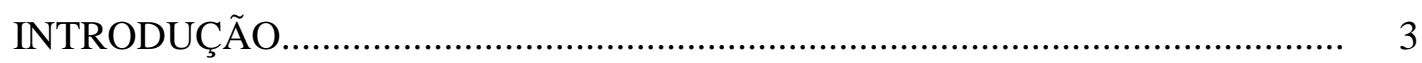

4 REVISÃO DE LITERATURA............................................................ 5

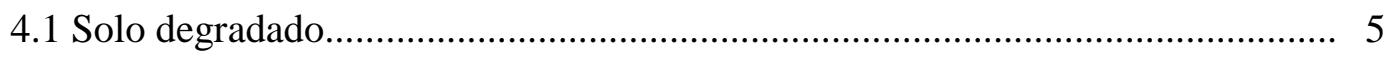

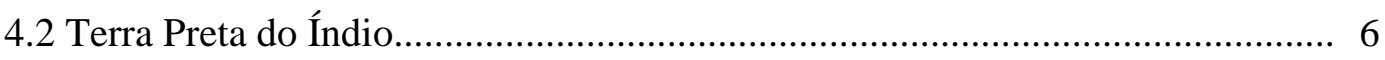

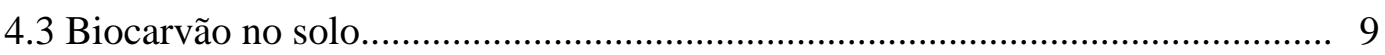

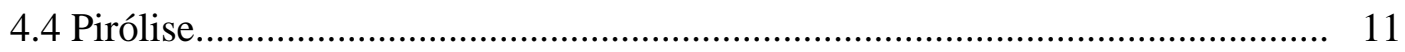

4.5 Matéria Orgânica................................................................................... 13

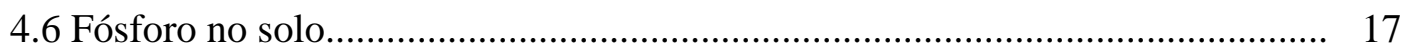

4.6.1. Reações de P no solo............................................................................ 18

5 MATERIAL E MÉTODOS........................................................................... 25

5.1 Descrição do Local.................................................................................... 25

5.2 Produção de biocarvão.................................................................................. 26

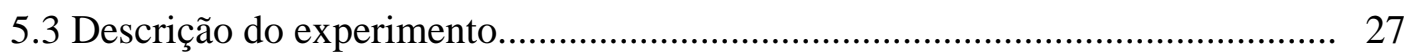

5.4 Caracterização do biocarvão................................................................. 29

5.4.1 Porosidade e área superficial específica................................................... 29

5.4.2 Microscopia eletrônica de varredura........................................................ 29

5.4.3 Análise termogravimétriva (TGA) ..................................................... 30

5.4.4 Difração de raio-X........................................................................ 30

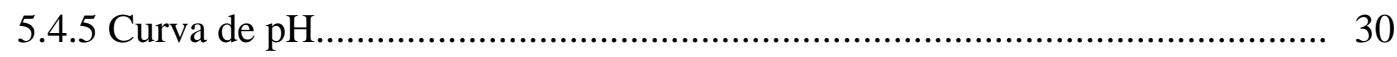

5.4.6 Extrações aquosas para análise de carbono orgânico dissolvido, $\mathrm{P}, \mathrm{pH}$, eletrocondutividade e sais $(\mathrm{Na}, \mathrm{Mg}, \mathrm{Ca}$ e k)............................................. 30

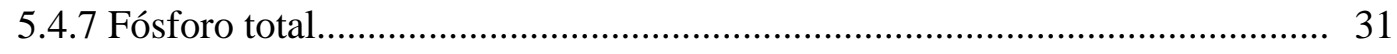

5.5 Caracterização do Ensaio 1 - Matéria orgânica.................................................. 32

5.5.1 Quantificação de grupos funcionais........................................................... 32 


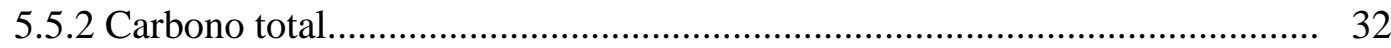

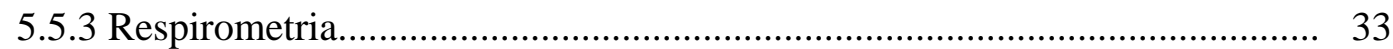

5.6 Caracterização do Ensaio 2 - Fósforo......................................................... 33

5.6.1 Cinética de sorção de P......................................................................... 34

5.6.2 Cinética de dessorção de P................................................................... $\quad 35$

5.6.3 Reações de sorção de P........................................................................ 35

5.6.4 Reações de dessorção............................................................................... 35

5.7 Análise química da mistura $($ solo + BC) ...................................................... 36

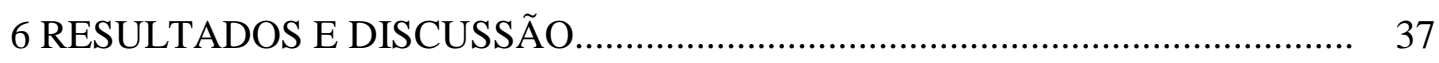

6.1 Caracterização do biocarvão................................................................... 37

6.2 Ensaio 1 - Matéria orgânica................................................................... 51

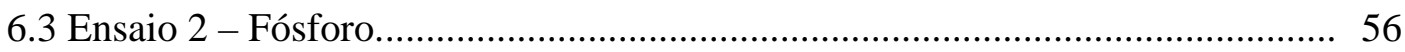

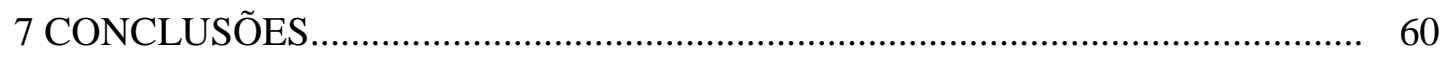

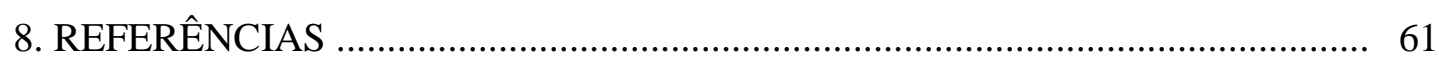




\section{LISTA DE FIGURAS}

Figura 1. Comparação entre os perfis de Terra preta do Índio (A) e solo adjacente (B) circunvizinho

Figura 2. Conceito de pirólise e sequestro de carbono por LEHMANN (2007).... 12

Figura 3. Reações do P no solo 20

Figura 4. Planta piloto de pirólise rápida, matéria-prima (Biomassa), produto (Bio-óleo) e subprodutos (Extrato ácido e Biocarvão)

Figura 5. Desenho experimental.

Figura 6. Imagens do BC composto por uma mistura de biocarvões, produzidos com capim elefante, serragem e palha de cana de açúcar.

Figura 7. Imagens feitas por microscopia eletrônica de varredura em três diferentes tipos de partículas que compõem o BC, ampliadas em 600 vezes (esquerda) e 2000 vezes (direita).

Figura 8. Perfil da perda de massa do $\mathrm{BC}$, na região entre 25 a $700{ }^{\circ} \mathrm{C}$.

Figura 9. Análise mineralógica do BC por difração de raio-x, incinerado em 3 diferentes temperaturas, baseadas na análise termogravimétrica.

Figura 10. Eeletrocondutividade e $\mathrm{pH}$ sob extrações aquosas (A) e curva de $\mathrm{pH}$ (B) do BC.

Figura 11. Conteúdo de fósforo (A) e Carbono orgânico dissolvido (COD) no $\mathrm{BC}$ em 30 extrações aquosas.

Figura 12. Valores de pH para solo (SOLO) e solo com adição de $35 \%$ de BC (MO0), nos tempos 0, 80, 160 e 240 dias de incubação em estufa (Os .pontos seguidos de mesmas letras maiúsculas não diferem entre si para os tratamentos e as letras minúsculas não diferem entre si para os tempos dentre os tratamentos, a $5 \%$ de probabilidade pelo teste de Tukey; $\mathrm{p}<0,05)$. 
Figura 13. Valores de P para solo (SOLO) e solo com adição de $35 \%$ de BC (MO0), nos tempos 0, 80, 160 e 240 dias de incubação em estufa (Os pontos seguidos de mesmas letras maiúsculas não diferem entre si para os tratamentos e as letras minúsculas não diferem entre si para os tempos dentre os tratamentos, a $5 \%$ de probabilidade pelo teste de Tukey; $\mathrm{p}<0,05)$

Figura 14. Os valores de K para solo (SOLO) e solo com adição de $35 \%$ de BC (MO0), nos tempos 0, 80, 160 e 240 dias de incubação em estufa (Os pontos seguidos de mesmas letras maiúsculas não diferem entre si para os tratamentos e as letras minúsculas não diferem entre si para os tempos dentre os tratamentos, a $5 \%$ de probabilidade pelo teste de Tukey; $\mathrm{p}<0,05)$.

Figura 15. Os valores de Ca para solo (SOLO) e solo com adição de 35\% de BC (MO0), nos tempos 0, 80, 160 e 240 dias de incubação em estufa. (Os pontos seguidos de mesmas letras maiúsculas não diferem entre si para os tratamentos e as letras minúsculas não diferem entre si para os tempos dentre os tratamentos, a $5 \%$ de probabilidade pelo teste de Tukey; $\mathrm{p}<0,05$ )

Figura16. Os valores de $\mathrm{Mg}$ para solo (SOLO) e solo com adição de $35 \%$ de BC (MO0), nos tempos 0, 80, 160 e 240 dias de incubação em estufa. (Os pontos seguidos de mesmas letras maiúsculas não diferem entre si para os tratamentos e as letras minúsculas não diferem entre si para os tempos dentre os tratamentos, a $5 \%$ de probabilidade pelo teste de Tukey; $\mathrm{p}<0,05$ )

Figura 17. Os valores de Fe para solo (SOLO) e solo com adição de $35 \%$ de BC (MO0), nos tempos 0, 80, 160 e 240 dias de incubação em estufa. (Os pontos seguidos de mesmas letras maiúsculas não diferem entre si para os tratamentos e as letras minúsculas não diferem entre si para os tempos dentre os tratamentos, a $5 \%$ de probabilidade pelo teste de Tukey; $\mathrm{p}<0,05$ ).

Figura 18. Os valores de Mn para solo (SOLO) e solo com adição de $35 \%$ de BC (MO0), nos tempos 0, 80, 160 e 240 dias de incubação em estufa. (Os pontos seguidos de mesmas letras maiúsculas não diferem entre si para os tratamentos e as letras minúsculas não diferem entre si para os tempos dentre os tratamentos, a $5 \%$ de probabilidade pelo teste de Tukey; $\mathrm{p}<0,05)$

Figura 19. $C$ total em mg g-1 nos tempos $0,80,160$ e 240 dias de incubação em estufa, para os tratamentos Solo(S), Solo+BC (SB), Solo+BC+10t ha-1 de MO (SBMO-10), Solo+BC+40t ha-1(SBMO-40), Solo+BC+70t ha-1(SBMO-70), Solo+BC+100t ha-1 (SBMO-100).

Figura 20. Mineralização total do solo (S), solo+BC (SB) e solo+BC+ 10, 40, 70 e 100 t ha-1 de MO (SBMO-10, SBMO40, SBMO-70, SBMO-100) nos tempos $0,80,160,240$ e 320 dias de incubação em estufa. 
Figura 21. Mineralização total da matéria orgânica presente na mistura (solo+BC+10, 40, 70 e 100 tha-1 de MO) nos tempos de 0, 80, 160, 240 e 320 de incubação em estufa.

Figura22. Espectro de infravermelho médio para as amostras de $\mathrm{BC}$, solo e mistura (BC+solo+o, 10, 40, 70 e 100 tha-1 de MO)

Figura 23. Cinética de sorção de $\mathrm{P}$ em solo $(\mathrm{S})$, solo + BC (SBC) e somente biocarvão (BC).

Figura24. Comparação entre os métodos de Cinética de sorção de $\mathrm{P}$ (400 mg kg1) em solo feitos com tubos de diálise (TD) e tubos de centrífuga (TC).

Figura 25. Sorção de $\mathrm{P}$ em solo $(\mathrm{S})$, solo com adição de $\mathrm{BC}$ in natura (sBCin natura) e solo com adição de BC submetido a extrações aquosas (sBCsob extrações aquosas)

Figura 26. Curva de dessorção sequencial de $\mathrm{P}$, representada pelo $\mathrm{P}$ restante sorvida à mistura, para os tratamentos $\mathrm{P}_{75}, \mathrm{P}_{150}, \mathrm{P}_{200}$ e $\mathrm{P}_{300}$, utilizando tubos de diálise. 


\section{LISTA DE TABELAS}

Tabela 1. Estatística descritiva de propriedades selecionadas do horizonte A de solos Terra Preta de Índio $(\mathrm{n}=27)$ e Latossolos e Argissolos amazônicos $(n=19)$.

Tabela 2. Conteúdo de grupos oxigenados (meq/100g) e ácidos húmicos e fúlvicos extraídos de diferentes tipos de solos.

Tabela 3. Propriedades químicas do solo Latossolo Vermelho.

Tabela 4. Propriedades químicas do biocarvão

Tabela 5. Propriedades químicas da matéria orgânica.

Tabela 6. Propriedades químicas e físicas do BC.

Tabela 7. Distribuição dos poros do BC

Tabela 8. Propriedades químicas do solo e da mistura (Solo+35\%BC) nos tempos 0 e 240 dias de incubação em casa de vegetação.

Tabela 9. Porcentagem de grupos funcionais carboxílicos, lactonas e fenólicos, quantificados por titulação de Bohem nos tempo 0 e 240 dias de incubação em estufa. 


\section{RESUMO}

Suprir a demanda de alimento para mais de 6 bilhões de pessoas promovendo agricultura de forma sustentável é o desafio do novo milênio. O biocarvão (BC), ingrediente que proporciona ao solo capacidade de reter matéria orgânica e nutrientes, pode ser uma ferramenta de grande importância na busca de soluções para esse desafio. Portanto, entender o efeito do $\mathrm{BC}$ sobre o comportamento da matéria orgânica (MO) e o ciclo do fósforo inorgânico $(\mathrm{Pi})$ em solo degradado foram os objetivos deste trabalho. A taxa de mineralização e o teor de carbono total foram monitorados nas misturas de solo degradado $+35 \% \mathrm{BC}+$ doses de MO iguais a $0,10,40,70$ e $100 \mathrm{t} \mathrm{ha}^{-1}$, nos tempos 0, 80, 160, 240 e 320 dias de incubação em estufa. Reações de sorção e dessorção de Pi foram avaliadas nas misturas de solo degradado + 35\% BC + doses de $\mathrm{P}$ com 0, 75, 150, 200 e $300 \mathrm{mg} \mathrm{kg}^{-1}$, no tempo 240 dias de incubação, além do controle com somente solo, para ambos os estudos. A adição de BC ao solo promoveu a mineralização da mistura; entretanto, o BC apresentou tendência à recalcitrância ao longo do período, dobrou o tempo de reação com o P tanto para as reações de sorção quanto dessorção, diminuiu a sorção de $\mathrm{P}$ do solo e dessorveu quantidades ideais para a maioria das culturas. $\mathrm{O}$ BC possui poder fertilizante, porém sua utilização deve ser assistida por possuir características químicas limitantes como pH e sais.

Palavras chave: Fertilidade do solo, sorção, dessorção, mineralização. 
BIOCHAR EFFECT ON ORGANIC MATTER AND PHOSPHORUS BEHAVIOR IN DEGRADED TORPICAL SOIL. Botucatu, 2010. 90p. Tese (Doutorado em Agronomia/Energia na Agricultura) - Faculdade de Ciências Agronômicas, Universidade Estadual Paulista.

Author: MARINA MOURA MORALES

Advisor: IRAÊ AMARAL GUERRINI

Co-advisor: NICHOLAS BRIAN COMERFORD

\section{SUMMARY}

To supply the food demand for more than 6 billion people, promoting sustainable agriculture is the chellenge for the new milennium; the biochar (BC) ingredient that provides the ability to retain soil organic matter and nutrients can be an important tool to figure oout solutions for this challenge, thus, understand the effect of $\mathrm{BC}$ on the organic matter (OM) behavior and at inorganic phosphorus ( $\mathrm{Pi}$ ) cycle in degraded tropical soil has been our goal. The mineralization rate and total carbon content were monitored in mixtures of degraded tropical soil $+35 \% \mathrm{BC}+\mathrm{OM}$ doses, equal to $0,10,40,70$ and $100 \mathrm{t} \mathrm{ha}^{-1}$ at $0,80,160,240$, and 320 greenhouse incubation days. Pi Sorption and desorption Reactions were analysed in mixtures of degraded tropical soil $+35 \% \mathrm{BC}+\mathrm{P}$ rates of $0,75,150,200,300 \mathrm{mg} \mathrm{kg}^{-1}$, on 240 days of greenhouse incubation, beyond the control with soil by itself. The BC soil addition promote mineralization, however presented recalcitrance tendency in the incubation time, doubled the time of reaction with $\mathrm{P}$ for both the reactions of sorption and desorption, decreased $\mathrm{P}$ sorption and desorption of soil quantities ideal for most crops. The $\mathrm{BC}$ can act as a fertilizer, but its dosage should be well attended as it has the capacity to increase soil $\mathrm{pH}$ and salt.

Keywords: Soil fertility, sorption, desorption, mineralization. 


\section{INTRODUÇÃO}

Nos últimos 50 anos a população mundial dobrou, chegando a mais de 6 bilhões de pessoas (NEWBOLD, 2007), onde 1 bilhão é afetada pela fome. A demanda de alimentos e ao mesmo tempo, o incentivo para a produção de energia renovável, vem aumentando o uso indiscriminado do solo.

No mundo, cerca de 1,5 bilhões de hectares são de solos agricultáveis (FAO, 2006). Entretanto, estima-se que $23 \%$ do total dessas áreas já foram afetadas em um grau suficiente para ameaçar sua produtividade (GEO, 2004), cuja degradação é advinda, principalmente, de fatores antrópicos como: uso indevido do solo, práticas inadequadas de manejo, desmatamento, rotação incorreta de cultivos e práticas de irrigação inapropriadas.

O Brasil com 66.6 milhões de hectares de área agricultável, 4,3\% da área mundial (FAO, 2006), além dos fatores de degradação antrópicos, possui solos que sofrem também com alta acidez, fixação de fósforo e decomposição rápida da MO, resultante das altas temperaturas e umidade .

O impacto da degradação do solo no cenário da fome é indiscutível; portanto, boas práticas de manejo são indispensáveis para evitar e até recuperar áreas degradadas, aumentando a produção de alimentos. 
Na Amazônia existem áreas de solos de origem antropogênica, cuja formação é de 500 a 2500 anos atrás, conhecida pela sua grande fertilidade decorrente da deposição do carvão vegetal, restos de espinhas de peixe, ossos e cascos de animais. Possuem alta atividade biológica, alto conteúdo de fósforo e significativa presença de carvão, comumente chamado de biocarvão (BC), material quimicamente estável no solo. Tais solos são conhecidos como Terra Preta do Índio (TPI).

O grande diferencial das TPIs comparadas com os solos adjacentes é o conteúdo de $\mathrm{BC}$, até 70 vezes superior aos solos vizinhos, uma ferramenta no manejo de nutrientes, na melhoria das propriedades físicas e químicas do solo e, consequentemente, na produção agrícola, o que justifica a importância em estudar esse material em solos degradados.

Com base nisso, o objetivo deste trabalho foi avaliar o efeito do $\mathrm{BC}$ sobre as características químicas e biológicas da matéria orgânica (MO) e na cinética e no equilíbrio da solução do solo para reações de sorção e dessorção de P em solo degradado. 


\section{REVISÃO DE LITERATURA}

\subsection{Solo degradado}

O solo é um corpo vivo e dinâmico, produto do intemperismo sobre o material de origem da terra. É constituído de matéria mineral, matéria orgânica, água e ar, capaz de desenvolver vida vegetal, desempenhando papel essencial na Terra, participando diretamente ou indiretamente de todos os ciclos de vida presentes no planeta.

O solo fornece sustentação e nutrientes às plantas, dele depende a agricultura, que produz alimento, fibras e energia, necessários a uma população que vem crescendo indiscriminadamente, exigindo à interferência humana, que se utiliza de técnicas para exploração desse recurso, muitas vezes inadequadas à sua sustentabilidade.

Conforme dados da Global Assessment of Soil Degradation (Glasod), no mundo, cerca de 2 bilhões de hectares encontram-se degradados, e as principais causas dessa 
degradação são: manejo inadequado, exploração excessiva e desmatamento (OLDEMAN \& LYNDEN, 1998).

Para evitar a contínua degradação do solo, a qualidade dos produtos gerados pela agricultura, deve ser diretamente vinculada ao conceito de sustentabilidade e a todos os seus desdobramentos: balanço energético, reciclagem de nutrientes, manutenção e melhoria da fertilidade do solo, conservação dos recursos naturais e aumento da produtividade (ANDREOLI et al., 1999). Esse conceito se resume nas palavras "manejo adequado", visto que um manejo bem feito tem a capacidade de impedir o processo de degradação do solo, que uma vez instalado, tem grande grau de dificuldade para ser revertido.

A recuperação do solo se deve a complexos processos químicos, físicos e biológicos, onde o grande desafio a ser alcançado é o estabelecimento do horizonte A do solo, onde esses processos sejam catalisados pela biosfera, surgindo outros horizontes conforme o condicionamento natural do solo. Deste modo, interfere-se em um ou mais fatores de formação do solo, na tentativa de acelerar sua gênese (KITAMURA et al., 2008).

Sendo assim, o trabalho interdisciplinar com profissionais das áreas de agronomia, engenharia, geografia, química, biologia e ciências humanas no entendimento dos mecanismos de degradação e recuperação do solo, assim como no desenvolvimento de técnicas de recuperação de áreas degradadas, são indispensáveis para manter a qualidade dos produtos extraídos do campo e atender as necessidades de alimentos, roupas e energia da população.

\subsection{Terra Preta de Índio}

Na Amazônia existem unidades de solo com elevada fertilidade, incorporadas em uma paisagem de solos de baixa fertilidade. São solos alterados pelo homem pré-histórico, com origens datadas entre 500 a 2500 anos atrás. Possuem alto teor de matéria orgânica (MO) e nutrientes, como nitrogênio $(\mathrm{N})$, fósforo $(\mathrm{P})$, potássio $(\mathrm{K})$ e cálcio $(\mathrm{Ca})$ (CUNHA et al, 2009), além de fragmentos de cerâmica e artefatos indígenas incorporados a matriz do seu horizonte superficial, originando sua terminologia Terra Preta do Índio (TPI), Figura 1. 

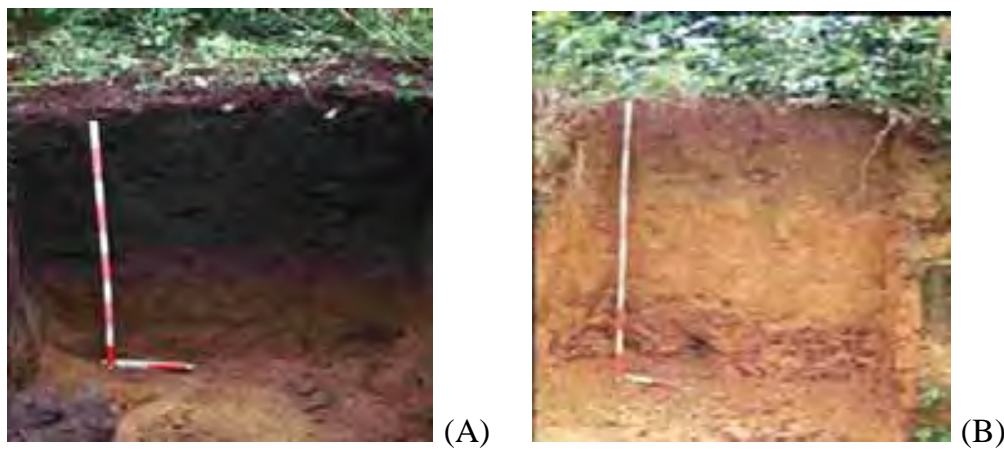

Figura 1. Comparação entre os perfis de Terra Preta de Índio (A) e solo adjacente (B) Fonte: WOOD \& GLASIER, (2004).

As áreas de localização das TPIs são consideradas pequenas, variando de 2 a 3 hectares (SMITH, 1980), mas podem ser encontradas ocasionalmente em áreas maiores, com mais de 100 ha. Segundo dados do Museu Paraense Emílio Goeldi, podem existir centenas de sítios espalhados pela região, comumente localizados próximos a cursos de água, ocupando várzeas, elevações marginais adjacentes e terra firme interior.

A cor escura das TPIs é decorrente da presença de produtos da combustão incompleta de material orgânico, formados pela queima da lenha utilizada no preparo de alimentos, que foram depositados ao longo do tempo e se acumularam no solo (GLASER et al., 2001).

Baseado na cultura indígena atual, que demonstra constante preocupação com a limpeza dos espaços públicos e de circulação (DeBOER \& LATHRAP, 1979 apud NEVES et al., 2003), acredita-se que restos de comida, cinzas e excretas teriam seus lugares de descarte fora da comunidade, formando um grande "lixão orgânico" (WOODS, 2003). O que explica sua alta fertilidade, com altos teores totais de $\mathrm{CaO}\left(1819 \mathrm{mg} \mathrm{kg}^{-1}\right), \mathrm{P}_{2} \mathrm{O}_{5}\left(4900 \mathrm{mg} \mathrm{kg}^{-1}\right) \mathrm{e}$ elevados teores de MO (FALCÃO et al., 2001), onde grande parte dessa MO é carvão vegetal, compostos que lhe dão maior atividade biológica quando comparado com os solos adjacentes.

Uma comparação das propriedades químicas entre os horizontes das TPIs e solos adjacentes (Tabela 1) mostram que as TPIs apresentam, usualmente, valores mais elevados de pH, P disponível, $\mathrm{Ca}^{2+}+\mathrm{Mg}^{2+}$, capacidade de troca catiônica (CTC) e saturação por bases (V). 
Tabela 1. Estatística descritiva de propriedades químicas do horizonte A de solos Terra Preta de Índio ( $n=27)$ e Latossolos e Argissolos amazônicos ( $n=19)$

\section{Latossolos e Agrissolos amazônico}

\begin{tabular}{|c|c|c|c|c|c|c|c|}
\hline Estatística & $\begin{array}{l}\text { C org. } \\
\text { g kg }^{-1}\end{array}$ & $\begin{array}{c}\text { P disponível } \\
\text { mg kg }^{-1}\end{array}$ & $\begin{array}{c}\mathrm{Ca}^{2+}+\mathrm{Mg}^{2+} \\
\mathbf{c m o l}_{\mathbf{c}} \mathbf{k g}^{-1}\end{array}$ & $\mathrm{pH}$ & $\begin{array}{c}\text { CTC } \\
\text { cmol }_{\mathbf{c}} \mathbf{k g}^{-1}\end{array}$ & $\begin{array}{l}\mathrm{V} \\
\%\end{array}$ & $\begin{array}{l}\text { Argila } \\
\text { g kg }^{-1}\end{array}$ \\
\hline Média & 16,4 & 1,7 & 1,4 & 4,5 & 8,2 & 17 & 450 \\
\hline DP & 7,3 & 0,8 & 2,1 & 0,8 & 3,3 & 21 & 280 \\
\hline $\mathrm{CV} \%$ & 44 & 46 & 152 & 18 & 40 & 122 & 610 \\
\hline Mínimo & 6,7 & 1 & 0,1 & 3,5 & 3,5 & 2 & 120 \\
\hline Mediana & 15,5 & 2 & 0,4 & 4,2 & 8,5 & 6 & 350 \\
\hline Máximo & 29,5 & 3 & 8,1 & 6,6 & 14,5 & 79 & 930 \\
\hline
\end{tabular}

\section{Terra Preta de Índio}

\begin{tabular}{lccccccc}
\hline Média & 38,9 & 507 & 9,4 & 5,6 & 17,4 & 53 & 240 \\
DP & 22,4 & 591 & 6,1 & 0,8 & 6,0 & 25,7 & 156 \\
CV \% & 57 & 116 & 65 & 15 & 34 & 48 & 66 \\
Mínimo & 4,6 & 8 & 0,4 & 3,7 & 9,1 & 5 & 20 \\
Mediana & 34,6 & 223 & 9,8 & 5,5 & 17,6 & 56 & 204 \\
Máximo & 98,0 & 2.145 & 22,9 & 7,1 & 38,4 & 97 & 740
\end{tabular}

Fonte: Andrade (1986); Embrapa (2001); Falesi (1970); Kern \& Kämpf (1989); Kern (1996); Lima (2001); Vieira (1975).

Essas áreas apresentam teores de MO estável que parecem não exaurir seu conteúdo químico mesmo em condições de floresta tropical, o que contrasta com a maioria dos solos encontrados em suas redondezas (SOMBROEK, 1996; KERN, 1996; SMITH, 1980; GLASER et al., 2001), despertando o interesse da comunidade científica de todo o mundo.

Essa estabilidade é questionada por ser um resultado das características mineralógicas desses solos orgânicos ou pelo conteúdo de carvão, 35-45\%, comparado a 14\% em solos circunvizinhos sem horizonte A antopogênico (GLASER et al., 2000).

$\mathrm{O}$ estudo sobre o efeito que o $\mathrm{BC}$ exerce sobre a $\mathrm{MO}$ e $\mathrm{P}$ em agroecossistemas brasileiros é um tema estratégico para melhoria da agricultura em ecossistemas tropicais e 
ainda na recuperação de solos degradados. Portanto, as informações extraídas das TPIs são de suma importância para a reprodução de parte de suas características em períodos de tempos menores, tornando nossos solos mais sustentáveis.

\subsection{Biocarvão no solo}

Biocarvão é o produto da combustão incompleta de restos de material orgânico ou de culturas voltadas à sua produção. Possui alto teor de $\mathrm{C}$ e grande área superficial devido a sua porosidade em consequiência do processo de queima (MADARI at al., 2009). Por não ser um produto padrão, suas características químicas, físicas e físico-químicas, variam de acordo com o processo de queima e seus desdobramentos (tipo de pirólise, temperatura, tempo de retenção, adição de oxigênio), tipo e granulometria da biomassa.

Entretanto, vários autores, usando diferentes tipos de $\mathrm{BC}$, encontraram contribuição à fertilidade e à sustentabilidade da fertilidade do solo, melhorando suas propriedades químicas, físicas e biológicas (GOLCHIN et al., 1997; SCHMIDT \& SKJEMSTAD, 2002; LEHMANN et al. 2003; STEINER et al., 2007). Isso porque o BC proporciona ao solo, retenção de nutrientes por melhorar a capacidade de troca catiônica (CTC), além de ter grande função nos processos biogeoquímicos do solo, como as reações de adsorção de nutrientes. A alta CTC ocorre pelo tipo de superfície encontrada no BC, com grande quantidade de compostos aromáticos (SCHMIDT \& NOACK, 2000).

A oxidação do carbono e a formação de grupos carboxílicos podem ser a principal razão para a alta CTC observada (GLASER et al., 2003). Tal formação de grupos carboxílicos ou outros grupos funcionais com cargas negativas em ampla faixa de $\mathrm{pH}$ pode ser resultado de dois processos: (i) oxidação das partículas superficiais do carvão; ou (ii) adsorção de grande quantidade de MO sobre as superfícies do BC, ou um efeito combinado de ambos (LEHMANN et al., 2005).

Comparado a outros solos orgânicos, o BC é também capaz de adsorver fortemente fosfato, embora ele seja um ânion; porém, este mecanismo ainda não está completamente esclarecido (LEHMANN, 2007; FALCÃO et al., 2003). 
A aplicação de $\mathrm{BC}$ aumenta o $\mathrm{pH}$ do solo e, consequentemente, diminui a saturação de Al nos solos ácidos, melhorando a produtividade agrícola (SANCHEZ \& COCHRANE, 1980), além de ser mais resistente à mineralização quando comparada com a MO do solo (LEHMANN, 2007).

O BC embora possa ser considerado estável no sistema solo, também sofre biodegradação e transformação quando comparado a outras formas de MO (MADARI et.al., 2006). O BC pode ser significativamente degradado dentro da escala de tempo de décadas ou séculos em solos sob clima subtropical. A meia-vida das partículas carbonizadas com tamanho $<2 \mathrm{~mm}$ foi estimada em menos de 50 anos, e a de partículas com > $2 \mathrm{~mm}$ em menos de 100 anos (BIRD et. al., 1999). A biodegradação do BC no solo é um processo relativamente lento que resulta na mobilização do carbono e na alteração das propriedades da superfície do carvão, aumentando a concentração de sítios quimicamente reativos que contribuem para a CTC do solo.

Dois aspectos sobre a aplicação do BC em solo são valiosos: (1) estabilidade em relação à decomposição e (2) sua habilidade superior em reter nutrientes quando comparado a solos ricos em MO. E três benefícios ambientais podem ser alcançados por estas propriedades: (1) mitigação nas mudanças climáticas; (2) melhoria na fertilidade dos solos; e (3) redução de poluição ambiental (LEHMANN, 2007).

Estas propriedades fazem do $\mathrm{BC}$ um material sem igual na retenção e disponibilização de nutrientes do solo para as plantas, melhorando significativamente o crescimento, a nutrição das plantas e consequentemente, a produtividade das culturas (LEHMANN et al., 2003; STEINER et al., 2007). Chidumayo (1994) encontrou melhora de $30 \%$ na germinação das sementes, de $24 \%$ no crescimento e de $13 \%$ na produção de biomassa, entre sete tipos de plantas lenhosas nativas, em solos contendo carvão e em solos como os Alfisols e Ultisols sem ação antropogênica.

Ainda não foram encontradas as quantidades ótimas de BC para o crescimento ideal das plantas, cuja quantidade deve ser determinada para cada tipo de solo e planta. Dados recentes mostraram rendimentos de culturas bem maiores com adição de $\mathrm{BC}$ do que com adição de fertilizantes inorgânicos ou orgânicos (GLASER et al., 2002b; LEHMANN et al., 2002). 
Em solos onde o sistema de manejo possibilita acúmulo de material orgânico, como a adição de $\mathrm{BC}$, as condições são favoráveis à fertilidade do solo, ao desenvolvimento microbiano, além da reciclagem de resíduos e de nutrientes (MADARI et al, 2009).

\subsection{Pirólise}

A partir da crise do petróleo de 1973, a implementação de fontes de energia alternativas passou a ter um crescimento contínuo no mundo todo. Vários programas começaram a ser desenvolvidos visando principalmente o aproveitamento energético de resíduos agrícolas ou biomassa (SÁNCHEZ, 1994).

A quantidade estimada de biomassa existente na Terra é da ordem de 1,8 trilhões de toneladas segundo o estudo da Estatistical Review of World Energy. No Brasil, em 2007, a biomassa teve participação de $31,1 \%$ na matriz energética, sendo a segunda principal fonte de energia, superada apenas por petróleo e derivados (ANEEL, 2009).

Conforme relata estudo sobre o tema inserido no Plano Nacional de Energia 2030, a melhor região do planeta para a produção da biomassa é a faixa tropical e subtropical, entre o Trópico de Câncer e o Trópico de Capricórnio, que abrange alguns países das Américas Central e do Sul, entre eles o Brasil, o continente africano e Austrália. Estes últimos são caracterizados pela existência de áreas desérticas e, portanto, pouco propensos à produção agrícola (ANEEL, 2009).

O Brasil, porém, apresenta solo e condições climáticas adequadas para a produção agrícola, gerando biomassa para a produção de biocombustíveis e energia elétrica.

Pirólise é uma das muitas formas de se produzir energia a partir de biomassa (BRIDGWATER, 2003). O que distingue a pirólise dos outros modos alternativos de se converter biomassa em energia é a produção de um subproduto rico em carbono orgânico: o biocarvão.

Os produtos obtidos dependem tanto da matéria-prima utilizada quanto da tecnologia de processamento para obtenção dos energéticos. O processo pode ser ajustado para a produção de $\mathrm{BC}$, bio-óleo ou gás. 
Na pirólise, a biomassa é aquecida com ausência parcial ou total de oxigênio, em temperaturas ótimas entre 450 a $550^{\circ} \mathrm{C}$, para produção de $\mathrm{BC}$ (LEHMANN, 2007). Nestas temperaturas, a biomassa sofre decomposição térmica de seus precursores orgânicos por processo exotérmico, liberando grandes quantidades de componentes voláteis e calor, produzindo uma matriz carbonosa com estrutura porosa rudimentar (CZERNIK \& BRIDGWATER, 2004), além de gás rico em hidrocarbonetos e bio-óleo (Figura 2). Ambos, os gases e o bio-óleo, podem ser aproveitados na produção de energia elétrica, biocombustíveis e hidrogênio para uso doméstico e em carros.

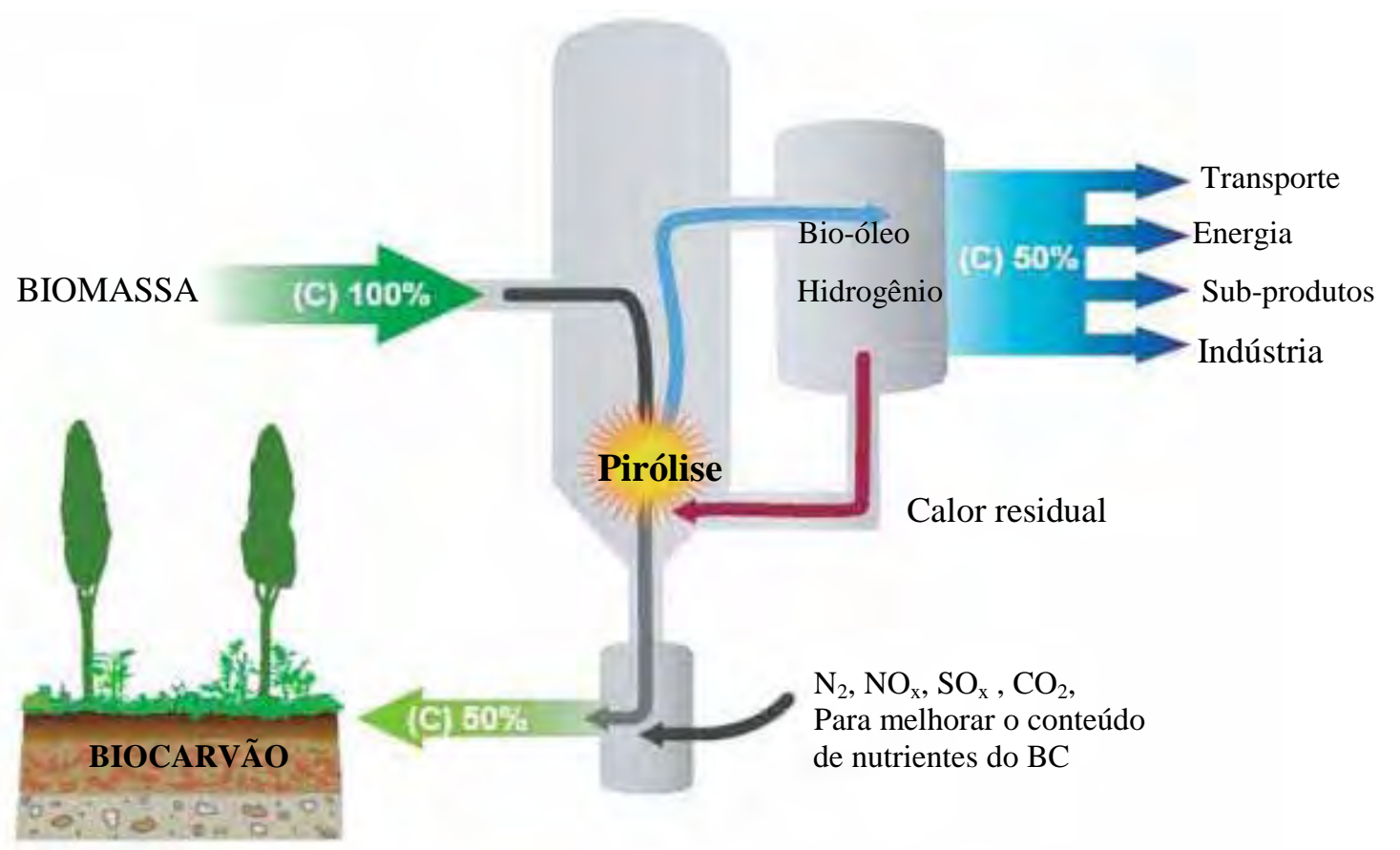

Figura 2. Conceito de pirólise e sequestro de carbono por LEHMANN (2007).

Além da energia, podem ser obtidos valiosos co-produtos como conservantes para madeira, corante para carne, condimento de comida, adesivo ou compostos químicos específicos (CZERNIK \& BRIDGWATER, 2004), como também pode ser utilizado no seqüestro de carbono (LEHMANN, 2007).

Três fatores principais influenciam as propriedades do BC produzido por pirólise: (I) natureza e estado físico da MO utilizada, (II) o ambiente da queima como: temperatura, 
conteúdo de oxigênio, tempo de retenção e (III) adições durante o processo de queima, de compostos contendo nitrogênio $(\mathrm{N})$, enxofre $(\mathrm{S})$, potássio $(\mathrm{K})$, fósforo $(\mathrm{P})$.

As condições de queima influenciam no grau de compostos aromáticos e nas características de adsorção do BC. O grau de compostos aromáticos no BC é maior quanto maior for a temperatura (SHAFIZADEH \& SEKIGUCHI, 1983) o tempo de retenção e a presença de ar (GLASER et al., 2002a).

\subsection{Matéria orgânica}

$\mathrm{Na}$ natureza, o solo encontra-se como um sistema aberto, trocando matéria e energia com o meio. Este sistema atinge um estado estável quando as taxas de adição e de perda se equivalem (ADDISCOT, 1992). Dentro deste conceito, a adição de MO ocorre via adição de $\mathrm{C}$ pela síntese de compostos orgânicos no processo de fotossíntese, que no caso da vegetação natural encontra-se em equilíbrio.

Entretanto, sob intervenções antropogênicas, a quantidade de carbono adicionado depende das espécies e dos sistemas de cultivos utilizados. Já as perdas de C ocorrem principalmente pela liberação de $\mathrm{CO}_{2}$ na respiração, decomposição microbiana da $\mathrm{MO}$ do solo, perdas dos compostos orgânicos por lixiviação e erosão. A magnitude desses processos depende direta ou indiretamente do manejo do solo (MIELNICZUK, 2008).

Em solos de regiões tropicais, solos altamente intemperizados, a MO tem grande importância como fonte de nutrientes, na retenção de cátions, complexação de elementos tóxicos, estabilidade da estrutura, infiltração, retenção de água e aeração, e serve como fonte de nutrientes e energia para os microrganismos do solo, constituindo-se, assim, num componente fundamental do potencial produtivo destes solos (BAYER \& MIELNICZUK, 2008).

De maneira geral, os efeitos benéficos da MO na agricultura tornam-se mais expressivos em solos quimicamente mais pobres e naqueles com texturas mais grosseiras, textura média ou arenosa. Nestes solos, pode-se destacar como principais características: baixa capacidade da troca de cátions (CTC), baixo teor de fósforo disponível, baixa fertilidade 
natural ou capacidade de adsorção do nutriente, insignificantes teores de micronutrientes, baixo conteúdo de MO, alto nível de alumínio trocável (SOUZA, 2005).

No solo, a MO acumulada e a deterioração lenta contribuem com o seqüestro de C-atmosférico. Os resíduos de plantas (ex. folhas, galhos, frutos) que caem sobre o solo são gradualmente alterados por meio da fragmentação física, interações entre a fauna do solo, microorganismos e formação de húmus.

Estima-se que os solos contenham cerca de $1500 \mathrm{Gt}$ de $\mathrm{C}$ no primeiro metro de profundidade, dos quais $44 \%$ encontram-se em solos dos trópicos (JOBBAGY \& JACKSON, 2000), isto devido às condições climáticas mais favoráveis à decomposição nessa região. A dinâmica de C no solo ganhou importância para se compreender o papel do solo como fonte ou dreno de $\mathrm{CO}_{2}$ da atmosfera (ALVES et al., 2005).

A quantidade de MO na matriz do solo é a diferença entre o aporte e a decomposição, sendo que uma variedade de fatores químicos, físicos e biológicos do ecossistema controla a concentração final da MO presente no solo.

A manutenção apropriada dos níveis de $\mathrm{MO}$ e do ciclo biológico de nutrientes é crucial para o sucesso do manejo em qualquer solo tropical. Cobertura vegetal, material vegetal, composto, adições de esterco animal e também o BC tem sido utilizado com sucesso, no suprimento de nutrientes para as culturas, auxiliando o rápido ciclo de nutrientes através da biomassa microbiana (GOYAL et al., 1999; TRUJILLO, 2002; LEHMANN et al. 2002).

Os benefícios de tal melhoramento, no entanto, são de vida curta, especialmente em solos tropicais onde as taxas de decomposição são altas (JENKINSON \& AYANABA, 1977) e a adição de MO é mineralizada a $\mathrm{CO}_{2}$ em poucos meses (BOL et al., 2000), com exceção do BC que possui poder recalcitrante no solo (ZECH et al., 1990; SCHMIDT \& NOACK, 2000; GLASIER et al., 2000, 2001 e 2002b).

A adubação orgânica apresenta liberação lenta de nutrientes quando comparada com os adubos minerais, dependente da mineralização da MO, proporcionando disponibilidade ao longo do tempo, o que muitas vezes favorece melhor aproveitamento, principalmente do fósforo e do nitrogênio (RAIJ et al., 1996). As quantidades de MO normalmente aplicadas variam de 10 a $100 \mathrm{t} \mathrm{ha}^{-1}$ de esterco bovino e dependem da cultura e do grau de pureza do esterco (RAIJ et al., 1996). 
A MO representa um conjunto de substâncias altamente heterogêneo, incluindo numerosos compostos de carbono, variando de açúcares, proteínas e outros constituintes biológicos, ácidos orgânicos de baixas massas moleculares, como os ácidos acético e oxálico, até o conjunto complexo de produtos recalcitrantes resultantes de transformações químicas e microbianas da MO do solo, as substâncias húmicas, que têm como principais constituintes, os ácidos húmico e fúlvico (NOVOTNY et al., 1999, apud BUDZIAK et al., 2004).

As substâncias húmicas interagem com o material mineral do solo aumentando sua capacidade em trocar cátions (STEVENSON, 1982), interferindo, assim, na dinâmica de nutrientes no sistema solo-planta, exercendo papel primordial na manutenção da fertilidade do solo (MENDOZA, 1996).

A importância das frações humificadas na dinâmica dos elementos no solo se estende também às interações com os fertilizantes, podendo aumentar ou reduzir sua efetividade, além de amortecer os efeitos adversos de altas doses, regulando desta forma, as condições de nutrição mineral das plantas (VAUGHAN \& ORD 1985).

Ácidos húmicos e fúlvicos apresentam alto teor de grupos funcionais contendo oxigênio, representados na Tabela 2, tais como, carboxilas, hidroxilas fenólicas e carbonilas de vários tipos (JORDÃO et al., 1993). Estes grupamentos são importantes na formação de cargas negativas no solo, aumentando sua CTC e, consequentemente, o estoque de nutrientes no solo. 
Tabela 2. Conteúdo de grupos oxigenados $\left(\mathrm{cmol}_{\mathrm{c}} \mathrm{kg}^{-1}\right)$ e ácidos húmicos e fúlvicos extraídos de diferentes tipos de solos

\begin{tabular}{|c|c|c|c|c|}
\hline \multirow{3}{*}{ Grupo Funcional } & \multicolumn{4}{|c|}{ Solo } \\
\hline & Ácido & Neutro & Subtropical & Tropical \\
\hline & \multicolumn{4}{|c|}{ Ácidos Húmicos } \\
\hline & \multicolumn{4}{|c|}{ 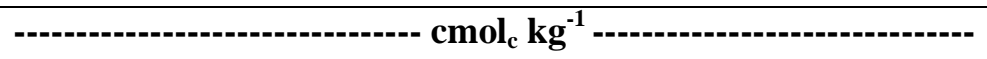 } \\
\hline Acidez total & $570-890$ & $620-660$ & $630-770$ & $620-750$ \\
\hline $\mathrm{COOH}$ & $150-570$ & $390-450$ & $420-520$ & $380-450$ \\
\hline OH ácido & $320-570$ & $210-250$ & $210-250$ & $220-300$ \\
\hline OH alcoólico & $270-350$ & $240-320$ & 290 & $20-160$ \\
\hline Quinona $\mathrm{C}=\mathrm{O} /$ Cetona $\mathrm{C}=\mathrm{O}$ & $10-180$ & $450-560$ & $80-150$ & $30-140$ \\
\hline \multirow[t]{3}{*}{$\mathrm{OCH}_{3}$} & 40 & 30 & $30-50$ & $60-80$ \\
\hline & \multicolumn{4}{|c|}{ Ácidos Fúlvicos } \\
\hline & --------------. & ----- ci & $g^{-1}$ & ------- \\
\hline Acidez total & $890-1420$ & - & $640-1230$ & $820-1030$ \\
\hline $\mathrm{COOH}$ & $610-850$ & - & $520-960$ & $720-1120$ \\
\hline OH ácido & $280-570$ & - & $120-270$ & $30-570$ \\
\hline OH alcoólico & $340-460$ & - & $690-950$ & $260-950$ \\
\hline Quinona $\mathrm{C}=\mathrm{O} /$ Cetona $\mathrm{C}=\mathrm{O}$ & $170-310$ & - & $120-260$ & $120-420$ \\
\hline $\mathrm{OCH}_{3}$ & $30-40$ & - & $80-90$ & $30-120$ \\
\hline
\end{tabular}

Fonte- Adaptado de STEVENSON (1985).

Reações de troca iônica do solo são processos reversíveis, ou temporariamente irreversíveis, pelos quais as partículas sólidas do solo, minerais, MO, adsorvem os íons da fase aquosa e ao mesmo tempo, dessorvem quantidades equivalentes de outros íons de mesma carga e estabelecem o equilíbrio dinâmico entre as fases.

Os principais mecanismos que levam a troca de íons são: (I) forças de natureza eletrostática: estas forças comandam a maior parte da dinâmica dos nutrientes em relação às plantas; (II) ligações de caráter covalente, complexos e quelatos: elementos ligados covalentemente ficam menos solúveis e disponíveis às plantas; (III) precipitação: implica na manutenção da eletroneutralidade do sistema e, conseqüentemente, trocas iônicas no solo (LUCHESE et al., 2002). 
A MO do solo, devido ao seu papel vital na manutenção da qualidade do solo, é fator chave nas modernas práticas de manejo do solo e para a manutenção da sustentabilidade dos agroecossistemas tropicais (MADARI et al, 2009).

\subsection{Fósforo no solo}

O fósforo é um nutriente essencial para as plantas, componente da adenosina difosfato (ADP) e adenosina trifosfato (ATP), compostos responsáveis pelo transporte de energia dentro das plantas. Componente também dos ácidos nucléicos, fazendo parte das moléculas de DNA e RNA, além dos fosfolipídios das biomembranas (NYLE, 2001).

Classificado como macronutriente, pela grande quantidade exigida pelas plantas, o P é o nutriente mais limitante da produtividade de biomassa na maioria dos solos tropicais (NOVAIS \& SMYTH, 1999), devido à carência existente em conseqüência do material de origem e da forte interação do P com o solo (RAIJ, 1991), fenômeno este conhecido como adsorção.

No solo, o P encontra-se nas formas orgânica e inorgânica. A forma orgânica está associada ao conteúdo de MO no solo, encontrado em maiores quantidades no horizonte superficial decrescendo em função da profundidade, variando de 15 a $80 \%$ na maioria dos solos (STEVENSON 1986; RHEINHEIMER \& ANGHINONI, 2003).

As principais formas de $\mathrm{P}$ já identificadas no solo são os fosfatos de inositol, que compõem de 10 a $80 \%$ do fósforo orgânico total, os fosfolipídios ( 0,5 a 7\%), ácidos nucléicos $(\sim 3 \%)$ e outros ésteres-fosfato ( $>5 \%)$. A estabilidade destes compostos depende de sua natureza e de sua interação com a fração mineral, pois são usados como fonte de carbono e elétrons pelos microrganismos, resultando na disponibilização do $\mathrm{P}$ pelo processo de mineralização (ENWEZOR, 1967; SHARPLEY, 1985)

A forma inorgânica, disponível para absorção pelas raízes das plantas e pelas hifas de micorrizas da solução do solo, se apresenta nas formas dos íons ortofosfato $\mathrm{H}_{2} \mathrm{PO}_{4}{ }^{-}$e $\mathrm{HPO}_{4}{ }^{2-}$, dependendo do $\mathrm{pH}$. O cultivo das plantas é indicado na faixa de $\mathrm{pH}$ de 5,0 a 6,5, onde predomina o íon monovalente $\mathrm{H}_{2} \mathrm{PO}_{4}{ }^{-}$(HALVIN et al., 2005). 
O fósforo inorgânico $(\mathrm{Pi})$ que está na solução do solo e que não é absorvido pelas plantas ou imobilizado pelos microrganismos está sujeito a sofrer inúmeras reações químicas. Uma combinação dinâmica dos processos: (I) adsorção/dessorção: processos fisioquímico onde o Pi é fixado/liberado pela superfície dos minerais no solo; (II) precipitação/dissolução: processos químico onde o Pi torna-se insolúvel/solúvel; (III) imobilização/mineralização: processos biológico onde o Pi torna-se orgânico e o $\mathrm{P}$ orgânico torna-se inorgânico, pela biomassa microbiana do solo (CAMPBELL \& EDWARDS, 2001; BARROS FILHO et al., 2005). A taxa em que cada um desses processos ocorre depende da proporção das diferentes formas de $\mathrm{P}$ no solo (P solúvel, $\mathrm{P}$ lábil e $\mathrm{P}$ não lábil), intemperismo e cobertura vegetal.

\subsubsection{Reações do $P$ no solo}

\section{- Precipitação}

Precipitação é uma reação lenta onde os ânions fosfato reagem com os cátions dissolvidos $\mathrm{Al}^{3+}, \mathrm{Fe}^{3+}, \mathrm{Mn}^{2+}$ (em solos ácidos) e $\mathrm{Ca}^{2+}$ (solos neutros e calcários), formando compostos insolúveis na forma de hidróxido de fosfato precipitado (SANCHEZ \& UEHARA, 1980), reação dependente de $\mathrm{pH}$.

Variscita $\left(\mathrm{AlPO}_{4} 2 \mathrm{H}_{2} \mathrm{O}\right)$ e Strengita $\left(\mathrm{FePO}_{4} 2 \mathrm{H}_{2} \mathrm{O}\right)$ são os minerais estáveis mais comuns em solos ácidos, enquanto que em solos alcalinos os minerais mais estáveis são os fosfatos de cálcio na forma de fosfato octacálcico $\left[\mathrm{Ca}_{8} \mathrm{H}\left(\mathrm{PO}_{4}\right)_{6} 5 \mathrm{H}_{2} \mathrm{O}\right]$ e hidroxiapatita $\left[\mathrm{Ca}_{5} \mathrm{H}\left(\mathrm{PO}_{4}\right)_{3} \mathrm{OH}\right]$. A solubilidade dos minerais Ca-P diminui com o aumento de $\mathrm{pH}$; entretantob os minerais Al-P e Fe-P exibem aumento da solubilidade com o aumento do pH (LINDSAY \& MORENO, 1960).

Em contraste com o processo de precipitação, a adsorção é relativamente rápida no início da reação envolvendo troca de ânions e ligantes. Cargas negativas do íon fosfato encontradas na solução do solo são atraídas pelas cargas positivas encontradas nas superfícies dos minerais do solo, via troca de ânions (SCHINDLER \& SPOSITO, 1991). 


\section{- Mineralização/ Imobilização}

A liberação do $\mathrm{P}$ da MO para a solução do solo ocorre através do processo de mineralização, ou seja, transformação do $\mathrm{P}$ orgânico em $\mathrm{P}$ inorgânico, enquanto o processo inverso é denominado imobilização. A mineralização é catalisada pelas enzimas do tipo fosfatase, produzidas por plantas, fungos e bactérias localizadas principalmente na rizosfera. $\mathrm{O}$ tipo da enzima varia de acordo com o pH do solo e o composto a ser degradado, denominando-se fosfatase ácida, com pH ótimo de atividade catalítica na faixa de 4 a 6 e fosfatase básica com maior eficiência na faixa de 9 a 11 (FERNANDES, 2000).

Os processos de mineralização/imobilização são influenciados pela temperatura, homogeneidade do material vegetal, aeração, tipo de cultivo e $\mathrm{pH}$ da solução do solo (STEWART \& TISSEN, 1987).

\section{- Sorção}

Uma vez que é difícil distinguir se a adesão das moléculas de $\mathrm{P}$ da solução do solo com a superfície sólida do solo foi por reação de adsorção ou precipitação, é usual referir-se como sorção de P.

A adsorção é um processo químico e específico, nele as moléculas de $\mathrm{P}$ unem-se à superfície do solo através da formação de ligações químicas (geralmente covalentes) e tendem a se acomodarem em sítios que propiciem o maior número de coordenação possível com o substrato.

Adsorção por trocas de ligantes resultam quando uma ligação covalente metal-O-P é formada para repor as hidroxilas nas pontes das camadas das argila-silicato e a superfície dos óxidos insolúveis de $\mathrm{Al}, \mathrm{Fe}$, e/ou Mn. Este processo refere-se à adsorção específica ou quimiosorção (SCHINDLER \& SPOSITO, 1991).

Sorção de $\mathrm{P}$ tende a aumentar ao longo do tempo, aparentemente devido à lentidão do processo de precipitação que é sobreposto à quimiosorção (VAN der ZEE \& VAN RIEMSDIJK, 1991).

Experimentalmente, mede-se a sorção em termos de quantidade de substâncias adsorvidas por quilograma do sólido, com a finalidade de se obter as chamadas isotermas de 
adsorção. Essas isotermas são gráficos onde estão representados miligramas de $\mathrm{P}$ adsorvido por quilograma de solo, versus concentração de $\mathrm{P}$ na solução do solo em equilíbrio, dadas em miligramas por litro.

As isotermas de adsorção descrevem as relações de equilíbrio entre a quantidade de um elemento adsorvido e a quantidade remanescente na solução final, sendo úteis para quantificar a adsorção de íons no solo (OLSEN \& WATANABE, 1954; NOVAIS \& SMYTH, 1999).

A fração inorgânica do $\mathrm{P}$ no solo encontra-se presente em duas fases, sólida e líquida, as quais estão em equilíbrio entre si. Desta forma, o P solúvel adicionado aos solos, como fertilizante, tende a passar rapidamente para formas menos solúveis, com consequente redução da disponibilidade às plantas, ficando precipitado ou adsorvido, Figura 3.

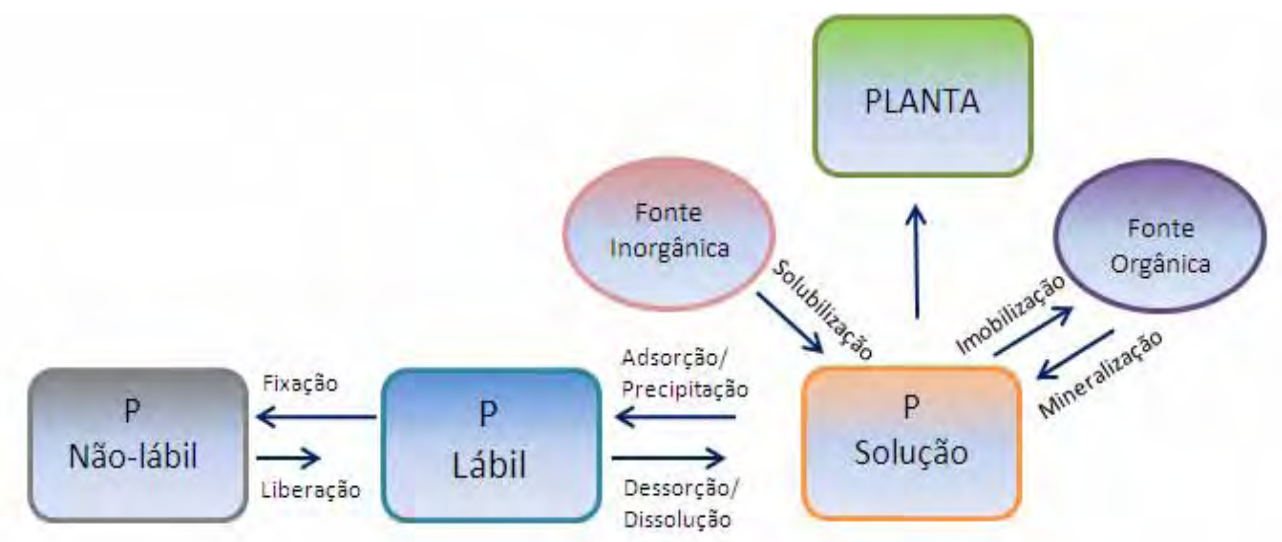

Figura 3. Reações do P no solo

Fonte: Adaptado de NOVAIS \& SMYTH (1999)

Para que a absorção pelas plantas seja contínua, o Pi deve liberar-se da fase sólida e movimentar-se, por difusão, até a superfície das raízes. E esta movimentação depende do $\mathrm{P}$ em solução e, consequentemente, do $\mathrm{P}$ disponível (P lábil), da umidade do solo, como também do $\mathrm{pH}$ do solo, pois a elevação do $\mathrm{pH}$ promove diminuição na retenção de $\mathrm{P}$ devido à liberação de hidroxilas que competem com os íons fosfatos pelos sítios de adsorção. 
Porém, com o tempo, parte do P-lábil é convertido em formas mais estáveis de difícil solubilização, tornando o elemento não disponível ou dificilmente disponível. Como conseqüência destes fatos, observa-se que há grande diminuição da concentração de $\mathrm{P}$ na solução do solo para as plantas, embora exista muito P no solo, mas em forma indisponível.

O fósforo é distribuído no solo da seguinte forma: 98 a $99 \%$ são associadas a minerais primários ou secundários e à $\mathrm{MO}, 1$ a $2 \%$ aos tecidos dos microrganismos e somente 0,01\% existente como a forma solúvel, assimilável às plantas (NYLE, 2001). Isto se deve à adsorção de P no solo, que ocorre através de ligações eletrostáticas e/ou covalentes, e de precipitação, com formação de compostos pouco solúveis ou insolúveis fixando o $\mathrm{P}$ ao entrarem em contato com a fase sólida do solo, não o disponibilizando às plantas (ALCARDE et al., 1991; AQUINO, 2004).

O fenômeno de fixação de $\mathrm{P}$ vem sendo estudado em várias partes do mundo, há algumas décadas. Já por volta de 1930, conforme afirmam Romine \& Metzger (1939), os solos amarelados fixavam fósforo mais prontamente que os avermelhados, devido à diferença nos compostos de ferro, e chegaram à conclusão de que os solos escuros, ricos em MO, tinham geralmente baixa capacidade de fixação do elemento.

Muitos são os fatores que podem influenciar a adsorção de $\mathrm{P}$, principalmente os que se relacionam com o comportamento físico-químico dos colóides como:

(I) Teor e mineralogia da fração argila dos solos: solos mais argilosos, com argilas do tipo $1: 1$, retém mais $\mathrm{P}$, comparadas às argilas $2: 1$, o que provavelmente se deve à maior quantidade de óxidos de $\mathrm{Fe}$ e $\mathrm{Al}$ associadas a elas. As formas de óxidos de ferro e alumínio de baixa cristalinidade apresentam maior área superficial específica, o que determina sua maior reatividade química com os fosfatos;

(II) Concentração hidrogeniônica (pH): a elevação do pH no solo diminui a retenção de $\mathrm{P}$, devido à liberação de hidroxílas que competem com os íons fosfatos pelos sítios de adsorção e também, por elevar a CTC em solos de cargas variáveis, aumentando a repulsão;

(III) Alumínio trocável: responsável por insolubilizar P no solo;

(IV) Cátions associados com o fosfato e MO: a presença de cátions como $\mathrm{Fe}^{3+}, \mathrm{Al}^{3+} \mathrm{e} \mathrm{Ca}^{2+}$ favorece a retenção de $\mathrm{P}$ nos solos, pois esses cátions reagem com os fosfatos, formando compostos de baixa solubilidade, como fosfatos de ferro, de alumínio e de cálcio, que se precipitam na solução. Já a MO, uma das principais características que influem na adsorção de 
P (GONÇALVES et al., 1985), interage com os óxidos de Al e Fe resultando em redução dos sítios de fixação, por causa do recobrimento da superfície desses óxidos por moléculas de ácidos húmicos, acético e málico, ou pela formação de compostos na solução do solo. Esse efeito, no entanto, é temporário (FONTES et al., 1992; AFIF et al., 1995; ANDRADE et al., 2003; NAKOS, 1987; MEHADI \& TAYLOR, 1998; BRENNAN et al., 1994; KER et al., 1996; FONTES \& WEED 1996, CAMPBELL \& EDWARDS, 2001; ABDALLA \& PROCHNOW, 2008).

Grande parte dos solos brasileiros são intemperizados e apresentam óxidos de ferro e de alumínio, além de argilas do grupo da caulinita como principais constituintes da fração argila, minerais caracterizados pela presença de cargas de superfície variáveis segundo a reação da solução do solo (VOLKSWEISS \& RAIJ, 1977).

$\mathrm{Na}$ maioria dos Latossolos, existem predomínio de cargas elétricas negativas variáveis, existindo também cargas elétricas positivas. Estas cargas positivas se tornam maioria quando o $\mathrm{pH}$ do solo é suficientemente ácido para causar o acoplamento excessivo dos íons $\mathrm{H}^{+}$aos grupos funcionais de superfície, como radicais hidroxilas $\left(\mathrm{R}-\mathrm{OH}^{-}\right)$, carboxílicos $\left(\mathrm{R}-\mathrm{COOH}^{-}\right)$e fenólicos $\left(\mathrm{Ar}-\mathrm{OH}^{-}\right)$, sendo assim capazes de reter em sua superfície vários tipos de ânions, predominantemente os íons fosfatos (KAMPRATH, 1977; VOLKSWEISS \& RAIJ, 1977; HEDLEY et al., 1990; NOVAIS et al., 1991).

O papel desempenhado pela MO é ambivalente, já que ela tanto pode adsorver o fósforo como também bloquear os sítios de adsorção que ocorrem nas superfícies das argilas e dos óxidos de ferro e alumínio (SANYAL \& de DATTA, 1991). Quanto à mineralogia e características de cristalinidade dos óxidos de ferro e alumínio, vários estudos têm mostrado que a capacidade de adsorção de fósforo parece estar relacionada com a área superficial do óxido (FONTES \& WEED, 1996) e com o seu grau de cristalinidade.

A capacidade de sorção de $\mathrm{P}$ nos solos brasileiros pode chegar a $4 \mathrm{t} \mathrm{ha}^{-1}$ (KER, 1995), o que pode equivaler a taxas de adsorção acima de 80\% (RODRIGUES, 1980; THOMAZI, 1988; SANCHES \& UEHARA, 1980), decorrente dos óxidos de ferro e alumínio presente nos solo. 


\section{- Dessorção}

Dessorção é um processo fundamental para definir a biodisponibilidade de P no solo. A liberação de Pi no solo ocorre devido ao desequilíbrio criado pela remoção de $\mathrm{P}$ da solução do solo ou em resposta à ação de troca de ligantes com o fosfato ou pela dissolução de compostos que contém fosfato em sua estrutura (SATO \& COMERFORD, 2006).

O fosfato é sorvido à fase sólida do solo com diversas energias de ligação, dependentes das características e quantidade dos colóides do solo (GATIBONI, 2003), que ocorre em três estágios temporais. No estágio I, predomina a neutralização das cargas positivas, que são saturadas quando todos os grupos $\mathrm{R}_{-} \mathrm{OH}_{2}{ }^{+}$forem compartilhados pelos íons fosfatos; no estágio II, ocorrem as trocas de ligantes e, no estágio III, interações de caráter físico entre o fosfato e a superfície dos colóides inorgânicos (PARFITT et al., 1975; RYDEN et al., 1977). Portanto, a reversibilidade destas reações é dependente da proporção de ocupação dos sítios de adsorção, ou de outros fatores que alteram a magnitude da energia de ligação como deste elemento com os colóides do solo (RHEINHEIMER \& ANGHINONI, 2003), gerando um desequilíbrio entre a fase sólida e líquida do solo, coerente com o princípio de Le Châtelier.

Este desequilíbrio pode ser gerado pela absorção de $\mathrm{P}$ da solução do solo pelas raízes das plantas, lixiviação do elemento, precipitação de minerais fosfatados secundários, mudança de $\mathrm{pH}$ da rizosfera que muda as cargas de superfície e solubilidade, ou durante a imobilização pela microbiota do solo. Ou seja, à medida que a concentração de $\mathrm{P}$ na solução diminui, o $\mathrm{P}$ é reposto através de dessorção pelo $\mathrm{P}$ adsorvido à superfície do solo na troca com outros ânions na solução, ou por dissolução de compostos relativamente solúveis (WOLF \& LONDON, 1994).

Deste modo, a escolha da metodologia de análise para dessorção deve ser a mais próxima possível à biodisponibilização natural do $\mathrm{P}$ no solo. $\mathrm{O}$ reservatório mais comum de $\mathrm{P}$ está relacionado a porção extraível de P lábil presente na reserva de Pi por extratores como Bray 1, Mehlich 1 ou 3, solução de Olsen (BRAY \& KURTZ, 1945; MEHLICH, 1953, 1984; OLSEN et al., 1954). Entretanto, essas análises são somente interpretadas quando combinadas com dados contendo plantações em experimentos de campo ou casa de vegetação 
(KLEINMAN et al., 2001). Portanto, não medem o reservatório de P biodisponível; agem somente como índice de P biodisponível no solo.

Não existe interpretação para a quantidade de $\mathrm{P}$ extraído por nenhum desses métodos, pois eles não definem um padrão de $\mathrm{P}$ disponível nem a influência da dessorção de $\mathrm{P}$ na concentração do elemento na solução do solo. Essas técnicas são limitadas pelo mecanismo modelo de biodisponibilidade de $\mathrm{P}$ no solo e sua absorção pelas plantas (SATO \& COMERFORD, 2006).

O processo de dessorção de $\mathrm{P}$ é pouco compreendido e praticamente nenhuma informação existe para solos tropicais (BORROW, 1974, BARROS et al., 2005); entretanto, é de grande importância, pois este é um dos fatores que controlam a concentração de $\mathrm{P}$ na solução do solo e podem ser caracterizados por isotermas de dessorção, onde o Pi ou P-labil na fase sólida $\left(C_{\mathrm{s}}\right.$, unidade $\left.=\mathrm{mg} \mathrm{kg}^{-1}\right)$ se encontra em equilíbrio com o $\mathrm{P}$ na solução do solo $\left(\mathrm{C}_{\mathrm{l}}\right.$, unidades $=\mathrm{mg} \mathrm{l}^{-1}$ ). E permite ainda estimar o poder tampão do solo, calcular o coeficiente de dessorção $\left(\mathrm{k}_{\mathrm{d}}=1 \mathrm{~kg}^{-1}\right)$, calculado pelo coeficiente angular da isoterma, que permite descrever a distribuição instantânea do P lábil entre a fase solida e líquida do solo, além de usar em modelos de absorção de nutriente (BARROS et al., 2005).

Isotermas de dessorção de $\mathrm{P}$ podem ser analisadas, a partir de diluição, extração sequencial com solução salina diluída $(\mathrm{KCl} 0,1 \mathrm{M})$, membranas de troca aniônica (BHATTI \& COMERFORD, 2002; SATO \& COMERFORD, 2006; BARROS et al., 2005). Mas atualmente não existe nenhum método padrão para o desenvolvimento de isotermas de dessorção (BARROS et al., 2005; SATO \& COMERFORD, 2006).

Para o método de análise de dessorção de $\mathrm{P}$ com membranas de troca aniônica, Sato \& Comerford (2005), utilizando Argissolo Vermelho distrófico encontraram um tempo ótimo de agitação de 2 a 4 horas, sendo que acima de 4 horas até 50 horas o conteúdo de $\mathrm{P}$ decresceu. Obtiveram resposta com utilização de até seis membranas, isto porque acima desse número, houve interferência entre as próprias membranas no tempo de agitação proposto. 


\section{MATERIAL E MÉTODOS}

\subsection{Descrição do Local}

A pesquisa foi realizada em casa de vegetação, no Departamento de Recursos Naturais - Ciência do Solo da Faculdade de Ciências Agronômicas/UNESP, em Botucatu-SP (22 $51^{\circ}$ " S, 48 $26^{\circ}$ " W e 786m), com clima temperado quente (mesotérmico), chuva no verão e seca no inverno (Cwa - Koppen), temperatura média anual de $21,6^{\circ} \mathrm{C}$ (CUNHA et al., 1999). Classificou-se o solo utilizado, degradado por erosão laminar, como Latossolo Vermelho distrófico equivalente aos critérios de classificação Embrapa (1999). Suas características químicas estão apresentadas na Tabela 3.

Tabela 3. Características químicas do solo Latossolo Vermelho

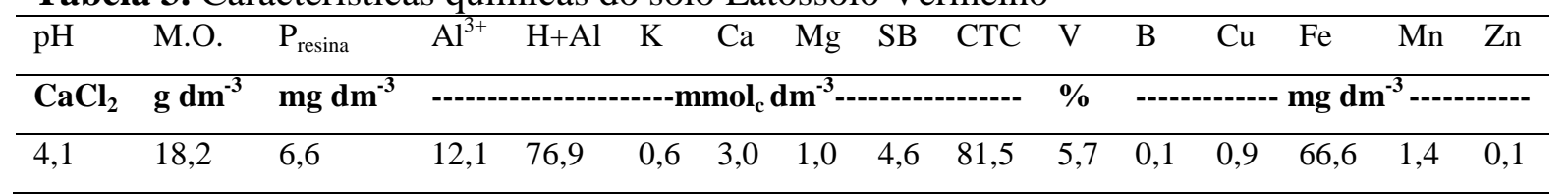

* Análise dos teores disponíveis dos elementos por RAIJ et al., 1996. 


\subsection{Produção de biocarvão}

A produção do $\mathrm{BC}$, subproduto do bio-óleo, foi realizada pela planta piloto de pirólise rápida da empresa Bioware, incubada pela UNICAMP, localizada em Campinas, a $174 \mathrm{Km}$ de Botucatu (Figura 4).

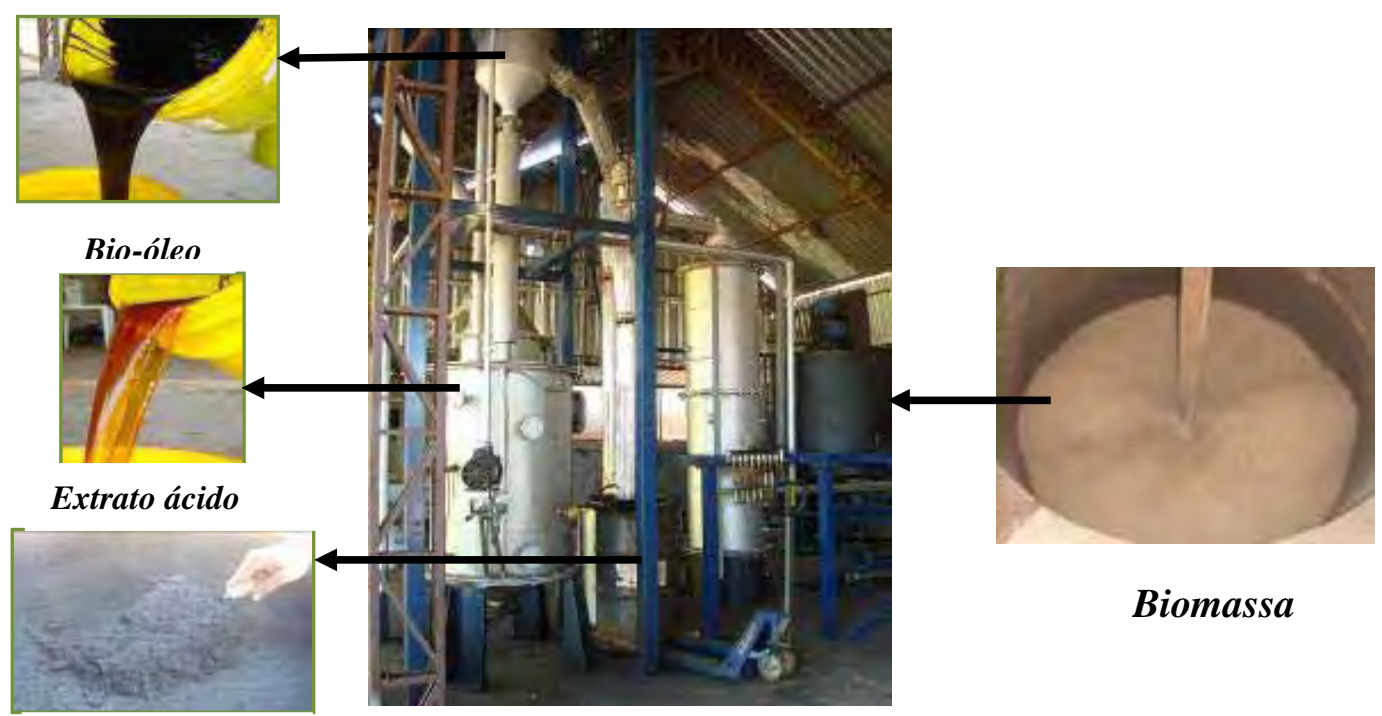

Biocarvão

Figura 4. Planta piloto de pirólise rápida, matéria-prima (Biomassa), produto (Bio-óleo) e subprodutos (Extrato ácido e BC).

Foram carbonizadas, separadamente, biomassas de capim elefante, serragem (vários tipos de madeiras) e palha de cana-de-açúcar, em reator de leito fluidizado borbulhante, com capacidade de queima de $200 \mathrm{~kg} \mathrm{~h}^{-1}$, com temperatura do leito na faixa de 450 a $500^{\circ} \mathrm{C}$ e pressão de 120 a $250 \mathrm{mmH}_{2} \mathrm{O}$; injetou-se $10 \%$ de ar em relação ao estequiométrico com tempo médio de residência de 8 segundos. As características químicas estão descritas na Tabela 4 e 5. 
Tabela 4. Características químicas dos elementos disponíveis do biocarvão

\begin{tabular}{lcccccccccccccccc}
\hline & $\mathrm{pH}$ & $\mathrm{Ca}$ & $\mathrm{Mg}$ & $\mathrm{K}$ & $\mathrm{Al}$ & $\mathrm{H}+\mathrm{Al}$ & $\mathrm{CTC}$ & $\mathrm{SB}$ & $\mathrm{P}$ & $\mathrm{Zn}$ & $\mathrm{Fe}$ & $\mathrm{Mn}$ & $\mathrm{B}$ & $\mathrm{Cu}$ & $\mathrm{M} . \mathrm{O}$ & $\mathrm{V}$ \\
\hline & $\mathbf{C a C l}_{2}$ & $-\cdots$ & -0 & &
\end{tabular}

Análise dos teores disponíveis dos elementos por RAIJ et al. (1996).

\subsection{Descrição do experimento}

O estudo foi realizado em dois ensaios (Figura 5). Para isso, homogeneizaram-se os carvões para o preparo da mistura (12 kg de solo+4,2 kg de BC), o que equivale a $35 \%$ de $\mathrm{BC}$ em relação ao peso seco, utilizados nos Ensaios 1 e 2 e também, 4 parcelas com somente Latossolo Vermelho degradado como controle

Ensaio 1. Matéria Orgânica - A MO utilizada nesse experimento foi esterco bovino curado, coletado no confinamento da Faculdade de Ciências Agronômicas/UNESP, campus de Botucatu-SP, e curado em abrigo da chuva, com controle de umidade e aeração durante 40 dias. As características químicas estão descritas na Tabela 5.

Tabela 5. Teores totais dos elementos químicos presentes na Matéria Orgânica e no Biocarvão

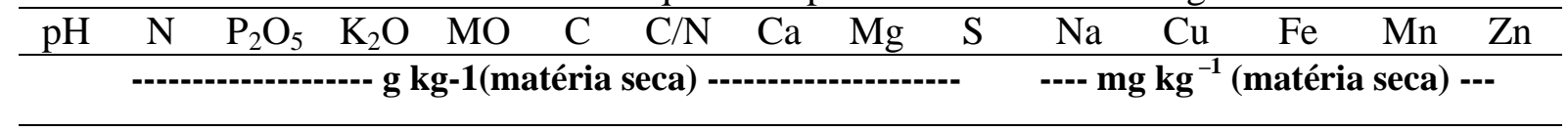

Matéria Orgânica

\begin{tabular}{lllllllllllllll}
\hline 7,4 & 22 & 12 & 12 & 560 & 310 & $14 / 1$ & 9 & 4 & 5 & 1900 & 113 & 9450 & 676 & 224 \\
\hline \multicolumn{10}{c}{ Biocarvão } \\
\hline 8,6 & 06 & 11 & 19 & 550 & 310 & $48 / 1$ & 21 & 2 & 190 & 580 & 22 & 4500 & 264 & 42 \\
\hline
\end{tabular}

*Análise dos teores totais por LANARV (1988).

Utilizou-se delineamento inteiramente ao acaso, com 4 repetições em fatorial 5x5 e cinco doses de matéria orgânica $(0,44,174,305,436 \mathrm{~g}$ em 16,2 g da mistura (Solo+BC), equivalente a $0\left(\mathrm{MO}_{0}\right), 10\left(\mathrm{MO}_{10}\right), 40\left(\mathrm{MO}_{40}\right), 70\left(\mathrm{MO}_{70}\right), 100\left(\mathrm{MO}_{100}\right) \mathrm{t}$ ha ${ }^{-1}$ incorporados à 
mistura, e quatro tempos de incubação: $0,80,160,240$ e 320 dias, sendo o tempo 0 coletado no sétimo dia após os vasos estarem com umidade próxima a capacidade de campo.

Ensaio 2. Fósforo - Utilizou-se delineamento inteiramente ao acaso, com 4 repetições e cinco tratamentos contendo $0,0,5,3,10,5,15,1,21,1 \mathrm{~g}$ de $\mathrm{KH}_{2} \mathrm{PO}_{4} \mathrm{em} 12 \mathrm{~kg}$ de solo, equivalente a $0\left(\mathrm{P}_{0}\right), 75\left(\mathrm{P}_{75}\right), 150\left(\mathrm{P}_{150}\right), 210\left(\mathrm{P}_{200}\right), 297\left(\mathrm{P}_{300}\right) \mathrm{mg}$ de $\mathrm{P}$ por kg do solo e homogeneizado a 4,2 $\mathrm{kg}$ de $\mathrm{BC}$, incubados por 240 dias, sendo o tempo 0 coletado no sétimo dia após os vasos estarem com umidade próxima a capacidade de campo. Os ensaios 1 e 2 estão esquematicamente apresentados na Figura 5.

Solo+BC+MO

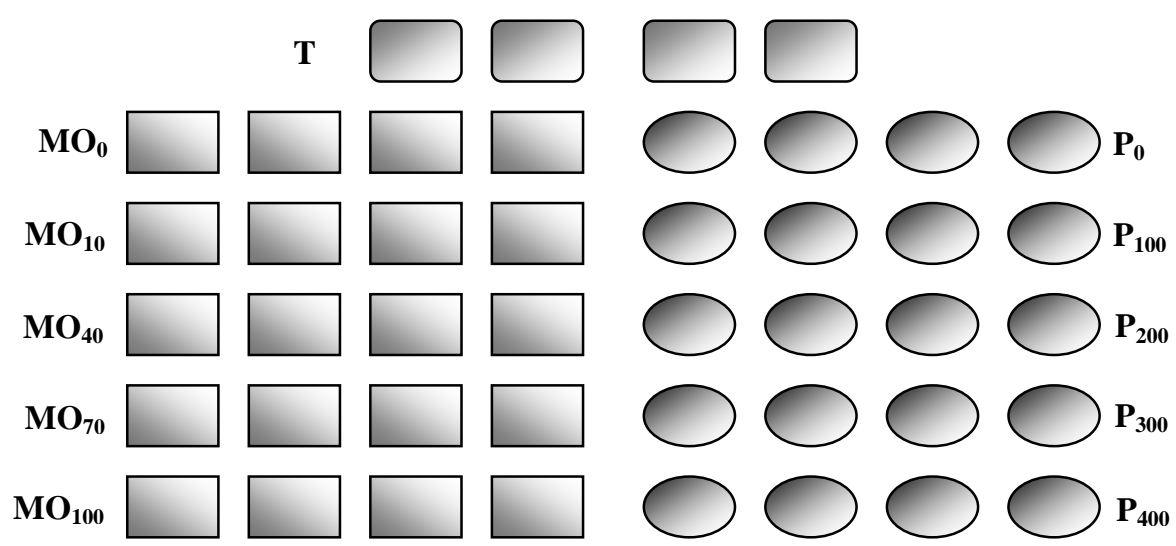

Ensaio 1
Solo+BC+P

Ensaio 2

Figura 5. Desenho experimental, sem escala e sem representação da casualização.

O teor de umidade foi mantido próximo à capacidade de campo, monitorado diariamente pela diferença de peso, tendo como referencial o peso inicial dos vasos em capacidade de campo.

Em ambos os ensaios ( 1 e 2), as análises estatísticas foram realizadas com o programa estatístico STATSOFT- STATISTICA 7. 


\subsection{Caracterização do Biocarvão}

Foram enviadas amostras do BC para ao laboratório de Ciência do Solo da Universidade da Flórida-FL/EUA, para as análises de porosidade e área superficial específica, análise termogravimétrica (TGA), difração de raio-X, curva de $\mathrm{pH}$ e extrações aquosas para análises de carbono orgânico dissolvido (COD), $\mathrm{P}, \mathrm{pH}$, eletrocondutividade (EC) e sais (Na, $\mathrm{Mg}$, Ca e K). Para isso, as mesmas foram embaladas em sacos de polietileno, retirando-se o ar em excesso. Para as análises de microscopia eletrônica de varredura, as amostras foram levadas ao centro de microscopia eletrônica de varredura no Instituto de Biociência da UNESP - Botucatu/SP.

\subsubsection{Porosidade e área superfícial específica}

Determinou-se a porosidade e a área superficial específica através do analisador Micromeritics ASAP 2021 sorptometer (Norcross, GA). Para tanto, adsorveu-se o gás $\mathrm{CO}_{2}$ em condições isotérmicas, pressão e vapor de equilíbrio, na superfície do sólido. Uma vez adquirida a isoterma, avaliou-se a quantidade de gás condensada na superfície do sólido. Calculou-se a área superficial e as características dos poros através da teoria desenvolvida para o tratamento dos dados de adsorção/dessorção pelo método Dubinin-Radushkevitch, descrito por Pennell (2002).

\subsubsection{Microscopia eletrônica de varredura}

Realizou-se a análise da microestrutura e a topografia da superfície do BC pelo aparelho SEM 515-Philips, com aumento de 42 a 2000 vezes e resolução na ordem de 3 a 100 nm. Para tanto, recobriu-se a amostra com uma fina camada de ouro, material condutor, que permite a geração das imagens (VERHOEVEN, 1984). 


\subsubsection{Análise Termogravimétrica (TGA)}

Mediu-se as variações térmicas características das transformações ou mudanças de fases da amostra de $\mathrm{BC}$ em função da temperatura, $25^{\circ} \mathrm{C} / \mathrm{min}$ até $1000^{\circ} \mathrm{C}$, com balança de precisão acoplada ao aparelho de análise termogravimétrica, modelo SDT 2960, sobre atmosfera oxidante. As mudanças de fases foram calculadas a partir da primeira derivada (dTG) da curva.

\subsubsection{Difração de raio-X}

Realizou-se a caracterização mineralógica do $\mathrm{BC}$ por difração de raio X. Para tanto, queimou-se amostras de $\mathrm{BC}$ às temperaturas de 400, 500 e $700^{\circ} \mathrm{C}$ por 4 horas (com base na análise termogravimétrica), a fim de eliminar a fração carbonosa sem alterar a composição mineral. Foram escaneadas as amostras com ângulo de difração $2 \theta$ de 2 a $60^{\circ}$, com radiação de $\mathrm{Cu} K_{\alpha}$ e monocromador de grafite, a $35 \mathrm{kV}$ e $20 \mathrm{~mA}$ com aparelho XRD (Philips Electronic Instruments, Inc., Mahwah, NJ).

\subsubsection{Curva de pH}

Em 0,2 $\mathrm{g}$ de $\mathrm{BC}$, adicionou-se alíquotas de $0,5 \mathrm{ml}$ de $\mathrm{HCl} 0,1 \mathrm{~N}$ até a estabilização do pH . Entre as adições do ácido, agitou-se a solução até pH estável.

\subsubsection{Extrações aquosas para análises de carbono orgânico dissolvido (COD), $\mathrm{P}, \mathrm{pH}$, eletrocondutividade (EC) e sais ( $\mathrm{Na}, \mathrm{Mg}, \mathrm{Ca}$ e K)}

$\mathrm{O}$ BC foi submetido a 30 extrações aquosas. Para isso, pesou-se $20 \mathrm{~g}$ de $\mathrm{BC}$ e adicionou-se $350 \mathrm{ml}$ de água bidestilada; agitou-se por 24 horas e filtrou-se em papel filtro $11 \mu \mathrm{m}$, substituindo-se o volume de água bidestilada, com auxílio de balança analítica, em cada uma das extrações. 
Analisou-se o COD nas soluções com o aparelho TOC-Analyser (Shimadzu TOC$\mathrm{VcpH})$.

Determinou-se o teor de P pelo método de Murphy e Riley (1962), onde adicionou-se alíquota da amostra em balão volumétrico de $25 \mathrm{ml} \mathrm{e} 4 \mathrm{ml}$ de reagente $\mathrm{B}$. Completou-se o volume até o menisco; deixou-se em repouso por 1 hora até a estabilização da cor azul. Analizou-se as amostras em espectrofotômetro, UV1- Spectrophotometer, com cela de $1 \mathrm{~cm}$.

Obteve-se as concentrações dos sais ( $\mathrm{Na}, \mathrm{Mg}, \mathrm{Ca}$ e $\mathrm{K})$ pelo laboratório de pesquisa analítica da Universidade da Flórida, UF/IFAS Analytical Research Laboratory.

\subsubsection{Fósforo Total}

Foram adicionados 0,2 $\mathrm{g}$ da amosta de $\mathrm{BC}$ em 6 tubos de digestão juntamente com 3 provas em branco. Após, adicionou-se $0,1 \mu \mathrm{g} \mathrm{P} \mathrm{ml}^{-1}$ aos brancos e a três dos tubos contendo amostra. Em todos os tubos foram adicionados $2 \mathrm{ml} \mathrm{de} \mathrm{H}_{2} \mathrm{SO}_{4}$ concentrado, os quais foram aquecidos em bloco digestor a $340^{\circ} \mathrm{C}$ por 30 minutos. Os tubos foram removidos do bloco digestor por 15 minutos, resfriados em temperatura ambiente para adição de $0,5 \mathrm{ml}$ de $\mathrm{H}_{2} \mathrm{O}_{2}$ a $30 \%$ e aquecidos novamente por 15 minutos, repetindo-se a adição de $\mathrm{H}_{2} \mathrm{O}_{2}$ até digestão total da amostra. Após obter-se uma solução límpida, os tubos foram aquecidos por 45 minutos até evaporação total do $\mathrm{H}_{2} \mathrm{O}_{2}$. Após o resfiamento, foi adicionado água deionizada até volume igual a $35 \mathrm{ml}$. Uma alíquota de $5 \mathrm{ml}$ da amostra foi acondicionada em balão volumétrico de 25 $\mathrm{ml}$, adicionando-se $4 \mathrm{ml}$ de reagente B e 3 gotas de solução de 2,4 dinitrofenol para ajustar o $\mathrm{pH}$, completando-se o volume do balão até o menisco. As amostras ficaram em repouso por 1 hora até desenvolver coloração azul, onde foram analizadas em espectrofotômetro UV1Spectrophotometercela, com cela de $1 \mathrm{~cm}$ (Murphy e Riley, 1962). 


\subsection{Caracterização do Ensaio 1- Matéria orgânica}

Foram enviadas amostras para o laboratório de Ciência do Solo da Universidade da Flórida-FL/EUA, para as análises de quantificação de grupos funcionais e carbono total. Para isso, as mesmas foram secas a $55^{\circ} \mathrm{C}$, peneiradas em malha de $2 \mathrm{~mm}$ de abertura, homogeneizadas e embaladas em sacos de polietileno, retirando-se o ar em excesso. Para as análises de Respirometria, as amostras foram levadas ao laboratório do Departamento de Recursos Naturais - Ciência do Solo da Faculdade de Ciências Agronômicas/UNESP. Para isso, as amostras foram mantidas com a umidade próxima à capacidade de campo.

\subsubsection{Quantificação dos grupos funcionais}

Determinou-se as concentrações relativas dos diferentes grupos funcionais de superfície no BC, baseado na diferenças de pK dos grupos funcionais. Para isso, pesou-se em quatro tubos de centrífuga, com capacidade de $50 \mathrm{ml}, 0,5 \mathrm{~g}$ do BC e adicionou-se $20 \mathrm{ml}$ das soluções: $0,1 \mathrm{M}$ de bicarbonato de sódio $\left(\mathrm{NaHCO}_{3}\right), 0,1 \mathrm{M}$ de hidróxido de sódio $(\mathrm{NaOH})$ e 0,2M de carbonato de sódio $\left(\mathrm{Na}_{2} \mathrm{CO}_{3}\right)$, em cada um dos tubos, separadamente. Agitou-se por 72 horas à temperatura ambiente. Centrifugou-se por 20 minutos e filtrou-se com filtro $0,45 \mu \mathrm{m}$ Millipore. Titulou-se alíquotas de $5 \mathrm{ml}$ de cada uma das soluções com $0,1 \mathrm{M}$ de $\mathrm{HCl}$ padrão. Utilizou-se como indicadores, alaranjado de metila para as soluções contendo $\mathrm{Na}_{2} \mathrm{CO}_{3}$ e $\mathrm{NaHCO}_{3}$ e fenolftaleína para $\mathrm{NaOH}$ (BOEHM, 1994).

\subsubsection{Carbono total}

Foram carbonizados $20 \mathrm{mg}$ da amostra a $1000^{\circ} \mathrm{C}$ no aparelho TOC-Analyser (Shimadzu TOC-VcpH,) e calculou-se a quantidade de carbono total a partir da curva de calibração do mesmo. 


\subsubsection{Respirometria}

Esse método estima a mineralização do solo, através da quantidade de $\mathrm{CO}_{2}$ liberado pelos microrganismos, em 30 dias de incubação. Para isto, coletou-se amostras do Ensaio 1 nos tempos de incubação em estufa de 0,80,160, 240 e 320 dias; foram pesadas 30 $\mathrm{g}$ da amostra em frasco de polietileno e confinadas em frascos de vidro, com capacidade de 3 litros, contendo um snap-cap com $10 \mathrm{~mL}$ de $\mathrm{NaOH}$ 1,0 M e $10 \mathrm{~mL}$ de água destilada na base do frasco de vidro, hermeticamente fechados durante todo o período de incubação. Titulou-se a solução de $\mathrm{NaOH}$ com $\mathrm{HCl}$ 0,5M, nos tempos 1, 3, 7, 11, 15, 20, 30 dias de incubação, substituindo-se a solução alcalina a cada titulação. Após o término das titulações, pesou-se as amostras antes e após a secagem, em estufa a $60^{\circ} \mathrm{C}$. Calculou-se os valores de $\mathrm{C} \mathrm{em} \mathrm{mg} \mathrm{g}^{-1} \mathrm{da}$ amostra pela equação (I):

$$
\begin{aligned}
& \left.\mathrm{mgC} / \mathrm{g} \text { solo }=\underline{\left(\mathrm{V}_{\text {branco }}\right.} \underline{\underline{\mathrm{V}_{\text {amostra }}}}\right) \cdot \underline{6} \cdot \underline{\mathrm{C}_{\mathrm{HCl}}} \quad \text { Equação (I). } \\
& \mathrm{M}_{\text {amostra }}
\end{aligned}
$$

Onde,

$\mathrm{V}_{\text {branco }}=$ Volume de $\mathrm{HCl}$ gasto na titulação do branco $(\mathrm{ml})$

$\mathrm{V}_{\text {amostra }}=$ Volume de $\mathrm{HCl}$ gasto na titulação das amostras (ml)

$\mathrm{C}_{\mathrm{HCl}}=$ Concentração de $\mathrm{HCl}$ padronizado

$\mathrm{M}_{\mathrm{amostra}}=$ Massa da amostra seca $(\mathrm{g})$

\subsection{Caracterização do Ensaio 2- Fósforo}

As amostras foram enviadas para o laboratório de Ciência do Solo da Universidade da Flórida-FL/EUA. Para isso, as mesmas foram secas, peneiradas em malha de $2 \mathrm{~mm}$ de abertura, homogeneizadas e embaladas em sacos de polietileno, retirando-se o ar em excesso. 


\subsubsection{Cinética de sorção de $P$}

Analisou-se a cinética de sorção por dois métodos:

1. Tubos de centrífuga, onde, confinou-se, separadamente, $2 \mathrm{~g}$ das amostras $\mathrm{P}_{0}$ (sem adição de Pi), solo e BC e $20 \mathrm{ml}$ de solução fosfatada $40 \mathrm{mg} \mathrm{l}^{-1}$, o equivalente a $400 \mathrm{mg}$ $\mathrm{P} \mathrm{kg}^{-1}$ da amostra, em 42 tubos de centrífuga (14 tempos x 3 repetições). Agitou-se cada uma das amostras a 96 ciclos $\min ^{-1}$, durante os tempos 0,$1 ; 0,2 ; 0,3 ; 0,5 ; 1,0 ; 1,5 ; 2,0 ; 3,0 ; 6,0 ; 12$; 24; 48; 72 e 96 horas. Centrifugou-se por 10 minutos a $2000 \mathrm{rpm}$ e filtrou-se a vácuo, em

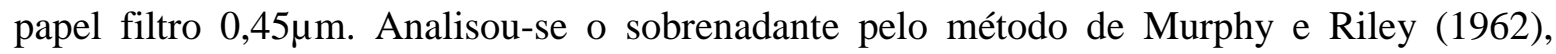
adicionou-se alíquota da amostra em balão volumétrico de $25 \mathrm{ml}$ e $4 \mathrm{ml}$ de reagente $\mathrm{B}$, completou-se o volume até menisco, deixou-se em repouso por 1 hora até desenvolver coloração azul. Analisou-se as amostras em espectrofotômetro UV1- Spectrophotometercela, com cela de $1 \mathrm{~cm}$ para concentrações acima de 0,2 ppm em concentrações abaixo de 0,2 ppm leu-se com cela de $5 \mathrm{~cm}$.

2. Tubos de diálise, onde manteve-se 3 tubos de diálise (3 repetições), imersos em água bidestilada por 10 minutos; após, confinou-se $2 \mathrm{~g}$ das amostras $\mathrm{P}_{0}$ e $20 \mathrm{ml}$ de água destilada, amarrando-se as extremidades com barbante previamente higienizados. Transferiuse os tubos de diálise para frascos de polietileno $(500 \mathrm{ml})$ contendo $200 \mathrm{ml}$ de solução fosfatada $4 \mathrm{mg} \mathrm{l}^{-1}$, o equivalente a $400 \mathrm{mg} \mathrm{P} \mathrm{kg}^{-1}$ da amostra e agitou-se cada uma das amostras a 96 ciclos $\min ^{-1}$ durante os tempos 0,$1 ; 0,2 ; 0,3 ; 0,5 ; 1,0 ; 3,0 ; 6,0 ; 12 ; 24 ; 48 ; 72$ e 96 horas, retirando-se $0,5 \mathrm{ml}$ da solução em cada um dos tempo para análise pelo método de Murphy e Riley (1962), adicionando-se um volume igual ao retirado de água bidestilada à solução fosfatada, em cada um dos tempos analisados. Manteve-se o controle de temperatura a $25^{\circ} \mathrm{C}$ para ambos os métodos. 


\subsubsection{Cinética de dessorção de $P$}

Analisou-se a cinética de dessorção pelo método tubos de diálise nas amostras $\mathrm{P}_{75}, \mathrm{P}_{150}, \mathrm{P}_{200}$ e $\mathrm{P}_{300}$. Para tanto, manteve-se 12 tubos de diálise (4 amostras x 3 repetições) imersos em água bidestilada por 10 minutos; após, confinou-se 2 g das amostras e $20 \mathrm{ml}$ de água destilada, amarrando-se as extremidades com barbantes previamente higienizados. Transferiu-se os tubos de diálise para frascos de polietileno $(500 \mathrm{ml})$ contendo $200 \mathrm{ml}$ de água bidestilada e 4 gotas de tolueno. Agitou-se a 96 ciclos $\min ^{-1}$, durante os tempos 0,$1 ; 0,2 ; 0,3$; 0,$5 ; 1,0 ; 3,0 ; 6,0 ; 12 ; 24 ; 48 ; 72$ e 96 horas, retirando-se $10 \mathrm{ml}$ da solução em cada um dos tempos para análise pelo método de Murphy e Riley (1962), adicionando-se um volume igual ao retirado de água bidestilada à solução aquosa, em cada um dos tempos analisados.

Para as testemunhas, realizou-se primeiro a sorção de $\mathrm{P}$, como descrito no item (4.6.1), método (2) - "Tubos de diálise”, uma vez que incubou-se as amostras sem adição do fertilizante inorgânico fosfatado, transferindo-se os tubos de diálise, previamente lavados com água bidestilada aos frascos de polietileno, como descrito acima, para as demais amostras.

\subsubsection{Reações de sorção de fósforo}

Confinou-se $2 \mathrm{~g}$ das amostras $\mathrm{P}_{0}$, testemunha e $\mathrm{BC}$, e $20 \mathrm{ml}$ das soluções fosfatadas 0,$0 ; 0,6 ; 1,6 ; 4,0 ; 6,0 ; 8,0 ; 10,0 ; 20,0 ; 30,0$ e 40,0 $\mathrm{mg}^{-1}$, o equivalente a $0,6,16$, 40, 60, 80, 100, 200, 300 e $400 \mathrm{mg}$ de $\mathrm{P} \mathrm{kg}^{-1}$ da amostra, em 40 tubos de centrífuga (10 soluções fosfatadas x 4 repetições). Agitou-se cada uma das amostras a 96 ciclos $\min ^{-1}$ por 72 horas para as amostras P0 e BC e 24 horas para as testemunhas. Centrifugou-se por 10 minutos a $2000 \mathrm{rpm}$ e filtrou-se a vácuo, em papel filtro $0,45 \mu \mathrm{m}$. Analisou-se o sobrenadante pelo método de Murphy e Riley (1962).

\subsubsection{Reações de dessorção}

Para a realização desta análise fez-se necessário uma pré-análise para otimização do método. Para isso, manteve-se 6 tubos de diálise (3 repetições x 2 soluções) imersos em 
água bidestilada por 10 minutos. Após, foram confinados $20 \mathrm{ml}$ de solução fosfatada $40 \mathrm{mg} \mathrm{l}^{-1}$, amarrando-se as extremidades com barbantes previamente higienizados. Transferiram-se os tubos de diálise (3500 MWCO) para frascos de polietileno $(500 \mathrm{ml})$ contendo $280 \mathrm{ml}$ de água bidestilada e $\mathrm{KCl} 1 \mathrm{M}$ separadamente. Agitou-se a 96 ciclos $\min ^{-1}$ e analisou-se o conteúdo de $\mathrm{P}$, que passou pela membrana para a solução aquosa a cada 24 horas, segundo Murphy e Riley (1962), até que a concentração de $\mathrm{P}$ fora do tubo de diálise fosse igual a concentração inicial dentro do tubo para tanto foram despendidas 72 horas.

Após a pré-análise, escolheu-se o tempo e a solução ideal para a realização da análise de dessorção sequencial de $\mathrm{P}$ nas amostras $\mathrm{P}_{0}, \mathrm{P}_{75}, \mathrm{P}_{150}, \mathrm{P}_{200}$ e $\mathrm{P}_{300}$. Para isso, foram mantidos 20 tubos de diálise (5 amostras x 4 repetições), imersos em água bidestilada por 10 minutos. Após, foram confinados $2 \mathrm{~g}$ das amostras e $20 \mathrm{ml}$ de água bidestilada, amarrando-se as extremidades com barbantes previamente higienizados. Transferiram-se os tubos de diálise para frascos de polietileno $(500 \mathrm{ml})$ contendo $200 \mathrm{ml}$ de água bidestilada e 4 gotas de tolueno. Agitou-se a 96 ciclos min $^{-1}$ por 72 horas e realizou-se análise de P segundo Murphy e Riley (1962). Trocou-se a solução aquosa e os frascos de polietileno, previamente higienizados a cada análise e mediu-se o conteúdo de $\mathrm{P}$ dessorvido da amostra até valores confiavelmente detectáveis pelo espectro-UV.

\subsection{Análise química da mistura (solo+BC)}

As amostras foram secas, destorradas e passadas em peneira com malha de $2 \mathrm{~mm}$ de abertura, homogeneizadas e conduzidas ao laboratório de Fertilidade do Solo do Departamento de Recursos Naturais - Ciência do Solo da Faculdade de Ciências Agronômicas/UNESP para análises químicas de: $\mathrm{pH}\left(\mathrm{CaCl}_{2}\right), \mathrm{MO}, \mathrm{P}, \mathrm{K}, \mathrm{Ca}, \mathrm{Mg}, \mathrm{Al}, \mathrm{H}+\mathrm{Al}$, Zn, Mn, Fe (RAIJ et al., 1996) e, com essas variáveis foram calculados os valores de Soma de bases trocáveis $(\mathrm{S})$, capacidade de troca de cátions efetiva $(\mathrm{t})$, percentagem de saturação de alumínio (m\%), capacidade de troca de cátions a pH 7,0 (T), percentagem de saturação por bases da CTC a pH 7,0 (V\%). 


\section{RESULTADOS E DISCUSSÃO}

\subsection{Caracterização do biocarvão}

As propriedades sortivas, características físicas e química do BC estão representadas nas Tabelas 4 e 6 . Possui área superficial específica igual a $9 \mathrm{~m}^{2} \mathrm{~g}^{-1}$, com tamanho médio de poros igual a 112,11 A; demonstra capacidade de absorção de partículas inferiores a meso e micro poros, uma vez que o BC não possui macro poros em sua estrutura.

O BC possui funcionalidades ácidas em sua superfície, decorrente da presença de $79,81 \%$ grupos fenólicos, 16,63\% de lactonas e 3,56\% de grupos carboxílicos, o que indica seu potencial em adsorver nutrientes e, consequentemente, evitar perdas por lixiviação. 
Tabela 6. Características químicas e físicas do BC

\begin{tabular}{llc}
\hline Propriedades & & Valor \\
\hline $\mathrm{pH}$ & & 9,8 \\
Área superficial específica $\left(\mathbf{m}^{\mathbf{2}} \mathbf{g}^{\mathbf{- 1}}\right)$ & & 9 \\
Tamanho médio de poros $(\mathbf{\AA})$ & & 112,11 \\
Volume de poros $(\boldsymbol{\%})$ & Macro poros & 0,0 \\
& Meso poros & 13,3 \\
& Micro poros & 86,7 \\
Total de poros $\left(\mathbf{c m}^{\mathbf{3}} \mathbf{g}^{-\mathbf{1}}\right)$ & & 0,0112 \\
Grupos Funcionais $(\boldsymbol{\%})$ & Carboxílicos & 3,56 \\
& Lactonas & 16,63 \\
Carbono total $(\boldsymbol{\%})$ & Fenóis & 79,81 \\
Teor de cinza $(\boldsymbol{\%})$ & & 38 \\
\hline
\end{tabular}

O conteúdo de $\mathrm{C}$ total no $\mathrm{BC}$, igual a $38 \%$, é consequência do seu processo de produção, pois a pirólise rápida tem como produto principal o bio-óleo. Portanto, a maior parte do $\mathrm{C}$ existente na biomassa é convertida a este produto, restando maior teor de cinzas (62\%), o que eleva o $\mathrm{pH}$ do $\mathrm{BC}$ a 9,8 .

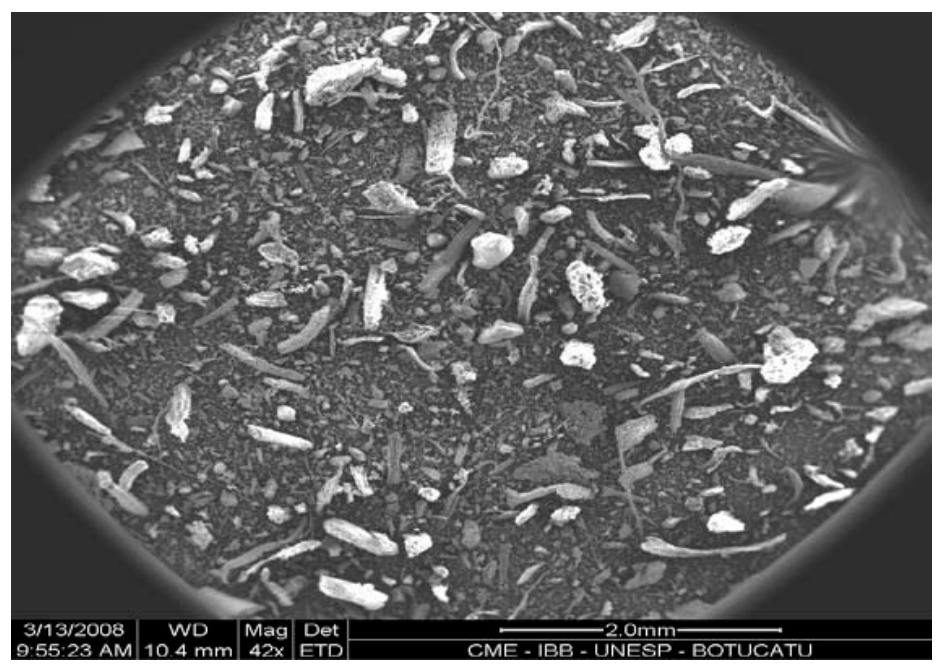

Figura 6. Imagens do BC composto por uma mistura de biocarvões, produzidos com capim elefante, serragem e palha de cana-de-açúcar. 
O BC possui diferentes morfologias, com tamanhos em torno de $200 \mu \mathrm{m}$ e formatos variados em suas partículas (Figura 6). Uma vez que, foi preparado a partir de diferentes fontes de biomassa, mas com mesma granulometria, em torno de $2 \mathrm{~cm}$. A baixa ocorrência de grânulos de mesma aparência denota boa pré-homogeneização dos biocarvões que compõem o material.
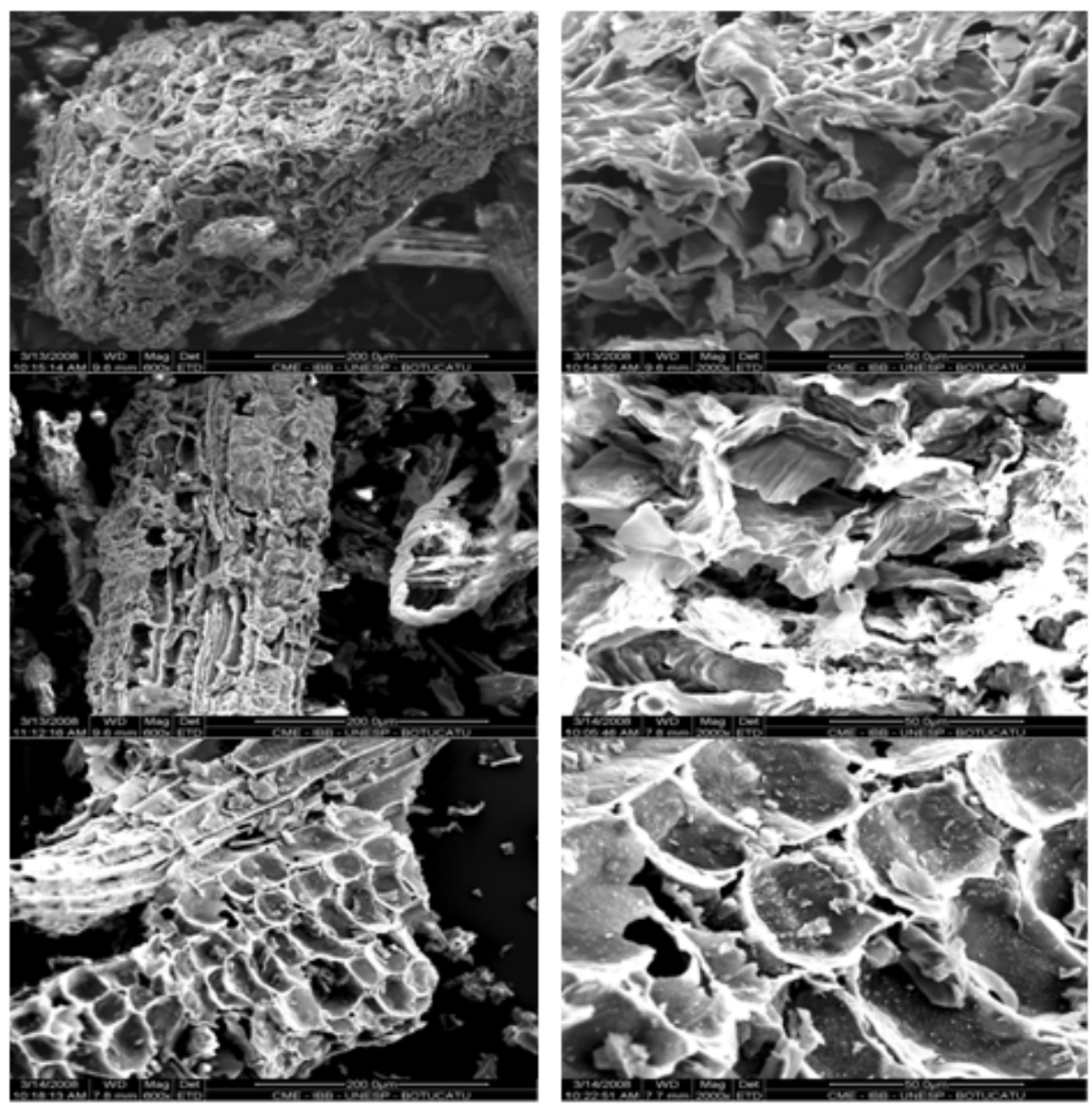

Figura 7. Imagens feitas por microscopia eletrônica de varredura em três diferentes tipos de partículas que compõem o BC, ampliadas em 600 vezes (esquerda) e 2000 vezes (direita).

O conjunto de micrografias evidencia a diferença morfológica das partículas que compõem o BC (Figura 7). A textura da superfície das partículas é irregular, com maior incidência de micro poros (entre 20 a $500 \AA$ ), $86,7 \%$ do total de poros, e meso poros $(<20 \AA)$, com $13,3 \%$, sem ocorrência de macro poros, variando numa faixa de 12,59 a 398,11 Å (Tabela 
7). Essas propriedades caracterizam seu poder em absorver nutrientes, além de poder servir como abrigo para microrganismos do solo (GRADY \& RUSH, 2007).

Tabela 7. Distribuição dos poros do BC

\begin{tabular}{cccc}
\hline $\begin{array}{c}\text { Diâmetro dos poros } \\
(\mathbf{A})\end{array}$ & $\begin{array}{c}\text { Diâmetro dos poros } \\
(\mathbf{m e ́ d i a})\end{array}$ & $\begin{array}{c}\text { Volume dos poros } \\
\left(\mathbf{c m}^{\mathbf{3}} \mathbf{g}^{-\mathbf{~}}\right)\end{array}$ & $\begin{array}{c}\text { Área superfícial } \\
\left(\mathbf{m}^{\mathbf{2}} \mathbf{g}^{\mathbf{-}} \mathbf{)}\right.\end{array}$ \\
\hline $12,59-15,85$ & 14,22 & $7,13 \mathrm{E}-04$ & $1,66 \mathrm{E}+00$ \\
$15,85-19,95$ & 17,90 & $5,12 \mathrm{E}-04$ & $7,00 \mathrm{E}-01$ \\
$19,95-25,12$ & 22,54 & $4,97 \mathrm{E}-04$ & $6,58 \mathrm{E}-01$ \\
$25,12-31,62$ & 28,37 & $3,77 \mathrm{E}-04$ & $6,53 \mathrm{E}-01$ \\
$31,62-39,81$ & 35,72 & $5,88 \mathrm{E}-04$ & $8,13 \mathrm{E}-01$ \\
$39,81-50,12$ & 44,96 & $1,10 \mathrm{E}-03$ & $1,21 \mathrm{E}+00$ \\
$50,12-63,10$ & 56,61 & $1,31 \mathrm{E}-03$ & $1,16 \mathrm{E}+00$ \\
$63,10-79,43$ & 71,26 & $8,70 \mathrm{E}-04$ & $6,15 \mathrm{E}-01$ \\
$79,43-100,00$ & 89,72 & $8,10 \mathrm{E}-04$ & $4,46 \mathrm{E}-01$ \\
$100,00-125,89$ & 112,95 & $6,35 \mathrm{E}-04$ & $2,88 \mathrm{E}-01$ \\
$125,89-158,49$ & 142,19 & $1,90 \mathrm{E}-04$ & $6,64 \mathrm{E}-02$ \\
$158,49-199,53$ & 179,01 & $1,19 \mathrm{E}-03$ & $3,30 \mathrm{E}-01$ \\
$199,53-251,19$ & 225,36 & $9,64 \mathrm{E}-04$ & $2,16 \mathrm{E}-01$ \\
$251,19-316,23$ & 283,71 & $7,13 \mathrm{E}-04$ & $1,25 \mathrm{E}-01$ \\
$316,23-398,11$ & 357,17 & $7,43 \mathrm{E}-04$ & $1,05 \mathrm{E}-01$ \\
\hline
\end{tabular}

$\mathrm{O} \mathrm{BC}$ iniciou a perda de peso em torno dos $25^{\circ} \mathrm{C}$ e, ao final, em torno de $700^{\circ} \mathrm{C}$, apresentou perda de peso total igual a 39,8\%, onde todo material orgânico foi perdido, restando apenas material mineral decorrente da atmosfera oxidante utilizada na análise.

A curva termogravimétrica apresentou perdas de peso do BC com aumento da temperatura (Figura 8) e foi caracterizada em quatro fases da queima: (I) "água livre” com perda de peso igual 3,4\%; (II) degradação da MO, cujos principais componentes são celulose, hemicelulose e lignina (RIEGEL et al., 2008), com perda de peso igual a 30,1\%, maior fração presente no $\mathrm{BC}$, sendo que parte dessas perdas são grupos funcionais como ácidos carboxílicos, cetonas, lactonas e fenóis; (III) oxidação de carbono de $\mathrm{MeO}\left(\mathrm{R}-\mathrm{CH}+\mathrm{O}_{2} \rightarrow\right.$ $\mathrm{CO}_{2}+\mathrm{H}_{2} \mathrm{O}$ ), e lignina remanescente, cuja a decomposição, segundo Órfão et al. (1999), se inicia a baixas temperaturas, podendo continuar ocorrendo até temperaturas em torno de 900 ${ }^{\circ} \mathrm{C}$, com perda de peso igual a 4,4\% e (IV) perda de água proveniente de hidróxidos metílicos $\mathrm{Me}-\mathrm{OH} \rightarrow \mathrm{MeO}+\mathrm{H}_{2} \mathrm{O}(\mathrm{Me}=\mathrm{Al}, \mathrm{Fe}, \mathrm{Mn}$ entre outros$)$, com perda de peso igual a $1,9 \%$ (BEYER et al., 1998; MIYAZAWA et al., 2000). 


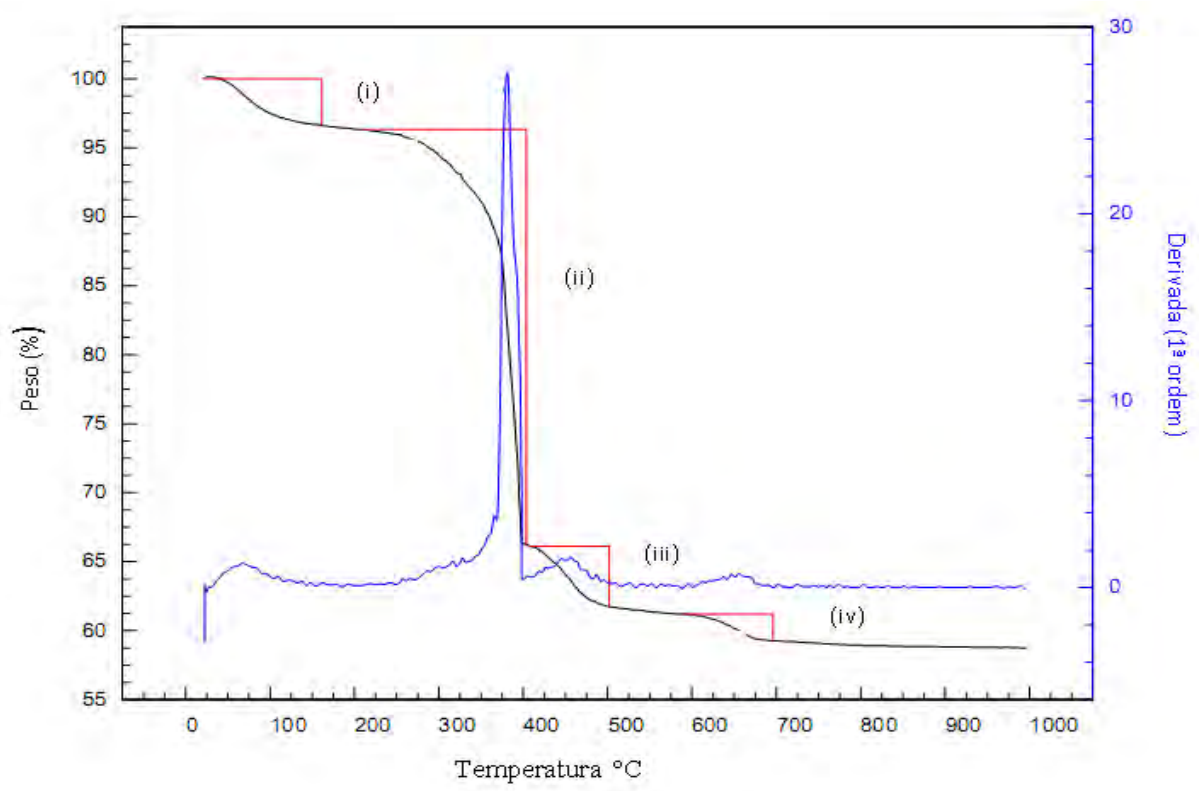

Figura 8. Perfil da perda de massa do $\mathrm{BC}$, na região entre 25 a $700{ }^{\circ} \mathrm{C}$

O BC apresentou incidência de Quartzo $\left(\mathrm{SiO}_{2}\right)$ em sua fase cristalina nas temperaturas de carbonização da amostra de 400,500 e $700^{\circ} \mathrm{C}$, proveniente da areia no manto de fluidização do reator, usada para manter temperatura do leito.

Nas temperaturas de carbonização igual a 400 e $500^{\circ} \mathrm{C}$, o BC apresentou calcita $\left(\mathrm{CaCO}_{3}\right)$, quando incinerado a $700^{\circ} \mathrm{C}$, apresentou além de calcita, silvita $(\mathrm{KCl})$ e portlandita $\left(\mathrm{Ca}(\mathrm{OH})_{2}\right)$ (Figura 9).

A não ocorrência dos minerais silvita e de portlandita nas temperaturas de $400 \mathrm{e}$ $500{ }^{\circ} \mathrm{C}$ pode ter sido decorrente da influência do material carbonoso ainda presente nas amostras, como mostrado na análise termogravimétrica (Figura 8). 


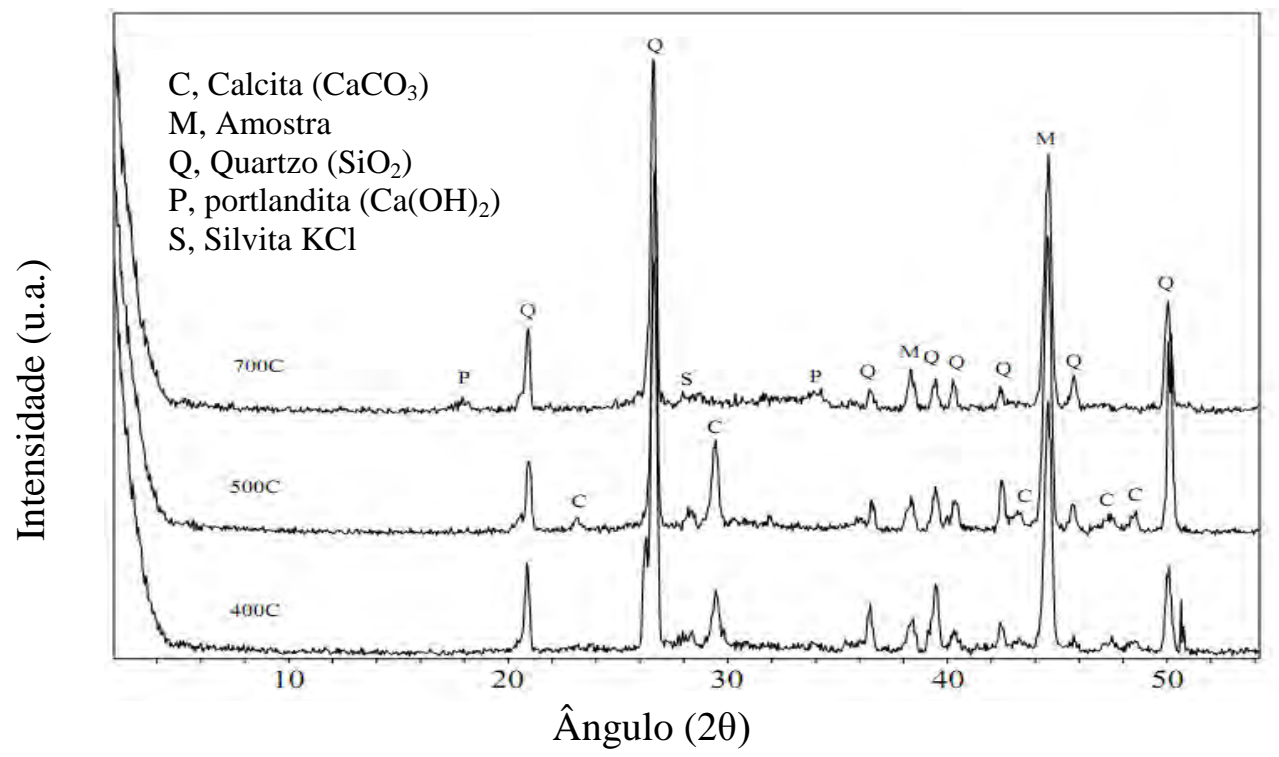

Figura 9. Análise mineralógica do BC por difração de raio-x, incinerado em 3 diferentes temperaturas, baseadas na análise termogravimétrica.

$\mathrm{O}$ BC apresentou alta extração aquosa de sais, com valor de EC na primeira extração igual a 1,7 dS m ${ }^{-1}$ (Figura 10-A), com teores totais nas 30 extrações de $\mathrm{K}, \mathrm{Ca}, \mathrm{Mg}$ e $\mathrm{Na}$ iguais a $19.713,5.835,1.014,2.389 \mathrm{mg} \mathrm{kg}^{-1}$, respectivamente.

$\mathrm{O}$ pH manteve-se estável ao longo das 30 extrações aquosas (Figura 10-A) em concordância com a curva de pH (Figura 10-B) que apresentou pH inicial de 9,8 e alta resistência na mudança de $\mathrm{pH}$, estabilizando em torno de 5 , indicando poder tampão em $\mathrm{pH}$ em torno de 7, considerado alto para maioria das culturas brasileiras (SOUZA et al., 2007).
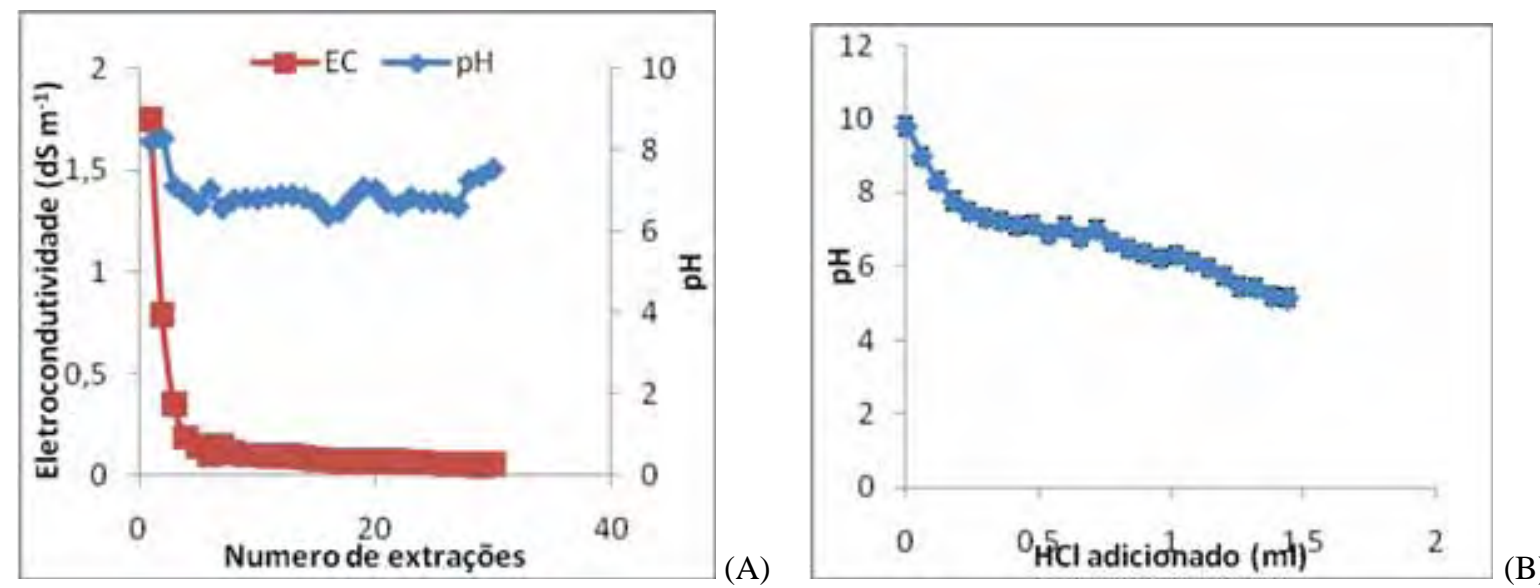

Figura 10. Eletrocondutividade e pH sob extrações aquosas (A) e curva de $\mathrm{pH}(\mathrm{B})$ do $\mathrm{BC}$. 
A curva de extração aquosa de $\mathrm{P}$ para o BC apresentou $909 \mathrm{mg} \mathrm{kg}^{-1}$ de fósforo disponível nas 30 extrações e $1484 \mathrm{mg} \mathrm{kg}^{-1}$ de $\mathrm{P}$ total, ou seja, $61 \%$ do conteúdo de $\mathrm{P}$ no BC foi disponibilizado em 30 extrações (Figura 11-A), sendo 31\% desse conteúdo extraido nas 4 primeiras extrações.

O alto conteúdo de COD total nas 30 extrações do BC igual a 23,9 $\mathrm{g} \mathrm{kg}^{-1}$ (Figura 11-B, pode ser atribuído ao seu processo de preparo, pois a pirólise rápida converte em torno de $75 \%$, do material orgânico em bio-óleo com porções acima de 30\% de material insolúvel (MESA et al., 2003), restando cadeias orgânicas menores e, consequentemente, mais solúveis no BC (MAHAN \& MAYER, 2002).
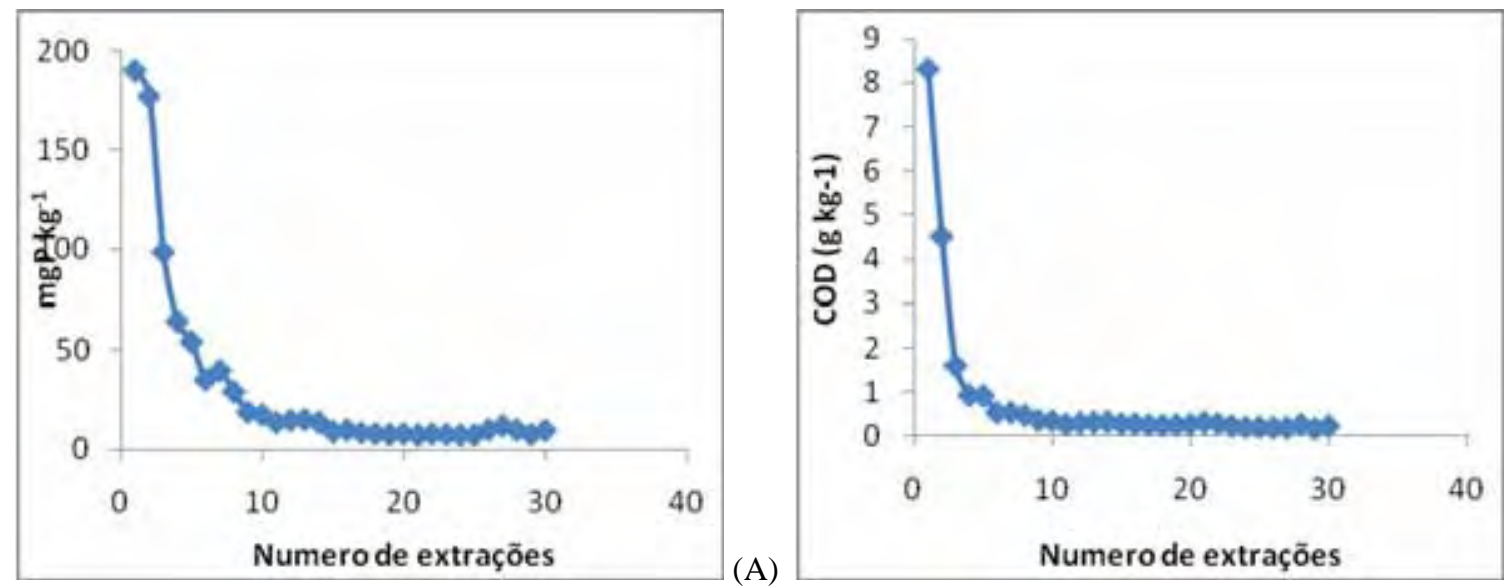

(B)

Figura 11. Conteúdo de fósforo (A) e carbono orgânico dissolvido (COD) no BC em 30 extrações aquosas.

O teor de MO aumentou 43\% no solo com adição de BC e apresentou estabilidade ao longo do período de incubação em estufa para ambos os tratamentos, comportamento esperado, uma vez que o BC possui $38 \%$ de $\mathrm{C}$ total e nenhuma cultura foi desenvolvida nos vasos ao logo dos 240 dias de incubação (Tabela 8).

O parâmetro $\mathrm{H}+\mathrm{Al}$ diminuiu $89 \%$ na mistura em relação ao solo e teve seus valores alterados ao longo de 240 dias de incubação para o solo, permanecendo estável na mistura. $\mathrm{O}$ conteúdo de $\mathrm{H}+\mathrm{Al}$ pode predizer o comportamento do $\mathrm{Al}^{+3}$ no solo, elemento tóxico para a maioria das plantas em concentrações maiores que $5 \mathrm{mmol}_{\mathrm{c}} \mathrm{dm}^{-3}$ (RAIJ et al., 1996). 
No solo, $\mathrm{H}+\mathrm{Al}$ decresceu ao longo do tempo de 76,9 para $56,1 \mathrm{mmol}_{\mathrm{c}} \mathrm{dm}^{-3}$, porque as bases $\mathrm{Ca}, \mathrm{Mg}$ e $\mathrm{K}$ aumentaram seu conteúdo em 77, 38 e $77 \%$ respectivamente, competindo com o $\mathrm{H}^{+}$e $\mathrm{Al}^{+3}$ na solução do solo (RAIJ et al., 1996).

$\mathrm{Na}$ mistura, $\mathrm{H}+\mathrm{Al}$ diminuiu de 7,7 para $6,8 \mathrm{mmol}_{\mathrm{c}} \mathrm{dm}^{-3}$, provavelmente devido ao controle da atividade do $\mathrm{Al}^{3+}$ por reações de complexação com a $\mathrm{MO}$ presente no $\mathrm{BC}$ (BERGREEN \& MULDER, 1995; WESSELINK et al., 1996; VAN HEES et al., 2001).

Os parâmetros CTC, SB e V\% foram significativamente maiores na mistura quando comparados ao solo e aumentaram ao longo do tempo de incubação (Tabela 8).

A CTC aumentou $44 \%$ com adição de BC, decorrente do aumento do teor de $\mathrm{MO}$ e consequentemente, do número de cargas negativas dependentes de $\mathrm{pH}$, controladas pelas concentrações dos íons $\mathrm{H}^{+}$e $\mathrm{HO}^{-}$. Sob condições elevadas de $\mathrm{pH}$, os íons $\mathrm{HO}^{-}$da solução do solo provocam a dissociação dos íons $\mathrm{H}^{+}$dos grupos funcionais orgânicos, contidos na MO $\left(\mathrm{R}-\mathrm{COOH} \rightarrow \mathrm{R}-\mathrm{COO}^{-}\right)$, assim como dos colóides do solo $\left(-\mathrm{AlOH} \rightarrow-\mathrm{AlO}^{-}\right)$(LUCHESE et al., 2002).

Tabela 8. Propriedades químicas do solo e da mistura (Solo+35\%BC) nos tempos 0 e 240 dias de incubação em casa de vegetação

\begin{tabular}{|c|c|c|c|c|c|c|c|}
\hline M.O. & $\mathrm{H}+\mathrm{Al}$ & SB & CTC & $\mathrm{V}$ & Boro & Cobre & Zinco \\
\hline $\mathrm{g} \mathrm{dm}^{-3}$ & 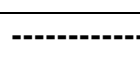 & $-\mathrm{mg} \mathrm{dm}^{-3}$ & 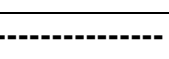 & $\%$ & & $\mathrm{mg} \mathrm{dm}^{-3}$ & \\
\hline \multicolumn{8}{|c|}{ SOLO - TEMPO 0} \\
\hline $18,2 \mathrm{aA}$ & $76,9 \mathrm{aA}$ & $4,6 \mathrm{bB}$ & $81,5 \mathrm{bA}$ & $5,7 \mathrm{bB}$ & $0,1 \mathrm{bA}$ & $0,9 \mathrm{aA}$ & $0,1 \mathrm{bB}$ \\
\hline \multicolumn{8}{|c|}{ SOLO - TEMPO 240} \\
\hline $19,0 \mathrm{aA}$ & \multicolumn{7}{|c|}{ MISTURA - TEMPO 0} \\
\hline $31,3 \mathrm{bA}$ & 7,7bA & $146,9 \mathrm{aA}$ & $154,7 \mathrm{aA}$ & $95 \mathrm{aA}$ & $4,3 \mathrm{aA}$ & $0,6 \mathrm{bA}$ & $1,0 \mathrm{aB}$ \\
\hline \multicolumn{8}{|c|}{ MISTURA - TEMPO 240} \\
\hline $33,9 \mathrm{bA}$ & $6,8 \mathrm{bA}$ & $119 \mathrm{aB}$ & $125,8 \mathrm{aB}$ & $94,6 \mathrm{aA}$ & $1,1 \mathrm{aA}$ & $0,4 \mathrm{bB}$ & $1,9 \mathrm{aA}$ \\
\hline
\end{tabular}

$\mathrm{MO}=$ matéria orgânica; $\mathrm{CTC}$ - capacidade de troca catiônica; $\mathrm{H}+\mathrm{Al}=$ acidez total; $\mathrm{SB}=$ soma de bases trocáveis; $\mathrm{V}=\%$ de saturação por base. As médias seguidas de mesmas letras minúsculas não diferem entre si para os tratamentos e as letras maísculas não diferem entre si para os tempos dentre os tratamentos, a $5 \%$ de probabilidade pelo teste de Tukey $(\mathrm{p}<0,05)$.

O V\% aumentou em torno de $83 \%$ e a SB em torno de $90 \%$ com adição do BC. Isso ocorreu pelo aumento dos teores de $\mathrm{K}, \mathrm{Ca}$ e $\mathrm{Mg}$ no $\mathrm{BC}$ (Figuras 14, 15, e 16), respectivamente. 
Os micro elementos $\mathrm{B}$ e $\mathrm{Zn}$ aumentaram 81 e $71 \%$, respectivamente, com a adição de $\mathrm{BC}$ ao solo, e o $\mathrm{Cu}$ diminuiu $44 \%$, provavelmente por se tornar insolúvel a pH básico.

A adição de BC (MO0) elevou o pH do solo de 4,3 para 7,8 (Figura 12). Ao longo dos 240 dias de incubação o $\mathrm{pH}$ do solo manteve-se estável, enquanto que o $\mathrm{pH}$ na mistura (MO0) diminuiu aos 80 dias, decorrente da lixiviação de $\mathrm{K}$ no mesmo período de incubação (Figura 14).

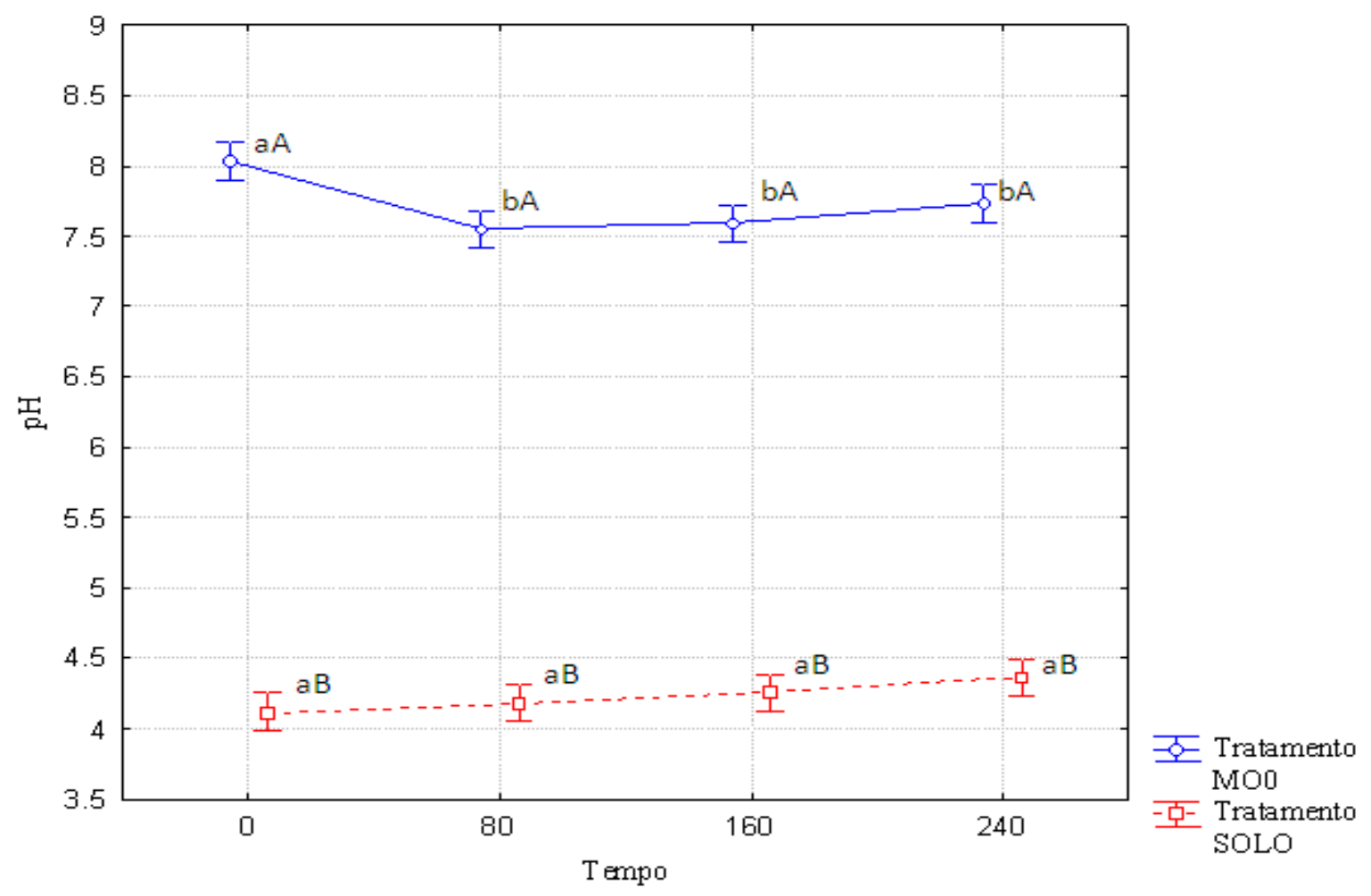

Figura 12. Valores de pH para solo (SOLO) e solo com adição de 35\% de BC (MO0), nos tempos 0, 80, 160 e 240 dias de incubação em estufa (Os pontos seguidos de mesmas letras maiúsculas não diferem entre si para os tratamentos e as letras minúsculas não diferem entre si para os tempos dentre os tratamentos, a $5 \%$ de probabilidade pelo teste de Tukey; $\mathrm{p}<0,05)$.

$\mathrm{A}$ adição de $\mathrm{BC}$ no solo (MO0) aumentou significativamente o teor de $\mathrm{P}$ em torno

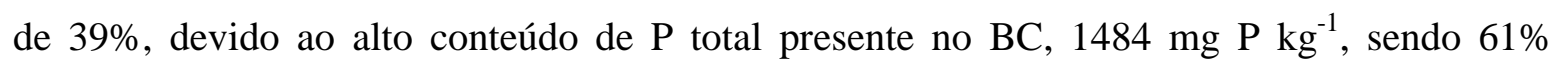
prontamente disponível (Figura 11-A). 
Ao longo do período de incubação em estufa esse conteúdo não teve diferença estatística para o solo (Figura13); entretanto, apresentou decréscimo significativo na mistura (MO0), resultado da reação de sorção de $\mathrm{P}$ na fase sólida da mistura ou pela precipitação do elemento na forma de fosfato de cálcio, favorecida pela concentração de $\mathrm{Ca}$ no $\mathrm{BC}$, igual a $5.835 \mathrm{mg} \mathrm{kg}^{-1}$ (AKINREMI \& CHO, 1991).

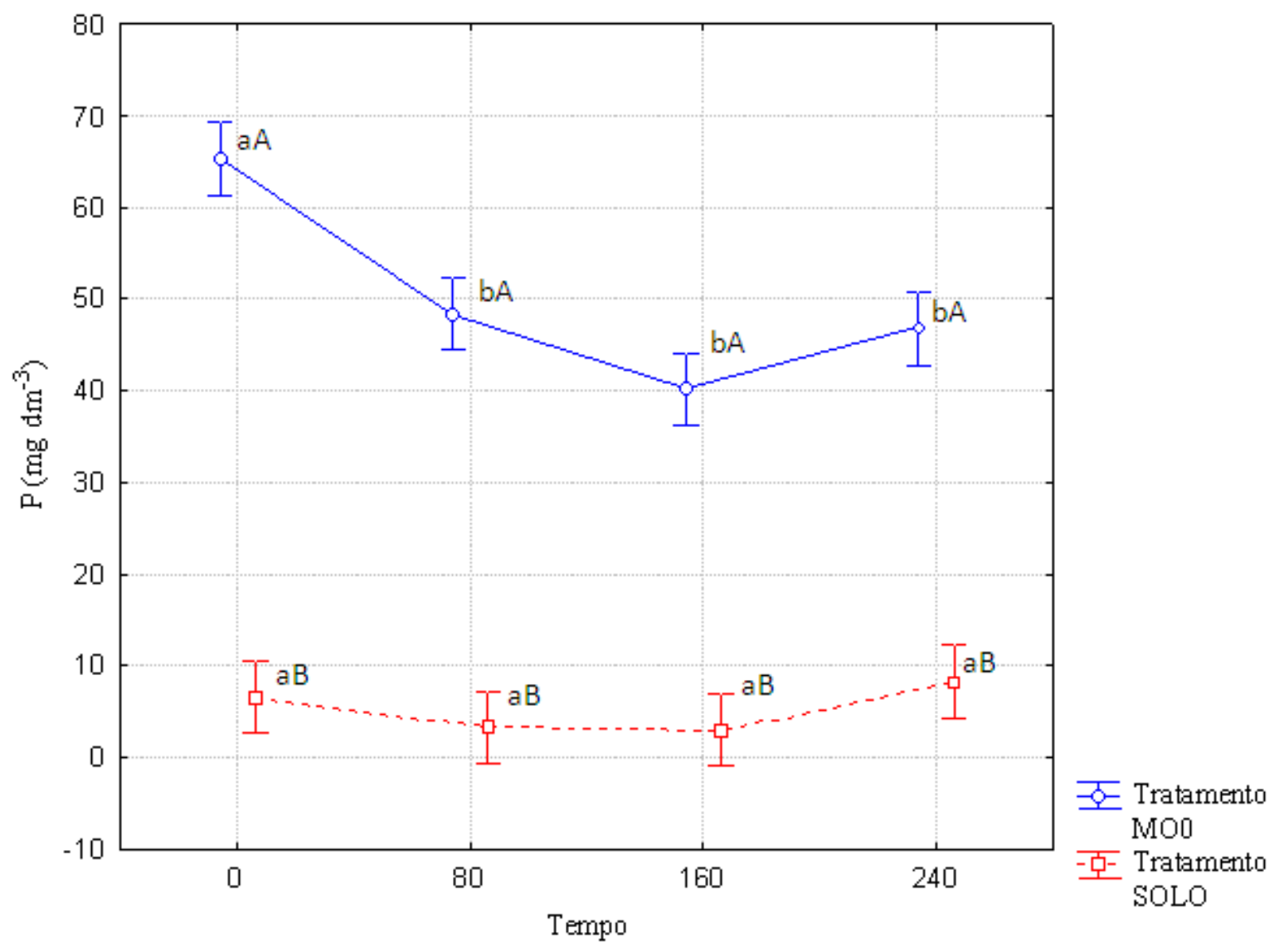

Figura 13. Valores de $\mathrm{P}$ para solo (SOLO) e solo com adição de $35 \%$ de $\mathrm{BC}$ (MO0), nos tempos $0,80,160$ e 240 dias de incubação em estufa (Os pontos seguidos de mesmas letras maiúsculas não diferem entre si para os tratamentos e as letras minúsculas não diferem entre si para os tempos dentre os tratamentos, a $5 \%$ de probabilidade pelo teste de Tukey; $\mathrm{p}<0,05)$.

Entre os tratamentos SOLO e MO0 houve diferença significativa no conteúdo de K (Figura 14), com aumento em torno de $27 \%$ quando BC foi adicionado. Ao longo dos 240 dias de incubação em estufa, houve aumento significativo do conteúdo de K no solo, decorrente, provavelmente, da adição do elemento pela água acrescentada aos vasos, uma vez 
que não foi utilizada água destilada para manter a umidade do solo, ao longo do período. $\mathrm{Na}$ mistura (MO0) houve decréscimo significativo no conteúdo de $\mathrm{K}$, provavelmente decorrente da lixiviação do elemento.

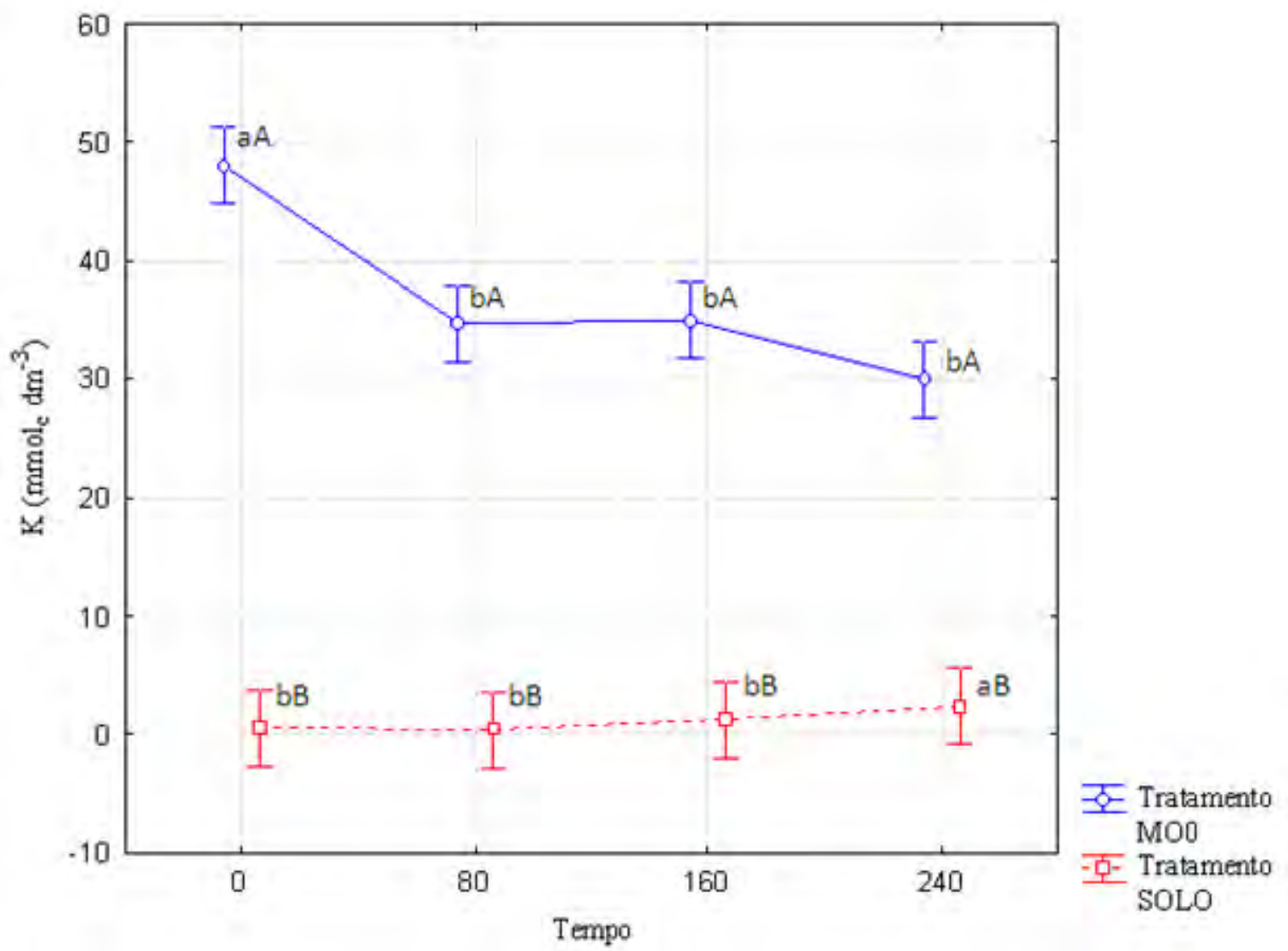

Figura 14. Os valores de K para solo (SOLO) e solo com adição de $35 \%$ de BC (MO0), nos tempos 0, 80, 160 e 240 dias de incubação em estufa (Os pontos seguidos de mesmas letras maiúsculas não diferem entre si para os tratamentos e as letras minúsculas não diferem entre si para os tempos dentre os tratamentos, a $5 \%$ de probabilidade pelo teste de Tukey; $\mathrm{p}<0,05)$.

A adição de $\mathrm{BC}$ ao solo (MO0) promoveu um aumento significativo de aproximadamente $89 \%$ no conteúdo de Ca (Figura 15). No solo, ao longo do período de incubação, houve diferenças significativas no seu conteúdo, decorrente provavelmente da adição do elemento $\left(0,3 \mathrm{mg} \mathrm{kg}^{-1}\right)$ pela água acrescentada aos vasos, uma vez que não foi 
utilizada água destilada para manter a umidade do solo neste período. O mesmo não foi perceptível na mistura, pela alta concentração do elemento presente no BC (5.835 $\left.\mathrm{mg} \mathrm{kg}^{-1}\right)$.

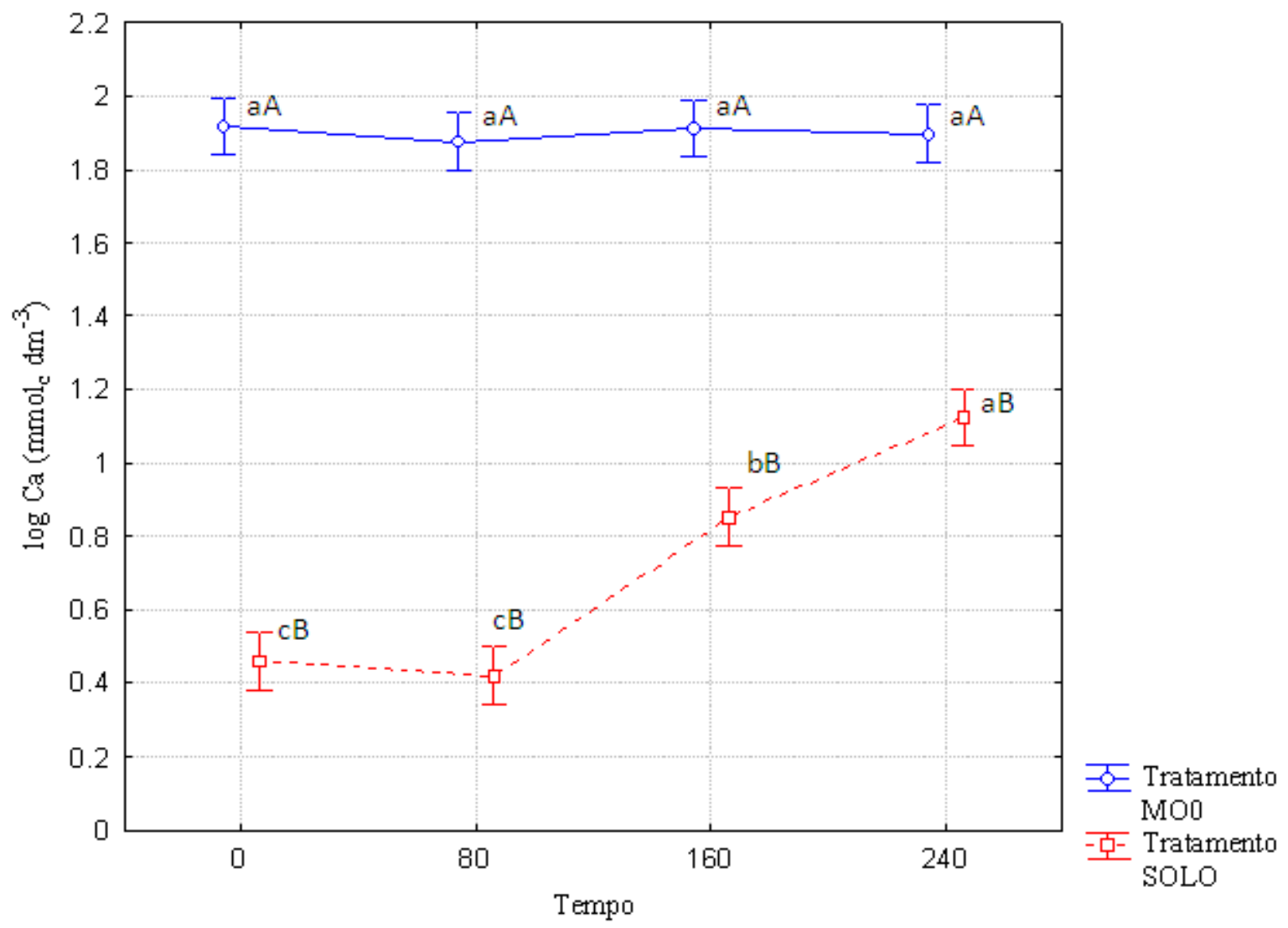

Figura 15. Os valores de Ca para solo (SOLO) e solo com adição de $35 \%$ de BC (MO0), nos tempos 0, 80, 160 e 240 dias de incubação em estufa. (Os pontos seguidos de mesmas letras maiúsculas não diferem entre si para os tratamentos e as letras minúsculas não diferem entre si para os tempos dentre os tratamentos, a $5 \%$ de probabilidade pelo teste de Tukey; $\mathrm{p}<0,05)$.

O BC proporcionou ao solo (MO0) um aumento significativo em torno de $87 \%$ no conteúdo de Mg (Figura 16). Ao longo dos 240 dias de incubação houve diferenças significativas no seu conteúdo para o solo, decorrente provavelmente da adição do elemento em torno de $23,4 \mathrm{mg} \mathrm{kg}^{-1}$, pela água acrescentada aos vasos. O mesmo não foi perceptível na mistura, pela alta concentração do elemento presente no BC $\left(1.014 \mathrm{mg} \mathrm{kg}^{-1}\right)$. 


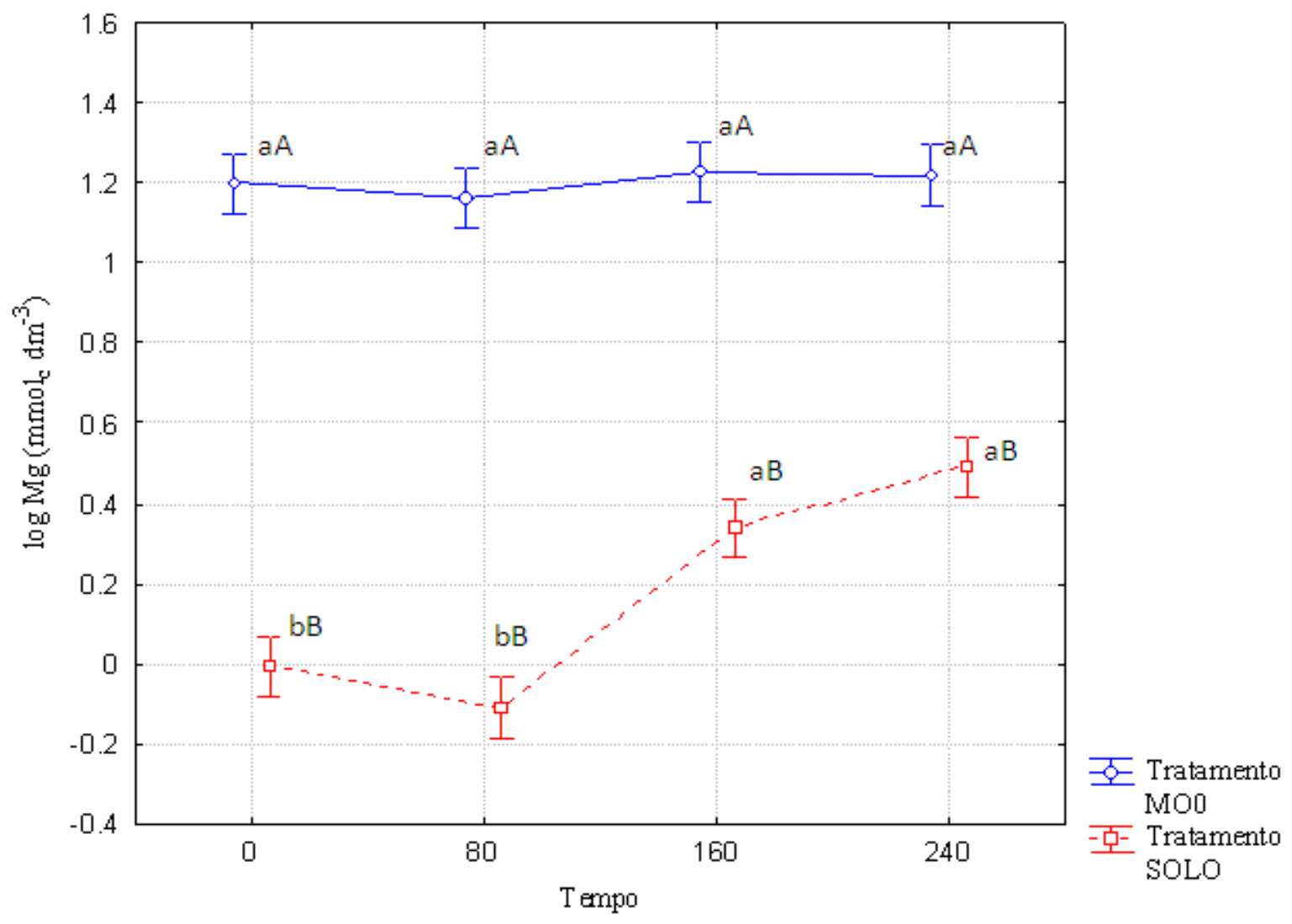

Figura 16. Os valores de $\mathrm{Mg}$ para solo (SOLO) e solo com adição de $35 \%$ de BC (MO0), nos tempos 0, 80, 160 e 240 dias de incubação em estufa. (Os pontos seguidos de mesmas letras maiúsculas não diferem entre si para os tratamentos e as letras minúsculas não diferem entre si para os tempos dentre os tratamentos, a $5 \%$ de probabilidade pelo teste de Tukey; $\mathrm{p}<0,05)$.

Entre os tratamentos SOLO e MO0 houve decréscimo (72\%) no conteúdo de Fe quando $\mathrm{BC}$ foi adicionado (Figura 17). Isso porque o Fe a pH acima de 7 é encontrado no solo na forma insolúvel $\mathrm{Fe}(\mathrm{OH})_{3}$, com valor de produto de solubilidade $\left(\mathrm{k}_{\mathrm{ps}}\right)$ igual a $1,110^{-36}$ (MAHAN \& MYERS, 2002). 


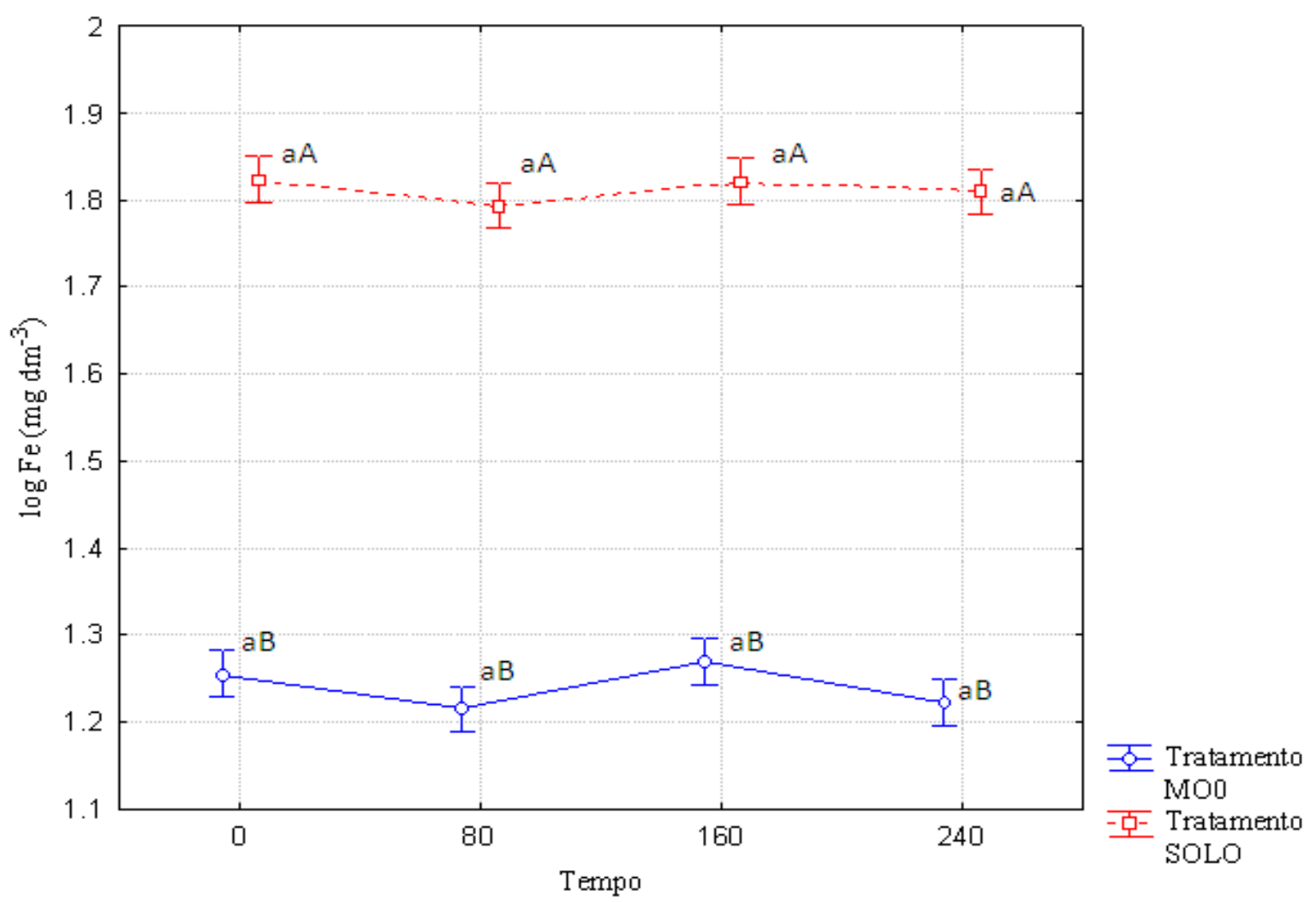

Figura 17. Os valores de Fe para solo (SOLO) e solo com adição de $35 \%$ de BC (MO0), nos tempos 0, 80, 160 e 240 dias de incubação em estufa. (Os pontos seguidos de mesmas letras maiúsculas não diferem entre si para os tratamentos e as letras minúsculas não diferem entre si para os tempos dentre os tratamentos, a $5 \%$ de probabilidade pelo teste de Tukey; $\mathrm{p}<0,05)$.

O conteúdo de Mn no solo com a adição de BC aumentou 80\% (Figura 18). Ao longo do período de incubação, diminuiu seu conteúdo na mistura e manteve-se estável no solo. O decréscimo de $\mathrm{Mn}$ na mistura se deve ao efeito do $\mathrm{BC}$ no $\mathrm{pH}$ do solo (Tabela 8). Em pH básico o manganês se encontra nas formas insolúveis na solução do solo: $\mathrm{Mn}(\mathrm{OH})_{2}$ com $\mathrm{K}_{\mathrm{ps}}=4,010^{-14}$ e $\mathrm{MnCO}_{3}$ com $\mathrm{k}_{\mathrm{ps}}=9,010^{-11}$ (MAHAN \& MYERS, 2002).

Quando o BC foi adicionado ao solo o conteúdo dos macronutrientes $\mathrm{P}, \mathrm{K}, \mathrm{Ca} \mathrm{e}$ $\mathrm{Mg}$ e dos micronutrientes B, Mn e $\mathrm{Zn}$ foram maiores que os recomendados para a maioria das culturas (RAIJ et al., 1996). Esses nutrientes foram concentrados no BC pelo processo de pirólise, podendo influenciar positivamente na fertilidade do solo. Para isso, sua dosagem deve ser bem assistida, uma vez que influencia diretamente no $\mathrm{pH}$ e no teor de nutrientes no solo. 


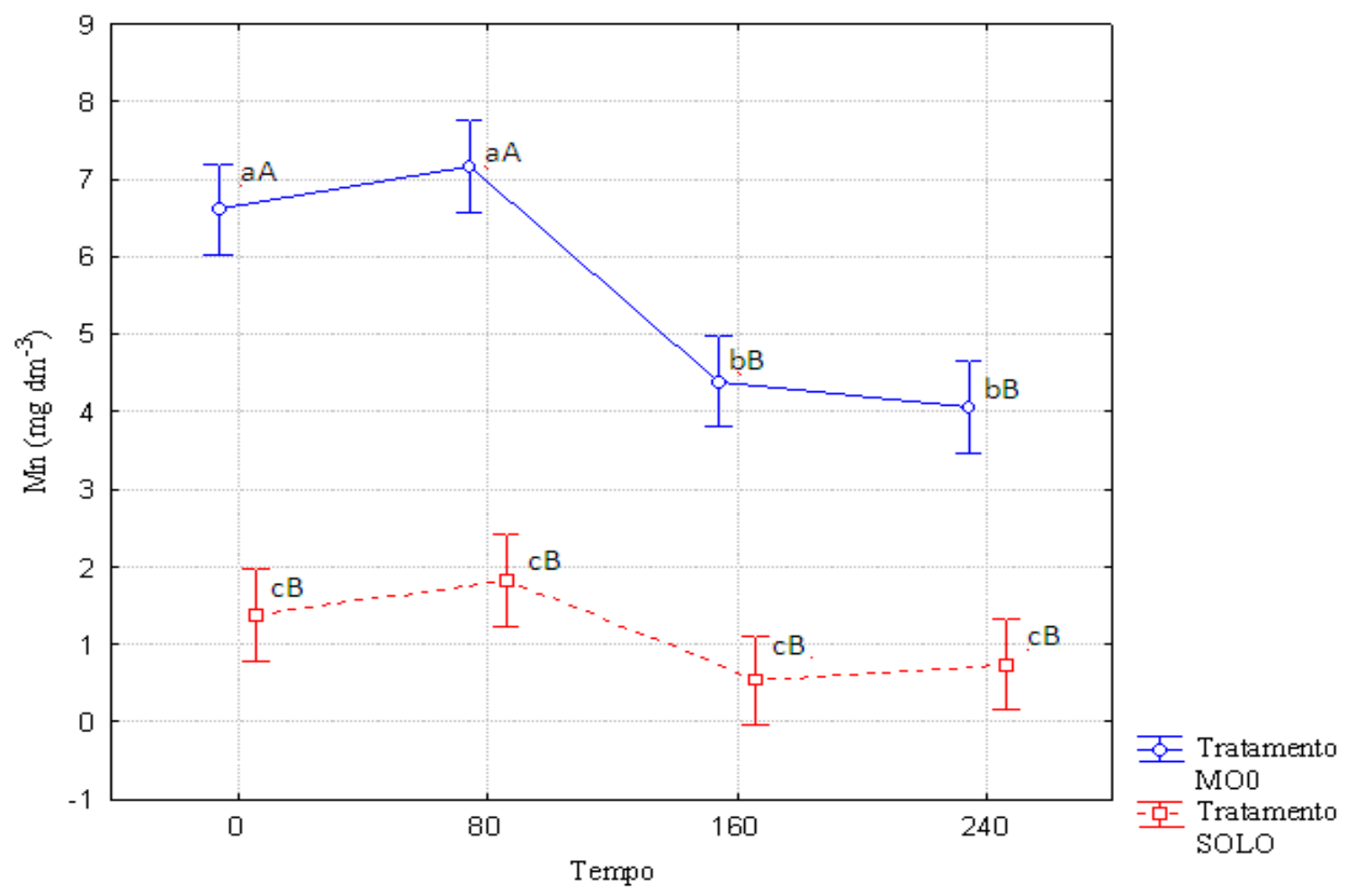

Figura 18. Os valores de Mn para solo (SOLO) e solo com adição de 35\% de BC (MO0), nos tempos $0,80,160$ e 240 dias de incubação em estufa. (Os pontos seguidos de mesmas letras maiúsculas não diferem entre si para os tratamentos e as letras minúsculas não diferem entre si para os tempos dentre os tratamentos, a $5 \%$ de probabilidade pelo teste de Tukey; $\mathrm{p}<0,05)$.

\subsection{Ensaio 1- Matéria Orgânica}

O C total entre o solo e os tratamentos com adição de carvão apresentaram diferença estatística significativa a 5\% pelo teste de Tukey ao longo dos 240 dias de incubação, não houve diferença para os tratamentos contendo $\mathrm{MO}$, independentemente das doses aplicadas (Figura 19). Mesmo não apresentando diferenças significativas nos tratamentos com adição de MO, é importante ressaltar que os valores na mistura aumentaram 0,26; 1,$07 ; 1,88$ e 2,69\% nos tratamentos SBMO-10, SBMO-40, SBMO-70 e SBMO-100, respectivamente. Isso pode ter ocorrido pelo alto teor de BC (35\% do peso) adicionado aos tratamentos, causando erro nas medidas de $\mathrm{C}$ total, não apontando o efeito das doses de MO na mistura. 


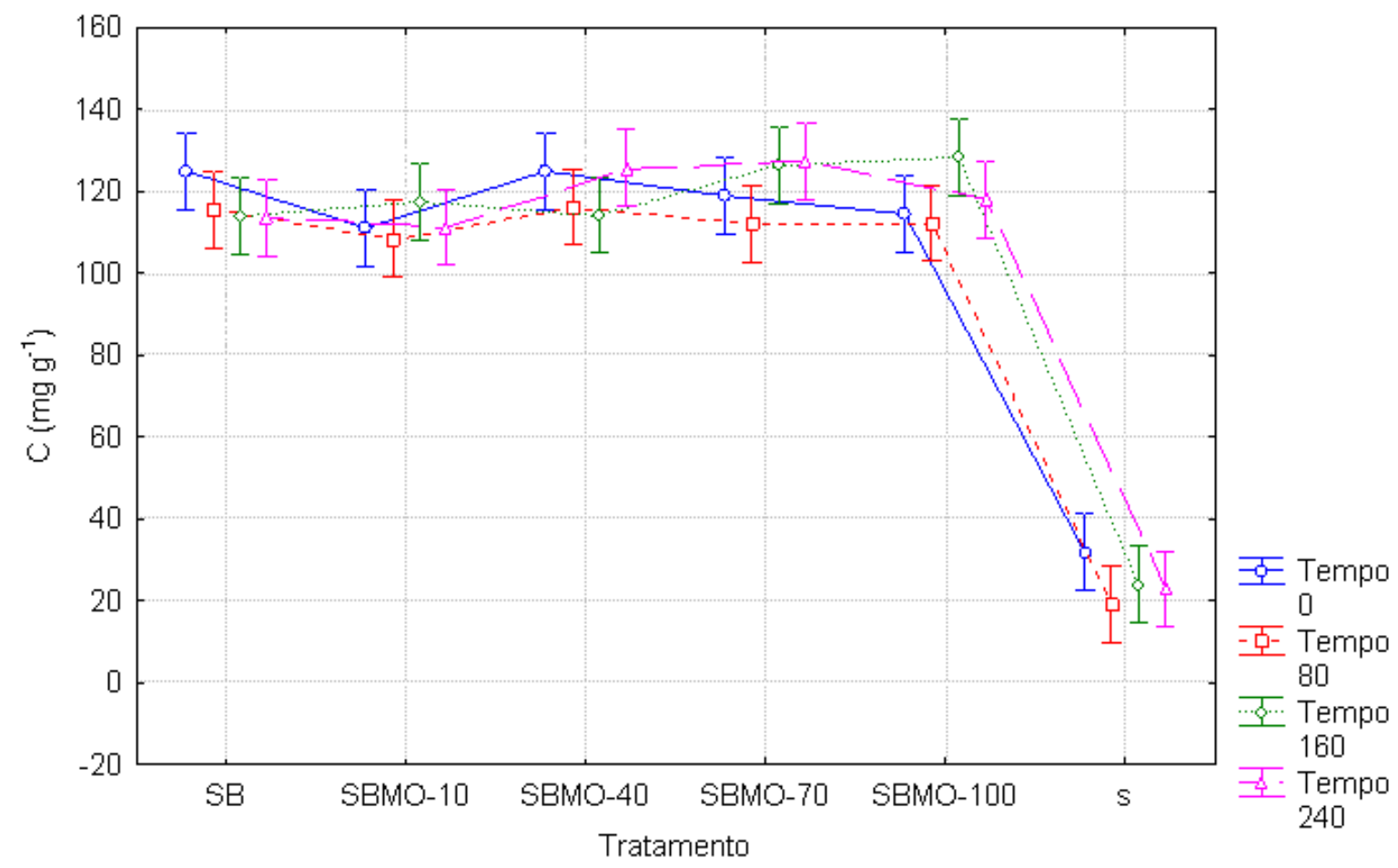

Figura 19. $\mathrm{C}$ total em $\mathrm{mg} \mathrm{g}^{-1}$ nos tempos $0,80,160$ e 240 dias de incubação em estufa, para os tratamentos Solo(S), Solo+BC (SB), Solo+BC+10t ha ${ }^{-1}$ de MO (SBMO-10), Solo+BC+40t ha ${ }^{-1}$ (SBMO-40), Solo+BC+70t ha ${ }^{-1}$ (SBMO-70), Solo+BC+100t ha ${ }^{-1}$ (SBMO-100).

A mineralização do solo manteve-se estável ao longo dos 320 dias de incubação em estufa, com valor da taxa de mineralização total igual a $135 \mathrm{mgC}^{-1}$ de solo, comportamento esperado uma vez que o solo, degradado por erosão laminar, possui baixo teor de MO, igual $18 \mathrm{~g} \mathrm{dm}^{-3}$.

Nos tratamentos com adição de BC e doses de $\mathrm{MO}$ não houve diferenças significativas na taxa de respiração pelos microrganismos do solo, provavelmente pelo alto teor de BC incorporado as tratamentos.

O BC não apresentou poder recalcitrante à mineralização aos 320 dias de incubação em estufa, com taxa de mineralização total para SB, SM-10, SBMO40, SBMO-70, SBMO-100, iguais a 1.630, 1.970, 2.084, 1.911 e $2.153 \mathrm{mgC} \mathrm{g}^{-1}$ da mistura, respectivamente. A taxa de mineralização para os tratamentos diminuiu ao longo do período (Figura 20). Isso porque no início do processo, principalmente até os 80 dias, ocorreu a mineralização dos 
compostos mais facilmente oxidáveis (lábeis) pelos microrganismos; depois disso permaneceram compostos cada vez mais difíceis de serem hidrolisados pelos microrganismos do solo, como compostos fenólicos (Tabela 8), mostrando uma tendência à recalcitrância do BC ao logo do tempo. Este fenômeno é observado nas TPIs (BIRD et al., 1999), que mesmo localizadas em regiões de clima propício a degradação de compostos orgânicos, não mudaram sua coloração enegrecida proveniente do BC incorporado ao solo, deixando evidente a olho nu a recalcitrância do $\mathrm{BC}$.

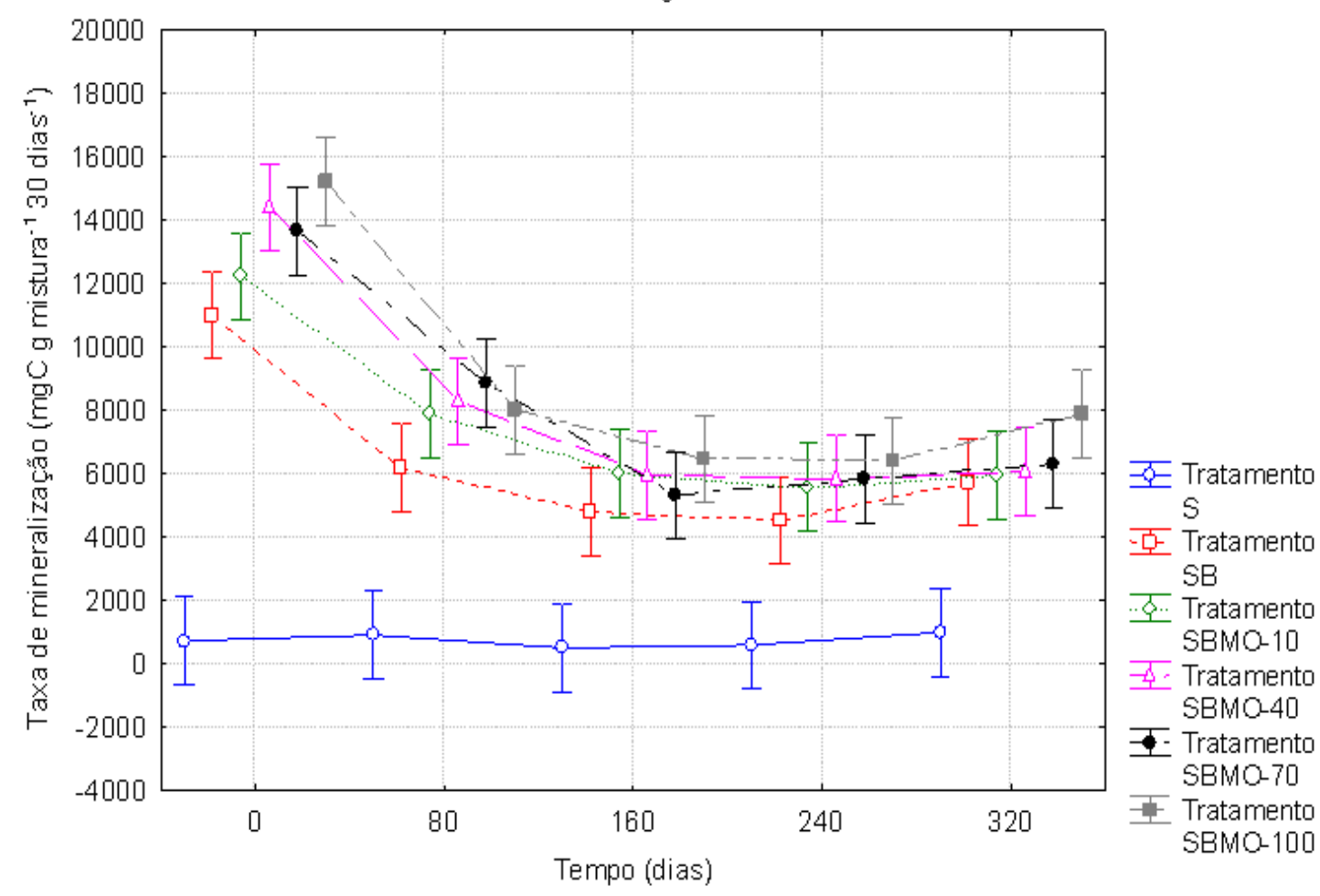

Figura 20. Mineralização total do solo $(\mathrm{S})$, solo+BC $(\mathrm{SB})$ e solo+BC+10, 40, 70 e $100 \mathrm{t} \mathrm{ha}^{-1}$ de MO (SBMO-10, SBMO40, SBMO-70, SBMO-100) nos tempos 0, 80, 160, 240 e 320 dias de incubação em estufa.

Entre os tratamentos, a mineralização da MO foi superior na dose de $100 \mathrm{t} \mathrm{ha}^{-1}$ (Figura 21). Nessa dose houve queda na taxa de mineralização aos 80 dias de incubação em estufa, estabilizando aos 160 dias e aumentando aos 320 dias, diferindo dos demais tratamentos. 


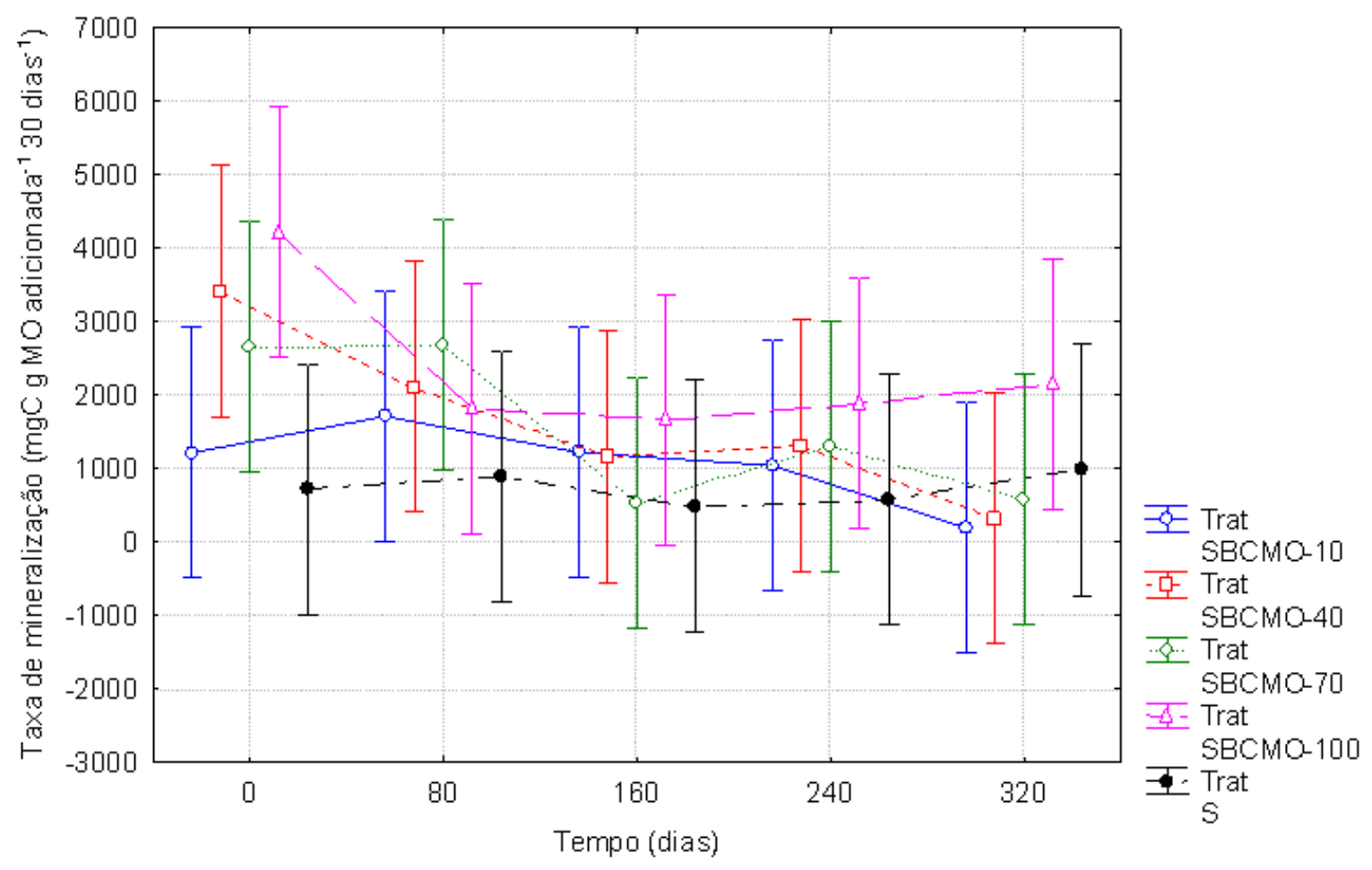

Figura 21. Mineralização total da matéria orgânica no solo $(\mathrm{S})$ e da mistura (solo+BC+10, 40, 70 e 100 t ha-1 de MO) nos tempos de 0, 80, 160, 240 e 320 de incubação em estufa.

As amostras de solo (S), biocarvão (BC), matéria orgânica (MO) e misturas (SBMO-10, SBMO-40, SBMO-70 e SBMO-100) possuem funcionalidades ácidas em suas superfícies, através de grupos carboxílicos, fenólicos e lactonas (Tabela 9). Para os grupamentos carboxílicos, houve decréscimo significativo do tempo 0 para 240 dias de incubação, decorrentes do processo de mineralização. Entre os tratamentos, o $S$ foi o que apresentou maior ocorrência desses grupamentos. 
Tabela 9. Porcentagem de grupos funcionais carboxílicos, lactonas e fenólicos, quantificados por titulação de Bohem nos tempo 0 e 240 dias de incubação em estufa

\begin{tabular}{|c|c|c|c|}
\hline \multicolumn{4}{|c|}{ Grupos Funcionais } \\
\hline Tratamentos & Carboxílicos & Lactonas & Fenóis \\
\hline \multicolumn{4}{|c|}{ 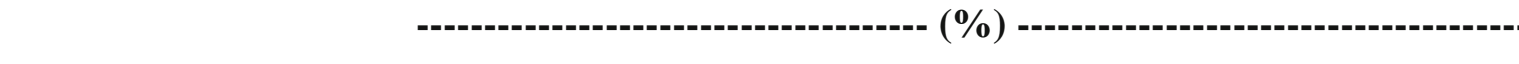 } \\
\hline $\mathrm{BC}$ & 3 & 17 & 80 \\
\hline MO & 23 & 12 & 65 \\
\hline \multicolumn{4}{|c|}{ Tempo 0} \\
\hline $\mathrm{S}$ & $75 \mathrm{aA}$ & $6 \mathrm{aA}$ & $19 \mathrm{bA}$ \\
\hline SB & $12 \mathrm{dA}$ & $20 \mathrm{aA}$ & $62 \mathrm{aA}$ \\
\hline SBMO-10 & $33 \mathrm{bcA}$ & $11 \mathrm{aA}$ & $55 \mathrm{aA}$ \\
\hline SBMO-40 & $17 \mathrm{cdA}$ & $19 \mathrm{aA}$ & $64 \mathrm{aA}$ \\
\hline SBMO-70 & $38 \mathrm{bA}$ & $12 \mathrm{aA}$ & 46abA \\
\hline SBMO-100 & $37 \mathrm{bA}$ & $24 \mathrm{aA}$ & 39abA \\
\hline \multicolumn{4}{|c|}{ Tempo 240} \\
\hline $\mathrm{S}$ & $67 \mathrm{aB}$ & $9 \mathrm{aA}$ & $24 \mathrm{cB}$ \\
\hline SB & $13 \mathrm{cbB}$ & $15 \mathrm{aA}$ & $72 \mathrm{baB}$ \\
\hline SBMO-10 & $12 \mathrm{cbB}$ & $20 \mathrm{aA}$ & $68 \mathrm{baB}$ \\
\hline SBMO-40 & $8 \mathrm{cB}$ & $11 \mathrm{aA}$ & $81 \mathrm{aB}$ \\
\hline SBMO-70 & $25 \mathrm{bB}$ & $16 \mathrm{aA}$ & $59 \mathrm{bB}$ \\
\hline SBMO-100 & $22 \mathrm{bB}$ & $14 \mathrm{aA}$ & $64 \mathrm{baB}$ \\
\hline
\end{tabular}

As médias seguidas de mesmas letras minúsculas não diferem entre si para os tratamentos e as maiúsculas para os tempos, a $5 \%$ de probabilidade pelo teste de Tukey $(\mathrm{p}<0,05)$.

O espectro de infravermelho das amostras de biocarvão (BC), solo (Solo), solo+biocarvão (SBC) e misturas (SBCMO-10, SBMO-40, SBMO-70 e SBMO-100 t ha ${ }^{-1}$ de MO) demonstraram feições similares entre si, com picos característicos em quatro regiões importantes: (i) a faixa entre 480 a $650 \mathrm{~cm}^{-1}$, é característica da ocorrência de anéis aromáticos; (ii) entre 700 a $800 \mathrm{~cm}^{-1}$, apresentam bandas causadas por deformação angular fora do plano de ligações C-H de anéis aromáticos (BAES \& BLOOM, 1989); (iii) entre 1270 a $1310 \mathrm{~cm}^{-1}$ com presença de bandas relacionadas à ligação $\mathrm{C}-\mathrm{O}-\mathrm{H}$, referentes às vibrações 
axial (C-O) e angular (OH); (iv) na região de 1530 a $1720 \mathrm{~cm}^{-1}$, onde normalmente se observa a sobreposição de várias bandas de absorção, houve ocorrência de picos característicos do estiramento da ligação $\mathrm{C}=\mathrm{C}$ de grupos aromáticos (SILVERSTEIN, et al., 1994) e do estiramento de carbonila $(\mathrm{C}=\mathrm{O})$, que juntamente com vibração de deformação axial da ligação C-O, podem sugerir a presença tanto de ácidos carboxílicos como de ésteres ou lactonas, ligados a grupos aromáticos (GUILARDUCI et al., 2006) (Figura 22). Para o BC o pico nesta faixa foi de baixa intensidade, decorrente da pequena ocorrência desses grupamentos.

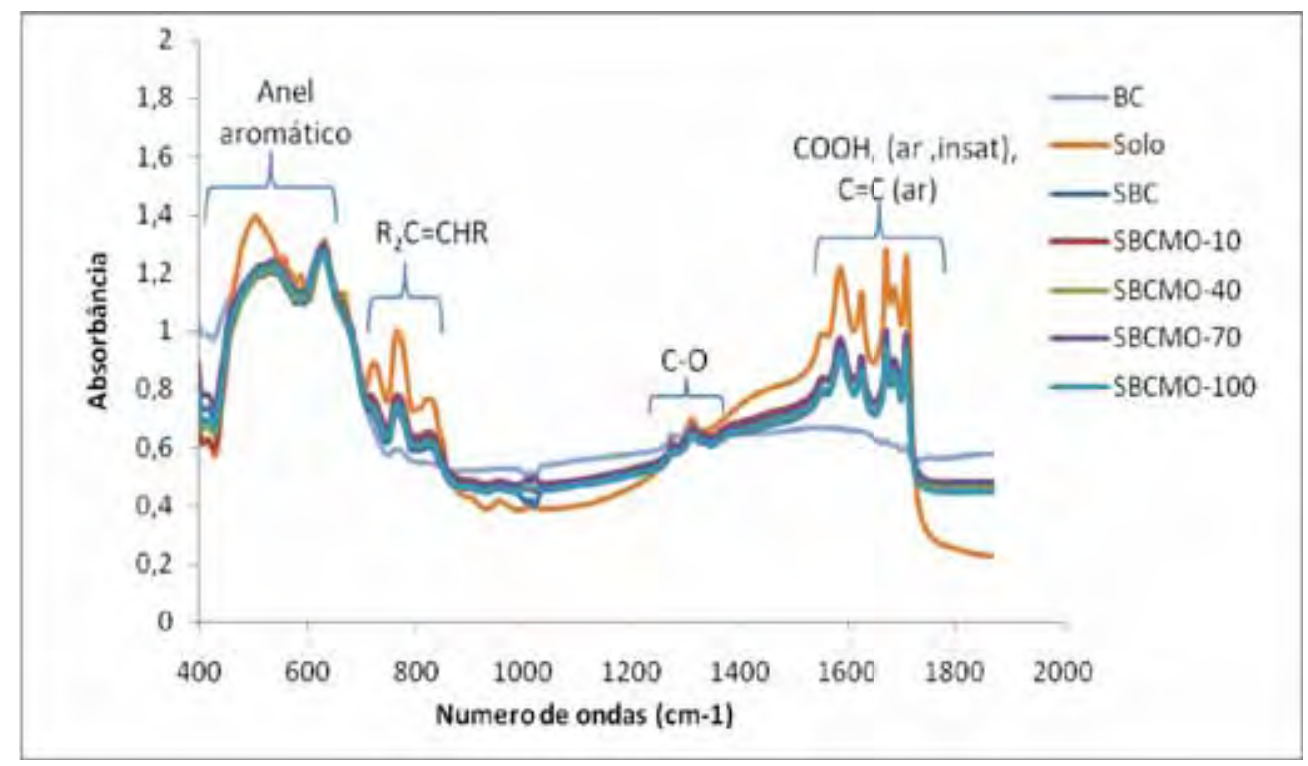

Figura22. Espectro de infravermelho médio para as amostras de BC, solo e mistura (BC+solo+ o, 10, 40, 70 e $100 \mathrm{t} \mathrm{ha}^{-1}$ de MO).

\subsection{Ensaio 2 - Fósforo}

O solo apresentou maior poder sortivo para o fósforo quando comparado com a mistura (solo $+35 \%$ de $\mathrm{BC}$ ), enquanto que o $\mathrm{BC}$ apresentou apenas dessorção de $\mathrm{P}$. Este comportamento é decorrente da grande concentração de $\mathrm{P}$ presente no $\mathrm{BC}$, igual a $1484 \mathrm{mg} \mathrm{kg}$ ${ }^{1}$ de P total.

A cinética de sorção de $\mathrm{P}$ na mistura (SBC) necessitou duas vezes mais tempo para chegar ao equilíbrio quando comparado ao S (Figura 23), pois o SBC possui dois, talvez, três 
passos para a reação de sorção, que são: difusão, dessorção (como mostra a curva para o BC) e sorção, enquanto o solo possui apenas a fase de sorção, decorrente do alto poder de sorção de $\mathrm{P}$ pelo $\mathrm{Fe}$ e $\mathrm{Al}$, principal fator de fixação de $\mathrm{P}$ em solos paulistas (AQUINO, 2004, ABDALLA \& PROCHNOW, 2008).

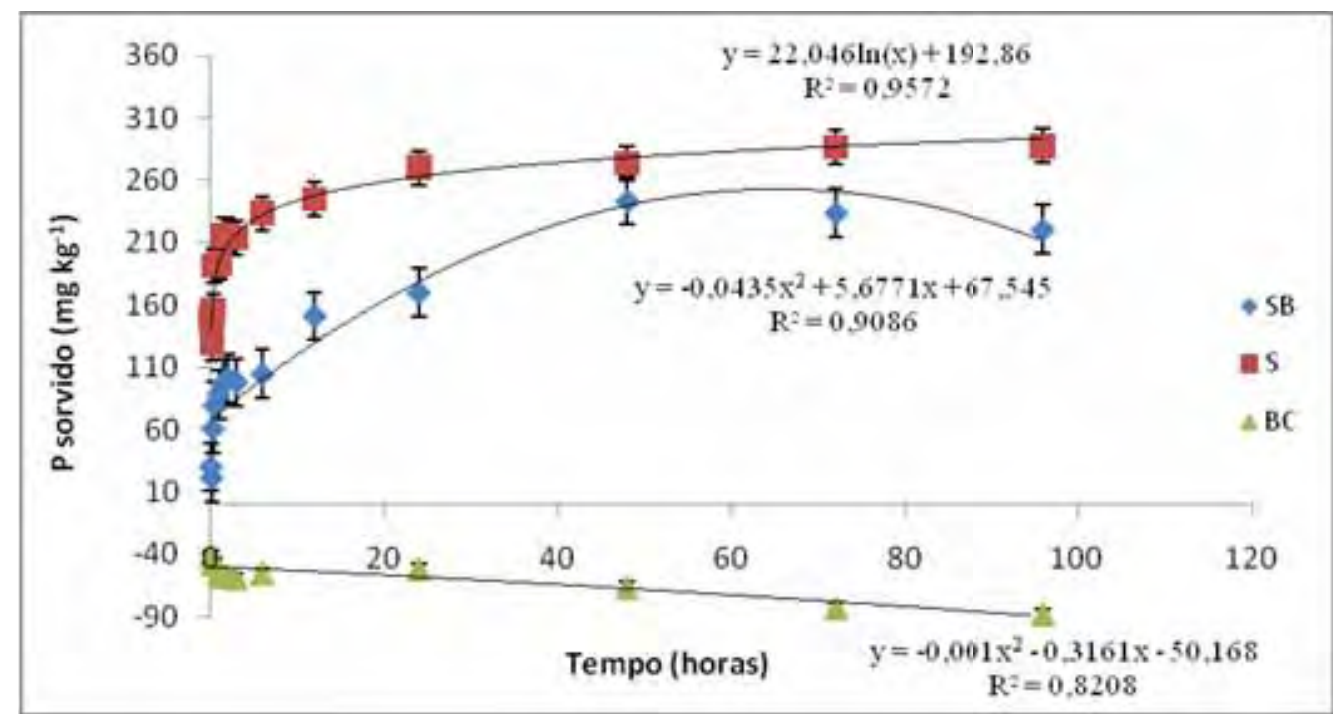

Figura 23. Cinética de sorção de P em solo (S), solo + BC (SBC) e somente biocarvão (BC), analisada utilizando tubos centrífuga.

A cinética de sorção de $\mathrm{P}$ analisada com tubos de centrífuga, apesar de necessitar maior quantidade de amostras, foi mais eficiente para o tempo de análise, entrando em equilíbrio em 24 horas quando comparado com os tubos de diálise que alcançaram o equilíbrio após 72 horas (Figura 24).

Os tubos de diálise para esta análise (Figura 24) apresentaram-se como barreiras, sorvendo $91 \%$ menos $\mathrm{P}$ quando comparado com as análises usando tubos de centrífuga, onde a solução estava em contato direto com a amostra. Em função disso, foi utilizado o método de centrifuga para as análises de equilíbrio de sorção de P. 


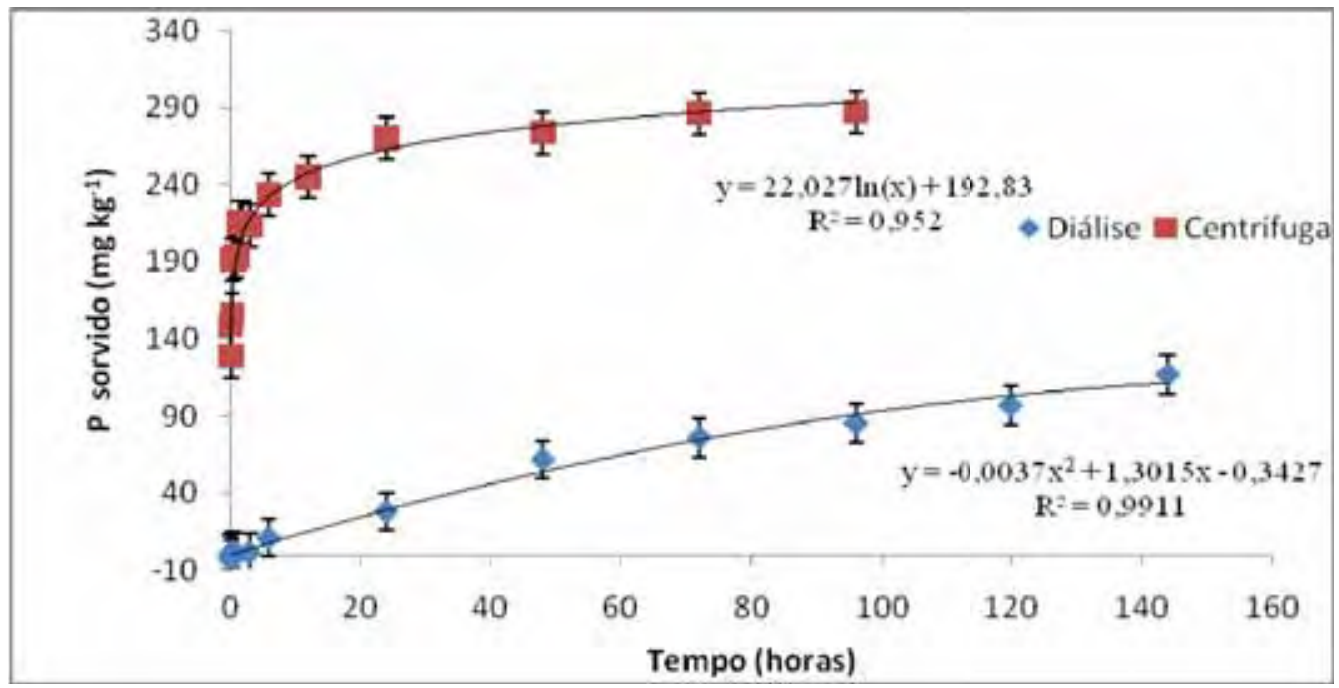

Figura24. Comparação entre os métodos de Cinética de sorção de $\mathrm{P}\left(400 \mathrm{mg} \mathrm{kg}^{-1}\right) \mathrm{em}$ solo feitos com tubos de diálise (TD) e tubos de centrífuga (TC).

Os tratamentos $\mathrm{S}$ e $\mathrm{SBC}_{\text {in natura }}$ apresentaram diferença significativa a 5\% entre si, pelo teste de Tukey, assim como entre os tratamentos $\mathrm{S}$ e $\mathrm{SBC}_{\text {sob extrações }}$ O mesmo não ocorreu

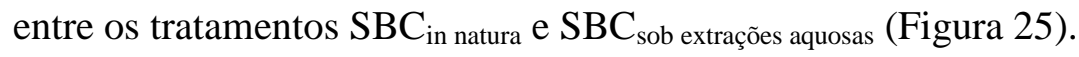

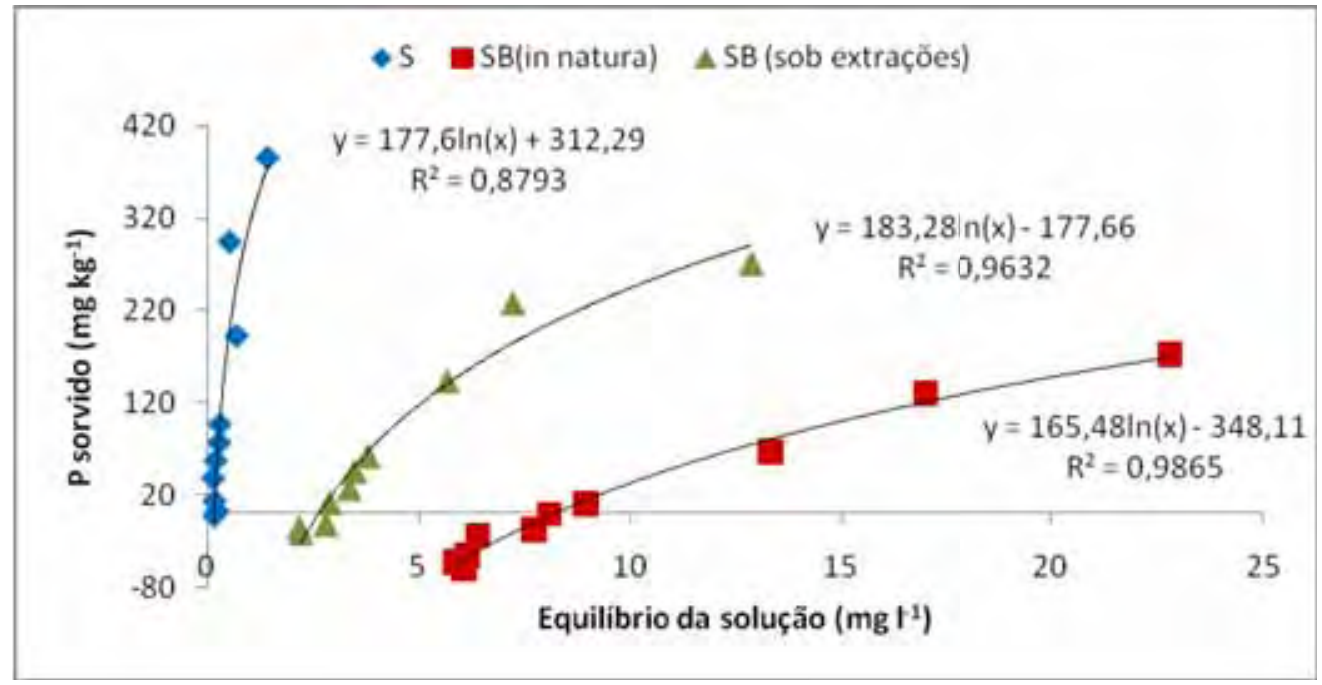

Figura 25. Sorção de $\mathrm{P}$ em solo $(\mathrm{S})$, solo com adição de $\mathrm{BC}$ in natura $\left(\mathrm{SBC}_{\mathrm{in} \text { natura }}\right)$ e solo com adição de $\mathrm{BC}$ submetido a extrações aquosas $\left(\mathrm{SBC}_{\text {sob extrações aquosas }}\right)$, analisadas com tubo centrífuga.

O solo apresentou maior poder sortivo para o fósforo quando comparado com as misturas $\left(\mathrm{SBC}_{\mathrm{in} \text { natura }}\right.$ e $\left.\mathrm{SBC}_{\text {sob extraçoes aquosas }}\right)$, aumentando proporcionalmente a sorção de $\mathrm{P}$ em 
relação às concentrações de $\mathrm{P}$ adicionadas à solução (Figura 25), decorrente dos óxidos de $\mathrm{Fe}$ e Al presentes no solo (AQUINO, 2004; ABDALLA \& PROCHNOW, 2008).

$\mathrm{A}$ adição de $\mathrm{BC}$ "in natura" ao solo promoveu a dessorção de $\mathrm{P}$ até concentração igual a $8 \mathrm{mg} \mathrm{l}^{-1}$, o equivalente a $80 \mathrm{mg} \mathrm{kg}^{-1}$, diminuindo a capacidade de sorção de $\mathrm{P}$ no solo. O conteúdo total de P no BC foi igual a $1.484 \mathrm{mg} \mathrm{kg}^{-1}$, onde $61 \%$, foi prontamente disponível, presente nas cinzas do BC.

$\mathrm{O}$ alto teor de $\mathrm{P}$ prontamente disponível no BC diminui a necessidade de adição de fertilizantes fosfatados ao solo quando aplicados juntamente com o $\mathrm{BC}$, pois à medida que se adiciona fosfato aos solos, estes vão reduzindo sua capacidade em fixar P (BORROW, 1974 e MOREIRA et al., 2006), por ocupar os sítios de adsorção de P no solo.

As concentrações iniciais na solução do solo para os tratamentos P100, P200, P300 e P400 foram 0,24; 0,36; 0,46 e 0,58, respectivamente (Figura 26). Todos os tratamentos se concentraram em uma mesma área de dessorção, demonstrando grande potencial de dessorção de $\mathrm{P}$ para todos os tratamentos, com alto valor dos coeficientes de partição $\left(\mathrm{K}_{\mathrm{d}}\right)$ igual a 1230 $1 \mathrm{~kg}^{-1}$, calculado assumindo valores dentro da área de dessorção. Esta área encontra-se numa faixa de 0,1 a $0,2 \mathrm{mg}^{-1}$, sendo $0,2 \mathrm{mg} \mathrm{l}^{-1}$ um valor considerado ótimo para concentração de $\mathrm{P}$ na solução para a maioria das culturas (SMETHURST, 2000).

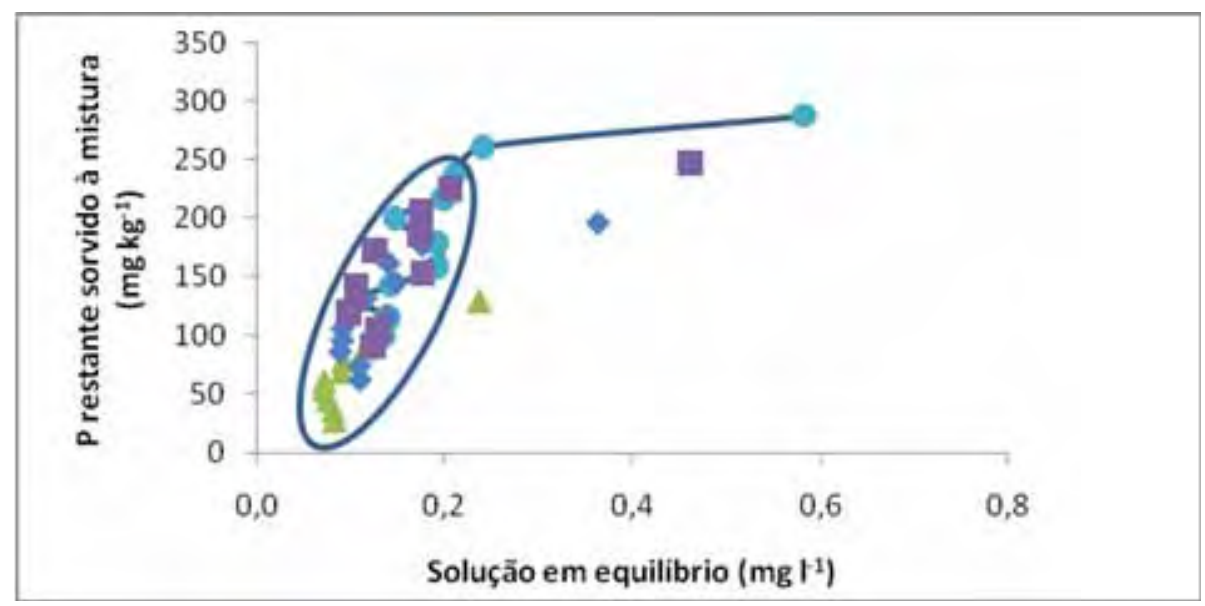

Figura 26. Curva de dessorção sequencial de $\mathrm{P}$, representada pelo $\mathrm{P}$ restante sorvida à mistura, para os tratamentos $\mathrm{P}_{75}, \mathrm{P}_{150}, \mathrm{P}_{200}$ e $\mathrm{P}_{300}$, utilizando tubos de diálise. 


\section{CONCLUSÕES}

- O BC tem poder fertilizante, sendo fonte de $\mathrm{P}, \mathrm{Ca}, \mathrm{K}, \mathrm{Mg}, \mathrm{Mn}, \mathrm{Zn}$ e B, porém sua utilização deve ser bem assistida por possuir características químicas limitantes como $\mathrm{pH}$ e sais.

- A adição de BC ao solo aumentou a taxa de mineralização dos compostos presentes na mistura; entretanto, apresentou tendência à recalcitrância ao longo de 320 dias.

- A cinética de sorção de $\mathrm{P}$ necessita duas vezes mais tempo para entrar em equilíbrio na presença do BC.

- A adição de BC ao solo diminuiu o poder de sorção de P.

- O BC possui capacidade de promover a dessorção de $\mathrm{P}$. 


\section{REFERÊNCIAS}

ABDALLA, S. R. S.; PROCHNOW, L. I. Uso racional de fósforo na agricultura com ênfase na cultura do milho. Informações Agronômicas, Piracicaba, n. 122, p. 8-12, jun. 2008.

ADDISCOT, T. M. Entropy and sustainability. European Journal of Soil Science, Dordrechster, v. 46, p. 161-168, 1992.

AFIF, E.; BARRON, V.; TORRENT, J. Organic matter delays but does not prevent phosphate sorption by cerrado soils from Brazil. Soil Science, Philadelphia, v. 159, p. 207-211, 1995.

AGÊNCIA NACIONAL DE ENERGIA ELÉTRICA - ANEEL. Atlas de energia elétrica no Brasil. 3. ed. Brasília, DF, 2009. 199 p.

AKINREMI, O. O.; CHO, C. M. Phosphate transport in calcium-saturated systems: II experimental results in a model system. Soil Science Society of America Journal, Madison, v. 55, p. $1282-1287,1991$.

ALCARDE, J. C.; GUIDOLIN, J. A.; LOPES, A. S. Os adubos e a eficiência das adubações. 2. ed. São Paulo: ANDA, 1991. 35 p. 
ALVES, B. J. R. et al. Emprego de isótopos estáveis para o estudo do carbono e nitrogênio no sistema solo-planta. In: AQUINO, A. M.; ASSIS, R. L. (Eds.). Processos biológicos no sistema solo-planta: ferramentas para uma agricultura sustentável. Brasília: Embrapa SPI, 2005. v. 1, p. 343-368.

ANDRADE, A. Investigación arqueológica de los Antrosoles de Araracuara. Bogotá: Fundación de Investigaciones Arqueológicas Nacionales, 1986. 103 p.

ANDRADE, F. V. et al. Addition of organic and humic acids to Latosols and phosphate adsorption effects. Revista Brasileira de Ciência do Solo, Viçosa, v. 27, p. 1003-1011, 2003.

ANDREOLI, C. V.; FERNANDES, F.; DOMASZAK, S. C. Reciclagem agrícola do lodo de esgoto: estudo preliminar para definição de critérios para uso agronômico e de parâmetros para normatização ambiental e sanitária. Curitiba: SANEPAR, 1999. 81p.

AQUINO, B. F. Conceitos fundamentais em fertilidade do solo. Fortaleza: UFC, 2004. 182 p. Apostilas didáticas.

BAES, A. U.; BLOOM, P. R. Diffuse reflectance and transmition Fourier transform infrared (DRIFT) spectroscopy of humic and fulvic acids. Soil Science Society of America Journal, Madison, v. 53, p. 695-700, 1989.

BARROS FILHO, N. F; COMERFORD, N. B.; BARROS, N. F. Phosphorus sorption, desorption and resorption by soils of the Brazilian Cerrado supporting eucalypt. Biomass $\&$ Bioenergy, New York, n. 28, p. 229-236, 2005.

BAYER, C.; MIELNICZUK, J. Dinâmica e função da matéria orgânica . In: SANTOS, G. A. et al. (Eds.). Fundamentos da matéria orgânica do solo: ecossistemas tropicais e subtropicais. Ed. Porto Alegre-RS: Genesis, 2008. cap. 2, p. 7-18.

BERGREEN, D.; MULDER, J. The role of organic matter in controlling aluminium solubility in acid soil horizon s. Geochimica Cosmochimica Acta, New York, v. 50, p. 4167-4180, 1995.

BEYER, L.; DESLIS, K.; VOGT, B. Estimation of soil organic matter composition according to a simple thermoanalytical approach. Communications in Soil Science and Plant Analysis. 29, pp. 1277-1297, 1998. 
BHATTI, J. S.; COMERFORD, N. B. Measurement of phosphorus desorption from a spodic horizon using two differente desorption methods and $\mathrm{pH}$ control. Communications in Soil Science anda Plant Analysis, Philadelphia, v. 33, p. 845-853, 2002.

BIRD, M. I. et al. Stability of elemental carbon in savanna soil. Global Biogeochemical Cycles, Washington, DC, v. 13, n. 4, p. 923-932, Dec. 1999.

BOEHM, H. P. Some aspects of surface chemistry of carbon blacks and other carbons. Carbon, Oxford, v. 32, p. 759-770, 1994.

BOL, R. et al. Tracing dung-derived carbon in temperate grassland using $13 \mathrm{C}$ natural bundance measurements, Soil Biology and Biochemistry, Netherlands, v. 32, p. 1337-1343, 2000.

BORROW, N.J., Effect of previous additions of phosphate on phosphate adsorption by soils, Soil Science, Philadelphia, v. 118, p. 82-89, 1974.

BRAY, R. H.; KURTZ, L. T. Determination of total, organic, and available forms of phosphorus in soils. . Soil Science, Piladelphia, v. 59, p. 39-45, 1945.

BRENNAN, R. F. et al. Phosphorus adsorption by a range of western Australian soils related to soil properties. Communications in Soil Science and Plant Analysis, Philadelphia-PA, v. 25, n. 15/16, p. 2785-2795, 1994.

BRIDGWATER, A. V. Renewable fuels and chemicals by thermal processing of biomass. Chemical Engineering Journal, Oxford, v. 91, p. 87-102, 2003.

BUDZIAK, C. R.; MAIA, C. M. B. F.; MANGRICH, A. S. Transformações químicas da matéria orgânica durante a compostagem de resíduos da indústria madeireira. Química Nova, São Paulo, v. 27, n. 3, p. 399-403, 2004.

CAMPBELL, K. L.; EDWARDS, D. R. Phosphorus and water quality. In: RITTER, W. F.; SHIRMONHAMMADI, A. (Eds.). Agricultural nonpoint source pollution: watershed management and hydrology. Boca Raton: Lewis, 2001. p. 91-107. 
CHIDUMAYO, E. N. Effects of wood carbonization on soil and initial evelopment of seedlings in miombo woodland, Zambia. Forest Ecology and Management, Netherlands, v. 70, p. 353-357, 1994.

CUNHA, A. R.; KLOSOWSKI, E. S.; GALVANI, E.; ESCOBEDO, J. F.; MARTINS, D. Classificação climatica para o município de Botucatu, SP, segundo Köppen. In: Simpósio em Energia na Agricultura, 1. 1999.Botucatu - SP: Anais... Botucatu: FCA/UNESP, 1999, v.1, p. 487-490.

CUNHA, T. J.F.; MARADI, B. E.; CANELLAS, L.P.; RIBEIRO, L.P.; BENITES, V. M.; SANTOS, G. A. Soil organic matter and fertility of anthropogenic dark earths (Terra Preta de Índio) in the Brazilian amazon basin. Revista Brasileira de Ciência do Solo. Viçosa, v. 33, p.85-93, 2009.

CZERNIK, S.; BRIDGWATER, A. V. Overview of applications of biomass fast pyrolysis oil. Energy and Fuels, New Jersey, v. 18, p. 590-98, 2004.

EMPRESA BRASILEIRA DE PESQUISA AGROPECUÁRIA. Estudos pedológicos e suas relações ambientais. In: . Projeto de gestão ambiental integrado do Estado do Amazonas. Rio de Janeiro, 2001. 157p. cap. 3B (Relatório técnico, 2001/2).

EMPRESA BRASILEIRA DE PESQUISA AGROPECUÁRIA. Centro Nacional de Pesquisa de Solos. Sistema brasileiro de classificação de solos. Rio de Janeiro, 1999. 412 p.

ENWEZOR, W. O. Significance of C-organic P ratio in mineralization of soil organic phosphorus. Soil Science, Philadelphia, v. 103, p. 62-66, 1967.

FALCÃO, N. P. S.; CARVALHO, E. J. M.; COMERFORD, N. Avaliação da fertilidade de solos antropogênicos da Amazônia Central. In: CONGRESSO DA SOCIEDADE DE ARQUEOLOGIA BRASILEIRA, 11. Anais..., Rio de Janeiro2001. 2p.

FALCÃO, N. P. S.; COMERFORD, N. B.; LEHMANN, J. Determining nutriente bioavalability of Amazonian dark earth soils: methodological challenges. In: LEHMANN, J. et al. (Eds.). Amazonian dark earths: origin, properties, and management. New York: Kluwer Academic, 2003. p. 255-270. 
FALESI, I. C. Solos de Monte Alegre. Belém: IPEAN, 1970. (Série solos da Amazônia, v. 2, n. 1).

FAO. FAOSTAT: online statistical service. Rome, 2006. Disponível em: <http://apps.fao.org/>. Acesso em: 20 nov. 2009.

FERNANDES, L. A.; Frações de fósforo e atividade da fosfatase ácida em plantas de feijoeiro cultivadas m solos de várzea. Revista Brasileira de Ciência do Solo, Viçosa, v. 24, p. 561$571,2000$.

FONTES, M. P. F.; WEED, S. B. Phosphate adsorption by clays from Brazilian Oxisols: relationships with specific surface area and mineralogy. Geoderma, Amsterdam, v. 72, p. 37$51,1996$.

FONTES, M. R.; WEED, S. B.; BOWEN, L. H. Association of microcrystalline goethite and humic acid in some Oxisols from Brazil. Soil Science Society of America, Madison, v. 56, p. 982-990, 1992.

GATIBONI, L. C. Disponibilidade de formas de fósforo do solo às plantas. 2003. 247 p. Tese (Doutorado em Agronomia/Biodinâmica dos Solos)-Universidade Federal de Santa Maria, Santa Maria, 2003.

GEO - GLOBAL ENVIRONMENT OUTLOOK. Estado do meio ambiente e retrospectiva política: 1972-2002. 2004. Disponível em: <www2.ibama.gov.br/ $\sim$ geobr/geo3-port/geo3port/cap2_\%20terra.pdf>. Acesso em: fev. 2007.

GLASER, B. et al. Black carbon in density fractions of anthropogenic soils of the Brazilian Amazon region. Organic Geochemistry, Bristol, v. 31, n. 7/8, p. 669-678, 2000.

GLASER, B. et al. The 'terra preta' phenomenon: a model for sustainable agriculture in the humid tropics. Naturwissenschaften, Berlin, v. 88, p. 37-41, 2001.

GLASER, B. et al. Potential of pyrolyzed organic matter in soil amelioration. Beijing: People's Republic of China Ministry of Water Resources; Ministry of Water Resources, 2002a. 426 p. 
GLASER, B.; LEHMANN, J.; ZECH, W. Ameliorating physical and chemical properties of highly weathered soils in the tropics with charcoal: a review. Biology and Fertility of Soils, Berlin, v. 35, p. 219-230, 2002b.

GLASER, B; GUGGENBERGER, G.; ZECH, W; RUIVO, M. L.. Soil organic matter stability in Amazonian Dark Earths. In: LEHMANN, J. et al. (Eds.). Amazonian dark earths: origin, properties, management. Dordrecht : Kluwer Academic, 2003. p. 141-158.

GOLCHIN, A. et al. The effects of vegetation and burning on the chemical composition of soil organic matter in a volcanic ash soil as shown by 13C NMR spectroscopy: I whole soil and humic acid fraction. Geoderma, Amsterdam, v. 76, p. 155-174, 1997.

GONÇALVES, J.L.M.; FIRME, D.J.; NOVAIS, R.F.\& RIBEIRO, A.C. Cinética de adsorção de fósforo em solos de cerrado. Revista Brasileira de Ciência do Solo, Viçosa, 9:107-111, 1985.

GOYAL, S. et al. Influence of inorganic fertilizers and organic amendments on soil organic matter and soil microbial properties under tropical conditions, Biology and Fertility of Soils, Berlin, v. 29, p. 196-200, 1999.

GRADY, O. R.; RUSH, R. The Terra Preta phenomenon: managing the carbon cycle. In: KATANNING WORKSHOP, 2007. Managing the carbon cycle: workshop papers... Disponível em: <http://www.amazingcarbon.com/O'Grady\%20and\%20Rush\%20\%20the\%20Terra\%20Preta\%20phenomenon.pdf>. Acesso em: 18 abr. 2009.

GUILARDUCI, V. V. S. et al. Adsorção de fenol sobre carvão ativado em meio alcalino.

Química Nova, São Paulo, v. 29, n. 6, p. 1226-1232, 2006.

HAVLIN, J. L. et al. Soil fertility and fertilizers: an introduction to nutrient management. 7th ed. New Jersey: Pearson-Prentice Hall, 2005. 515p.

HEDLEY, M. J.; HUSSIN, A.; BOLAN, M. S. New approaches to phosphoruus fertilization. In: SYMPOSIUM OF PHOSPHORUS REQUIREMENTS FOR SUSTAINABLE AGRICULTURE IN ASIA AND OCEANIA, 1., 1990, Los Banos. Proceedings... Manila: IRRI, 1990. p. 125-142. 
JENKINSON, D. S.; AYANABA, A. Decomposition of carbon-14 labeled plant material under tropical conditions. Soil Science Society of America, Madison, v. 41, p. 912-915, 1977.

JOBBAGY, E. G.; JACKSON, R. B. The vertical distribution of soil organic carbonand its relation to climate and vegetation. Ecologic Aplications, Washington, DC, v. 10, p. 423-436, 2000 .

JORDÃO, C. P. et al. Adsorção de cátions metálicos em ácidos húmicos de Latossolo. Química Nova, São Paulo, v. 16, p. 517-520, 1993.

KAMPRATH, E. J. Phosphorus fixation and availability in highly weathered soil. In: SIMPÓSIO SOBRE O CERRADO, 4., 1977, Belo Horizonte. Anais... São Paulo: Universidade de São Paulo, 1977. p. 333-347.

KER, L. C. Mineralogia, sorção e dessorção de fosfato, magnetização e elementos traços de Latossolos do Brasil. 1995. 181 p. Tese (Doutorado em Geologia)-Universidade Federal de Viçosa, Viçosa, 1995.

KER, J. C. et al. Adsorção de fósforo em alguns solos latossólicos: relação entre mineralogia e efeito da calagem. Revista Ceres, Viçosa, v. 43, n. 246, p. 216-226, 1996.

KERN, D. C.; KÄMPF, N. Antigos assentamentos indígenas na formação de solo com Terra Preta Arqueológica na região de Oriximiná, Pará. Revista Brasileira de Ciência do Solo, Viçosa, MG, v. 13, p. 219-225, 1989.

KERN, D. C. Geoquímica e pedogeoquímica de sítios arqueológicos com terra preta na floresta nacional de Caxiuanã (Portel-Pa). 1996. 124 p. Tese (Doutorado em Geologia)Centro de Geociências, Universidade Federal do Pará, Belém, 1996.

KITAMURA, A. E. et al. Recuperação de um solo degradado com a aplicação de adubos verdes e lodo de esgoto. Revista Brasileira de Solo, Viçosa, v. 32, p. 405-416, 2008.

KLEINMAN, P. J. A. et al. Interlaboratory comparison of soil phosphorus extracted by various soil test methods. Commun. Soil Science and Plant Analysis, New York, v. 32, p. 2325-2345, 2001. 
LABORATÓRIO NACIONAL DE REFERÊNCIA VEGETAL - LANARV. Análise de corretivos, fertilizantes e inoculantes - métodos oficiais. Brasília: Ministério de Agricultura, Secretaria Nacional de Defesa Agropecuária, 1988. 104 p.

LEHMANN, J. et al. Slash-and-char: a feasible alternative for soil fertility management in the central Amazon? In: WORLD CONGRESS OF SOIL SCIENCE, 7., 2002, Bangkok. Soil science: confronting new realities in the 21st Century... Baltimore: Bangkok, 2002.p. 1-12.

LEHMANN, J. et al. Nutrient availability and leaching in an archaeological Anthrosol and a Ferralsol of the Central Amazon basin:fertilizer, manure and charcoal amendments. Plant and Soil, Netherlands, v. 249, p. 343-357, 2003.

LEHMANN, J. et al. Near-edge x-ray absorption fine structure (NEXAFS) spectroscopy for mapping nano-scale distribution of organic carbon forms in soil: Application to black carbon particles. Global Biogeochemistry Cycles, Mainz, v. 19, p. 1013, 2005.

LEHMANN, J. Bio-energy in the black. Frontiers in Ecology and the Environment, Washington, v. 5, n. 7, p. 381-387, 2007.

LIMA, H. N. Gênese, química e micromorfologia de solos da Amazônia Ocidental. 2001. 176 p. Tese (Doutorado em Agronomia /Nutrição de Solos e Plantas)-Universidade Federal de Viçosa, Viçosa, MG, 2001.

LINDSAY, W. L. \& MORENO, E. C. Phosphate phase equilibria in soils. Proceedings Soils Science Society of America, Madison, v. 24, p. 177-182, 1960.

LUCHESE, E. B.; FAVERO, L. O. B.; LENZI, E. Fundamentos da química do solo: teoria e prática. 2. ed. Rio de Janeiro: Freitas Bastos, 2002. 159 p.

MADARI, B. E. et al. Carvão vegetal como condicionador do solo para arroz de terras altas (cultivar Primavera): um estudo prospectivo. Santo Antônio de Goiás: EMBRAPA, 2006. 6p. (Comunicado técnico, 125). 
MADARI, B. E. et al. Matéria orgânica dos solos antrópicos da Amazônia (Terra Preta de Índio): suas características e papel na sustentabilidade da fertilidade do solo. In: TEIXEIRA, W. G. et al. As terras pretas de índio da Amazônia: sua caracterização e uso deste conhecimento na criação de novas áreas. Manaus: EMBRAPA Amazônia Ocidental, 2009. p. 174-187.

MAHAN, B. M.; MYERS, R. J. Química um curso universitário. 4. ed. São Paulo: Edgard Blücher, 2002. 582 p.

MEHADI, A. A.; TAYLOR, R. W. Phosphate adsorption by two highly-weathered soils. Soil Science Society America Journal, Madison, v. 52, p. 627-632, 1998.

MEHLICH, A. Determination of P, Ca, Mg, K, Na, and NH4. Raleigh: Departmente of Agriculture, 1953. 53p.

MEHLICH, A. Mehlich 3 soil test extractant: a modification of Mehlich 2 extractant. Soil Science of Plant Analysis, New York, v. 15, p. 1409-1416, 1984.

MENDOZA, H. N. Efeitos de sistemas de colheita dos canaviais sobre propriedades químicas e biológicas em solos de Tabuleiro no Espírito Santo. 1996. 113 p. Dissertação (Mestrado em Agronomia/Nutrição de Solos e Plantas)-Universidade Federal Rural do Rio de Janeiro, Rio de Janeiro, 1996.

MESA, J.M.; ROCHA, J.D.; OLIVARES, E.; BARBOZA, L. A.; BROSSARD, L.E.; BROSSARD JUNIOR, L.E. Pirólise rápida em leito fluidizado: uma opção para transformar biomassa em energia limpa. Revista Analytica. São Paulo, , n.4. p. 32-36, 2003.

MIELNICZUK, J. Matéria orgânica e a sustentabilidade de sistemas agrícolas. In: SANTOS, G. A. et al. (Eds.). Fundamentos da matéria orgânica do solo: ecossistemas tropicais e subtropicais. Porto Alegre: Genesis, 2008. cap. 1, p. 1-5.

MOREIRA, F. L.M., MOTA, F. O. B., CLEMENTE, C. A., AZEVEDO, B. M., BOMFIM, G. V. Adsorção de fósforo em solos do Estado do Ceará. Revista Ciência Agronômica, Fortaleza, v.37, n.1, p.7-12, 2006.

MURPHY, J \& J.P. RILEY. A modified single solution method for the determination of phosphate in natural waters. Analytica Chimica Acta, Amsterdam 27:31-36. 1962 
MIYAZAWA, M., M.A. PAVAN, E.L. OLIVEIRA, M. IONASHIRO; A.K.. SILVA. Gravimetric determination of soil organic matter. Braz. Arch. Biol. Tech. 43:475-478. 2000.

NAKOS, G. Phosphorus adsorption by forest soils. Soil Science of Plant Analysis, New York, v. 18, n. 3, p. 279-286, 1987.

NEVES, E. G. et al. Historical and socio-cultural origins of Amazonian dark earths. In: LEHMANN, J. et al. (Eds.). Amazonian dark earths: origin, properties, management. The Netherlands: Kluwer Academic, 2003. p. 3-14.

NEWBOLD, K. B. Six billion plus: world population in the twenty-first century. 2nd ed. Toronto: Rowman \& Littlefield, 2007. 199 p.

NOVAIS, R. F.; NEVES, J. C. L.; BARROS, N. F. Aspectos físico-químicos envolvidos na fixação do fósforo no solo. In: ENCONTRO NACIONAL DE ROCHA FOSFÁTICA, 5., 1991, São Paulo. Anais... São Paulo: IBRAFOS, 1991. p. 133-177.

NOVAIS, F. R.; SMYTH, T. J. Fósforo em solo e planta em condições tropicais. Viçosa: UFV, 1999. 399 p.

NYLE, C. B. The nature and properties of soils. 13th ed. New Jersey: Pearson, 2001. 960 p.

OLDEMAN, L. R.; LYNDEN, G. W. J. van. Revisting the GLASOD methodology. In: LAL, R. et al. (Eds.). Methods of assessment of soil degradation. New York: CRC, 1998. p. 423440.

OLSEN, S. R.; WATANABE, F. S. A method to determine a phosphorus adsorption maximum of soil as measured by the Langmuir isotherm. Soil Science Society of American Proceedings, Madison, v. 21, p. 144-149, 1954.

ÓRFÃ̃, J. J. M.; ANTUNES, F. J. A.; FIGUEIREDO, J. L. Pyrolysis kinetics of lignocellulosic materialsthree independent reactions model. Fuel, London, v.78, p.349-358, 1999.

PARFITT, R. L.; ATKINSON, R. J.; SMART, R. C. The mechanism of phosphate fixation by iron oxides. Soil Science Society of American Journal, Madison, v. 39, p. 837-841, 1975. 
PENNELL, K. D. Specific surface area. In: TOPP, G. C.; DANE, J. H. (Eds.). Methods of soil analysis. Madison: SSSA, 2002. p. 295-315. (Soil book series, 5).

RAIJ, B. V. Fertilidade do solo e adubação. Piracicaba: Ceres; Potafos, 1991. 343 p.

RAIJ, B.VAN; CANTARELLA, H.; QUAGGIO, J.A. \& FURLANI, A.M.C (Eds.). Recomendações de adubação e calagem para o Estado de São Paulo. Boletim Técnico Instituto Agronômico de Campinas, Campinas, n. 100, 1996. 2. ed., 285 p.

RHEINHEIMER, D. S; ANGHINONI, I. Accumulation of soil organic phosphorus by soil tillage and cropping systems in subtropical soils. Communications in Soil Science and Plant Analysis, Philadelphia, v. 34, n. 15/16, p. 2339-2354, 2003.

RIEGEL, I. et al. Análise termogravimétrica da pirólise da acácia-negra (Acaciamearnsii de wild.) cultivada no Rio Grande do Sul, brasil. Revista Árvore, Viçosa, v. 32, n. 3, p. 533-543, 2008.

RODRIGUES, M. R. Fatores que afetam a fixação de fosfatos nos solos do estado de São Paulo. 1980. 88 p. Dissertação (Mestrado em Agronomia)-Escola Superior de Agricultura Luiz de Queiroz, Universidade de São Paulo, Piracicaba, 1980.

ROMINE, D. S.; METZGER, W. N. Phosphorus fixation by horizon of various soil types in relation to dilute acid extractable iron and aluminum. Journal American Society of Agronomy, Madison, v. 31, p. 99-108, 1939.

RYDEN, C. J.; McLAUGHLIN, J. R.; SYERS, J. K. Mechanism of phosphates sorption by soils and hydrous ferric oxide gel. Soil Science, Oxford, v. 28, p. 72-92, 1977.

SÁNCHEZ, C. G. Estudo da volatilização e da gaseificação de biomassa em leito

fluidizado. 1994. 143p. Tese (Doutorado em Engenharia mecânica)-Faculdade de Engenharia Mecânica, Universidade de Campinas, Campinas, 1994.

SANCHEZ, P.A.; COCHRANE, T.T. 1980. Soils constraints in relation to major farming systems of tropical America. International Rice Research Institute, Los Banos. Chemistry of tropical America. International Rice Research Institute, Los Banos. p.106-139. 1991. 
SANCHEZ, P. A.; UHERA, G. Management considerations for acid soils with high phosphorus fixation capacity. In: KHASAWNEH, F. E.; SAMPLE, E. C.; KAMPRATH, E. J. The role of phosphorus in agriculture. Madison: ASA; CSSA; SSSA, 1980. chap. 17, p. 471-514.

SANYAL, S. K.; De DATTA, S. K. Chemistry of phosphorus transformations in soil. Advances in Soil Science, New York, v. 16, p. 1-120, 1991.

SATO, S.; COMERFORD, N. B. Assessing method for developing phosphorus desorption isotherms using anion exchange membranes. Plant and Soil, Berlin, v. 279, p. 107-117, 2005.

SATO, S.; COMERFORD, N. B. Organic anions and phosphorus desorption and bioavailability in a humid Brazilian Ultisol. Soil Science, Baltimore, v. 171, p. 663-674, 2006.

SCHINDLER, P. W.; SPOSITO, G. Surface complexation at (hydr)oxides surfaces. In: BOLT, G. H. et al. (Eds.). Interaction at the soil colloid-soil solution interface. Dordrecht: Kluwer, 1991. p. 115-145.

SCHMIDT, M. W. I.; NOACK, A. G. Black carbon in soils and sediments: Analysis, distribution, implications, and current challenges. Global Biogeochemistry Cycles, Mainz, v. 14, p. 777-793, 2000.

SCHMIDT, M. W. I.; SKJEMSTAD, J. O. Carbon isotope geochemistry and nanomorphology of soil black carbon: black chernozemic soils in central Europe originate from ancient biomass burning. Global Biogeochemistry Cycles, Mainz, v. 16, p. 1123, 2002.

SHAFIZADEH, F.; SEKIGUCHI, Y. Development of aromaticity in cellulosic chars. Carbon, Oxford, v. 21, p. 511-516, 1983.

SHARPLEY, A. N. Phosphorus cycling in unfertilized and fertilized agricultural soils. Soil Science Society of American Journal, Madison, v. 49, p. 905-911, 1985.

SILVENSTEIN, R. M.; BASSLER, G. C.; MORRILL, T. C. Identificação spectrométrica de compostos orgânicos. 5. ed. Rio de Janeiro: Guanabara Koogan, 1994. 508 p. 
SMETHURST P J. Soil solution and other soil analyses as indicators of nutrient supply: a review. Forest Ecology and Management. Amsterdam, v. 138, p. 397-411, 2000.

SMITH, N. J. H. Anthrosols and human carrying capacity in Amazônia. Annals of the Association of American Geographer, Washington, DC, v. 70, p. 553-566, 1980.

SOMBROEK, W.G. Amazon soils. A reconnaissance of the soils of the Brazilian Amazon región. Wageningen, Center for Agricultural Publication and Documentation, Agricultural Research Report, 672. 292 p.. 1966.

SOUZA, J. A. Generalidades sobre os efeitos benéficos da matéria orgânica na agricultura. Informe Agropecuário, Belo Horizonte, v. 26, n. 224, p. 7-8, 2005.

SOUSA, D.M.G.; MIRANDA, L.N.; OLIVEIRA, S.A. Acidez do solo e sua correção. In: NOVAIS, R.F.; ALVAREZ V., V.H.; BARROS, N.F.; FONTES, R.L.F.; CANTARUTTI, R.B.; NEVES, J.C.L. Fertilidade do solo. Viçosa: SBCS, 2007. p.205-274.

STEINER, C. et al. Long term effects of manure, charcoal and mineral fertilization on crop production and fertility on a highly weathered Central Amazonian upland soil. Plant and Soil, Berlin, v. 291, p. 275-290, 2007.

STEVENSON, F. J. Húmus chemistry: gênesis, composition, reactions. New York: John Wiley, 1982. $443 \mathrm{p}$.

STEVENSON, F. J. Geochemistry of soil humic substance. In: AIKEN, G. R.; MCKNIGHT, D. M.; WERSHAW, R. L. (Eds.). Humic substances in soil, sediment and water. New York: John Wiley, 1985. p. 13.

STEVENSON, F. J. Cycles of soil: carbon, nitrogen, phosphorus, sulfur, micronutrients. New York: John Wiley, 1986. 379p.

STEWART, J. W. B.; TISSEN, H. Dynamica os soil organic phosphorus. Biochemistry, Dordrecht, v. 4, p. 41-60, 1987. 
THOMAZI, M. D. Fixação de fosfatos por solos do município de Piracicaba. 1988. 67 p. Tese (Doutorado em Agronomia)-Escola Superior de Agricultura Luiz de Queiroz, Universidade de São Paulo, Piracicaba, 1988.

TRUJILLO, C. L. Fluxos de nutrientes em solo de pastagem abandonada sob adubação orgânica e mineral na Amazônia central. 2002. 80p. Dissertação (Mestrado em BilologiaEcologia)-Instituto Nacional de Pesquisas da Amazônia, Universidade Federal da Amazônia, Manuas, 2002.

VAN DER ZEE, S. E. A. T. M.; VAN RIEMSDIJK, W. H.. Model for the reaction kinetics of phosphate with oxides and soil. In: BOLT, G. H. et al. (Eds.). Interactions at the soil colloid - soil solution interface. Dordrecht: Kluwer Academic, 1991. p. 205-239.

VAN HEES, P. A.; TIPPING, E.; LUNDSTRÖM, U. S. Aluminium speciation in forest soil solution-modelling the contribution of low molecular weight organic acids. The Science of the Total Environment. 278: 215-229. 2001.

VAUGHAN, D.; ORD, B. G. Soil organic matter: a perspective on its nature, extraction, turnover and role in soil fertility. In: VAUGHAN, V. \& MALCOLM, R.E. (eds.). Soil organic matter and biological activity. Boston: Martinus \& Junk, 1985. p. 1-34. (Developments in plant and soil sciences, 16).

VERHOEVEN, J. D. Scanning electron microscopy. In: ASM-HANDBOOK. [S.1.]: The Information Society, 1984. p. 84-109.

VIEIRA, L. S. Manual da ciência do solo. São Paulo: Agronômica Ceres, 1975. 464 p.

VOLKSWEISS, S.; RAIJ, B. van. Retenção e disponibilidade de fósforo em solos. In: SIMPÓSIO SOBRE O CERRADO, 4., 1977, Belo Horioznte. Anais... São Paulo: Universidade de São Paulo, 1977. p. 317-332.

WESSELINK, L. G. et al. A simple of soil organic matter complexation to predict to solubility of aluminium in acis forest soil. Europe Journal Soil Science, Bedfordshire, v. 47. p. 373384, 1996. 
WOLF, M. B.; LONDON, D. Apatite dissolution into peraluminous haplogranitic melts - An experimental study of solubilities and mechanisms. Geochimica Cosmochimica Acta, New York, v. 58, p. 4127-4145, 1994.

WOODS, W. I. History of anthrosol research. In: LEHMANN, J. et al. (Eds.). Amazonian dark earths: origin, properties, management. The Netherlands: Kluwer Academic, 2003. p. 314.

WOODS, W. I.; GLASER, B. Towards an Understanding of Amazonian Dark Earths. In Woods, W. I.; Glaser, B. Amazonian Dark Earths: Explorations in Space and Time,2004. pp. 1-8. Springer-Verlag, Berlin.

ZECH, W.; HAUMAIER, L.; HEMPFLING, R. Ecological aspects of soil organic matter in tropical land use. In: MCCARTHY, P. et al. (Eds.). Humic substances in soil and crop sciences: selected readings. Madison: ASA, SSSA, 1990. p. 187-201. 